EDUARDO DOMINGO MORALES

\title{
ANÁLISE DE CRITÉRIOS DE FALHA EM MATERIAIS DÚCTEIS: UM ESTUDO NUMÉRICO E EXPERIMENTAL
}


EDUARDO DOMINGO MORALES

\section{ANÁLISE DE CRITÉRIOS DE FALHA EM MATERIAIS DÚCTEIS: UM ESTUDO NUMÉRICO E EXPERIMENTAL}

Dissertação apresentada à Escola

Politécnica da Universidade de São Paulo para obtenção do título de Mestre em Engenharia. 
EDUARDO DOMINGO MORALES

\title{
ANÁLISE DE CRITÉRIOS DE FALHA EM MATERIAIS DÚCTEIS: UM ESTUDO NUMÉRICO E EXPERIMENTAL
}

\author{
Dissertação apresentada à Escola \\ Politécnica da Universidade de São Paulo \\ para obtenção do título de Mestre em \\ Engenharia. \\ Área de Concentração: \\ Engenharia Mecânica de Projeto e \\ Fabricação \\ Orientadora: Prof. ${ }^{a}$ D. ${ }^{\text {ra }}$ Larissa Driemeier
}


Este exemplar foi revisado e corrigido em relação à versão original, sob responsabilidade única do autor e com a anuência de seu orientador.

São Paulo, 15 de abril de 2013.

Assinatura do autor

Assinatura do orientador

Morales, Eduardo Domingo

Análise de critérios de falha em materiais dúcteis: um estudo numérico e experimental / E.D. Morales. - versão corr. -- São Paulo, 2013.

$112 \mathrm{p}$.

Dissertação (Mestrado) - Escola Politécnica da Universidade de São Paulo. Departamento de Engenharia Mecatrônica e de Sistemas Mecânicos.

1. Imperfeições e falhas dos materiais 2. Método dos elementos finitos I. Universidade de São Paulo. Escola Politécnica. Departamento de Engenharia Mecatrônica e de Sistemas Mecânicos II. t. 


\section{AGRADECIMENTOS}

À Prof. Dr. ․ㅡ Larissa Driemeier, pela atenção e orientação durante todo este projeto.

Ao Prof. Dr. Marcílio Alves, por toda a ajuda no desenvolvimento deste trabalho.

Ao pessoal do Grupo de Mecânica dos Sólidos e Impacto em Estruturas, pela ajuda na realização dos testes experimentais e orientação na elaboração desta dissertação.

À minha família, pelo apoio que sempre tive em todos os momentos. 


\section{RESUMO}

O presente trabalho visa o estudo e análise de desempenho de diferentes critérios de falha disponíveis na literatura, a diferentes estados triaxiais de tensão. Para isso, utiliza-se um corpo de prova ad hoc, aqui denominado Bifailure, que foi projetado com a finalidade de se obter falha em estado de tensão próximo ao cisalhamento puro e em estado de tensão de alta triaxialidade, em um único teste de tração. Foram realizados ensaios experimentais e simulações numéricas com 0 programa comercial de elementos finitos $L S-D y n a^{\circledast}$. A fim de utilizar critérios de falha recentes, ainda não disponíveis, uma subrotina de elementos finitos foi desenvolvida e implementada. Após as simulações, concluiu-se que, dentre os critérios analisados, não houve um critério que representasse perfeitamente $e$ simultaneamente os dois tipos de falha do espécime Bifailure. Por fim, o estudo concluiu que o grau de acuracidade de um critério de falha está relacionado ao número de parâmetros necessários e aos testes experimentais que foram realizados para sua caracterização.

Palavras-chave: Imperfeições e falhas dos materiais. Método dos elementos finitos. 


\begin{abstract}
The present work aims the study and analysis of performance of different failure criteria available in literature, in different triaxial stress states. For that, it is used an ad hoc specimen, here named Bifailure, that was designed with the purpose of obtain failure in a stress state near pure shear and in a stress state of high triaxiality, in a single tension test. Experimental tests and numerical simulations were done with commercial finite element software $L S-D y n a^{\circledR}$. In order to use recent failure criteria, that are still not available, a finite element subroutine was developed and implemented. After simulations, it was concluded that, among analysed criteria, there was not a criterion that represented perfectly and simultaneously the two types of failure of Bifailure specimen. Finally, the study concluded that the degree of accuracy of a failure criterion is related to the number of necessary parameters and to the experimental tests that were done for its characterization.
\end{abstract}

Keywords: Imperfections and failure of materials. Finite element method. 


\section{LISTA DE ILUSTRAÇÕES}

Figura 1 - Falha em casco de navio após colisão.

Figura 2 - a) Exemplo de falha em fuselagem de avião, resultante de colisão com pássaro. b) Falha no interior de carcaça de motor de avião, em evento de blade-off.

Figura 3 - Aplicações da simulação de falha com MEF. a) Impacto em pára-choque.

b) Impacto em casco de navio. c) Impacto de pássaro em asa de avião. 22

Figura 4 - Curva tensão-deformação para material dúctil.

Figura 5 - Corpo de prova de aço (a) antes e (b) após ensaio de tração uniaxial....25

Figura 6 - Estrutura granular de aço, mostrando nitidamente os contornos de grão..

Figura 7 - Discordância do tipo aresta, indicada pela seta, gerando distorção na rede cristalina.

Figura 8 - (a) Cone representativo de um único estado de triaxialidade, (b) Projeção de um estado de tensões no plano $\pi$

Figura 9 - Projeção do vetor de tensões no plano $\pi$ .30

Figura 10 - Deformação de falha em função do fator de triaxialidade e ângulo de

Lode para a) alumínio 2024-T351; b) aço 1045

Figura 11 - Representação de estados de tensão no espaço de triaxialidade versus parâmetro de Lode..

Figura 12 - Relação da deformação equivalente de falha com a triaxialidade para alumínio 2024-T351

Figura 13 - Nucleação de vazios em partículas, e falha dúctil da matriz cristalina para liga de alumínio 2024-T351.

Figura 14 - (a) Ligação de vazios por empescoçamento; (b) Ligação de vazios por contato; (c) Ligação de vazios por ligação de microvazios.

Figura 15 - Falha em teste de compressão de cilindros, nos planos de tensão cisalhante máxima

Figura 16 - Modelo de crescimento de vazios de McClintock.

Figura 17 - Primeira geometria do espécime Bifailure, e corpo de prova na máquina de tração .57

Figura 18 - Medidas da primeira geometria do espécime Bifailure. 
Figura 19 - Resultados experimentais para a primeira geometria do Bifailure, em alumínio

Figura 20 - A grande deformação das regiões destacadas dificulta a obtenção de cisalhamento puro na região central do espécime.

Figura 21 - Segunda proposta do espécime Bifailure.

Figura 22 - Medidas da segunda proposta do espécime Bifailure. 60

Figura 23 - Em a), distanciamento do centro dos furos dos entalhes menores em relação à parede lateral do espécime; em b), indicação de raio e espaçamento máximo da curvatura dos entalhes em relação à face superior.

Figura 24 - Corpo de prova montado na máquina de tração

Figura 25 - Corpo de prova Bifailure montado na máquina de tração com extensômetro 62

Figura 26 - Medidas do corpo de prova para ensaio de tração 63

Figura 27 - Corpo de prova padrão utilizado para ensaio de tração 63

Figura 28 - Curva tensão-deformação de engenharia para alumínio 2024-T351 ....64

Figura 29 - Resultado experimental dos testes de tração padrão ..........................64

Figura 30 - Curvas força-deformação para espécime Bifailure.............................65

Figura 31 - Região central do espécime Bifailure após o ensaio de tração. .65

Figura 32 - Fluxograma representando o funcionamento da solução numérica de elementos finitos. .69

Figura 33 - Representação esquemática da predição elástica / algoritmo de retorno para o modelo de von Mises.. 71

Figura 34 - Esquema do algoritmo de previsão elástica e retorno.........................75

Figura 35 - Esquema do algoritmo de Newton-Raphson..................................76

Figura 36 - Malha de elementos finitos utilizada na simulação do teste de tração comum. .77

Figura 37 - Curva tensão-deformação para teste de tração comum, com a curva extraída da simulação e curva do material utilizado por Wierzbicki et al. (2005) 78

Figura 38 - Malha do corpo de prova Bifailure, composta de 152220 elementos .....78

Figura 39 - Detalhe da malha do espécime Bifailure, na região dos entalhes ..........79

Figura 40 - Variação da triaxialidade para os entalhes do espécime Bifailure . 79 
Figura 41 - Curvas experimental e numérica da simulação com critério de falha da máxima deformação plástica equivalente.

Figura 42 - Resultado da simulação com critério de falha da máxima deformação plástica equivalente

Figura 43 - Curvas experimental e numérica da simulação com critério de falha da máxima tensão cisalhante

Figura 44 - Resultado da simulação com critério de falha da máxima tensão cisalhante

Figura 45 - Lugar geométrico de falha para o critério de falha de Johnson-Cook ....83

Figura 46 - Resultado da simulação com critério de falha de Johnson-Cook...........83

Figura 47 - Resultado da simulação com critério de falha de Johnson-Cook...........84

Figura 48 - Resultado da simulação com critério de falha de Wilkins.......................85

Figura 49 - Resultado da simulação com critério de falha de Wilkins.......................85

Figura 50 - Resultado da simulação com critério de falha de Cockcroft-Latham e valor crítico de 0,058

Figura 51 - Resultado da simulação com critério de falha de Cockcroft-Latham e valor crítico de 0,485

Figura 52 - Resultado da simulação com critério de falha de Cockcroft-Latham e valor crítico de 0,058

Figura 53 - Resultado da simulação com critério de falha de Cockcroft-Latham e valor crítico de 0,485

Figura 54 - Trincas ao redor do entalhe 3, para critério de falha de Cockcroft-Latham com valor crítico de 0,485

Figura 55 - Deformação de falha para o critério de Bao-Wierzbicki .89

Figura 56 - Resultado da simulação com critério de falha de Bao-Wierzbicki . .89

Figura 57 - Resultado da simulação com critério de falha de Bao-Wierzbicki..... .90

Figura 58 - Para o critério de falha de Bao-Wierzbicki, duas trincas foram geradas na região do entalhe central

Figura 59 - Superfície de deformação de falha para o critério de falha de XueWierzbicki.

Figura 60 - Resultado da simulação para o critério de Xue-Wierzbicki .91

Figura 61 - Resultado da simulação para o critério de Xue-Wierzbicki .92

Figura 62 - Obtenção do fator de triaxialidade médio para diferentes experimentos.. 
Figura 63 - Obtenção do lugar geométrico de falha a partir dos valores de deformação de falha e triaxialidade média obtidos numericamente.....103 


\section{LISTA DE TABELAS}

Tabela 1 - Propriedades do material alumínio aeronáutico ………........................58

Tabela 2 - Propriedades do material Alumínio 2024-T351 ...................................62

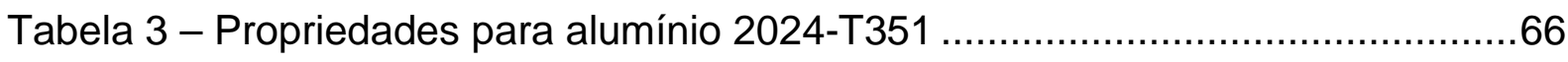

Tabela 4 - Parâmetros do modelo de von Mises para alumínio 2024-T351 .............77

Tabela 5 - Parâmetros do critério de falha de Johnson-Cook para alumínio 2024-

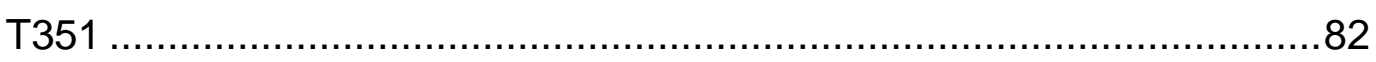

Tabela 6 - Parâmetros do critério de falha de Wilkins para alumínio 2024-T351 .....84

Tabela 7 - Parâmetros do critério de falha de Xue-Wierzbicki para alumínio 2024T351 


\section{LISTA DE ABREVIATURAS E SIGLAS}

ABS

GMSIE

MEF

DIC

$\mathrm{JC}$
Antilock Braking System

Grupo de Mecânica dos Sólidos e Impacto em Estruturas

Método dos Elementos Finitos

Digital Image Correlation

Johnson-Cook 


\section{LISTA DE SÍMBOLOS}

\begin{tabular}{|c|c|}
\hline$\sigma_{1}$ & Máxima tensão principal \\
\hline$\sigma_{2}$ & Tensão principal intermediária \\
\hline$\sigma_{3}$ & Mínima tensão principal \\
\hline$I_{n}$ & Invariante de tensão do tensor de tensões \\
\hline$s_{1}$ & Máxima tensão desviadora principal \\
\hline$s_{2}$ & Tensão desviadora principal intermediária \\
\hline$s_{3}$ & Mínima tensão desviadora principal \\
\hline$\delta_{i j}$ & Delta de Kronecker \\
\hline$J_{n}$ & Invariante de tensão do tensor desviador \\
\hline$\sigma_{m}$ & Tensão hidrostática \\
\hline $\bar{\sigma}$ & Tensão equivalente \\
\hline$\eta$ & Fator de triaxialidade \\
\hline$\theta_{L}$ & Ângulo de Lode \\
\hline$\xi$ & Terceiro invariante de tensão em forma normalizada \\
\hline $\bar{\theta}$ & Parâmetro de Lode \\
\hline$\sigma_{p}^{*}$ & Produto de triaxialidade \\
\hline $\bar{\varepsilon}_{f}$ & Deformação plástica equivalente de falha \\
\hline $\bar{\varepsilon}_{p}$ & Deformação plástica equivalente \\
\hline$\eta_{m}$ & Fator de triaxialidade médio \\
\hline $\bar{\theta}_{m}$ & Parâmetro de Lode médio \\
\hline$D$ & Variável de dano \\
\hline$T$ & Temperatura \\
\hline$\dot{\varepsilon}$ & Taxa de deformação \\
\hline$\varepsilon_{1}$ & Máxima deformação principal \\
\hline$\varepsilon_{2}$ & Deformação principal intermediária \\
\hline$\varepsilon_{3}$ & Mínima deformação principal \\
\hline$\tau_{\max }$ & Tensão cisalhante máxima \\
\hline
\end{tabular}




\begin{tabular}{|c|c|}
\hline$\left(\tau_{\max }\right)_{f}$ & Tensão cisalhante máxima de ruptura \\
\hline$\varepsilon_{c}$ & Função de deformação de falha \\
\hline$D_{1}$ & Primeiro parâmetro do modelo de falha de Johnson-Cook \\
\hline$D_{2}$ & Segundo parâmetro do modelo de falha de Johnson-Cook \\
\hline$D_{3}$ & Terceiro parâmetro do modelo de falha de Johnson-Cook \\
\hline$D_{4}$ & Quarto parâmetro do modelo de falha de Johnson-Cook \\
\hline$D_{5}$ & Quinto parâmetro do modelo de falha de Johnson-Cook \\
\hline$\dot{\varepsilon}_{p}$ & Taxa de deformação plástica \\
\hline$\dot{\varepsilon}_{0}$ & Taxa de deformação de referência \\
\hline$T_{f}$ & Temperatura de fusão do material \\
\hline$T_{0}$ & Temperatura de referência \\
\hline$a$ & Primeiro parâmetro do modelo de falha de Wilkins \\
\hline$\lambda$ & Segundo parâmetro do modelo de falha de Wilkins \\
\hline$\mu$ & Terceiro parâmetro do modelo de falha de Wilkins \\
\hline$p_{c r}$ & Tensão hidrostática crítica do modelo de falha de Wilkins \\
\hline$D_{c r i t}$ & Dano crítico \\
\hline$C_{1}$ & Primeiro parâmetro do modelo de falha de Xue-Wierzbicki \\
\hline$C_{2}$ & Segundo parâmetro do modelo de falha de Xue-Wierzbicki \\
\hline$C_{3}$ & Terceiro parâmetro do modelo de falha de Xue-Wierzbicki \\
\hline$C_{4}$ & Quarto parâmetro do modelo de falha de Xue-Wierzbicki \\
\hline $\mathrm{n}$ & Coeficiente de encruamento \\
\hline$b$ & Raio instantâneo do vazio cilíndrico do modelo de McClintock \\
\hline$b_{0}$ & Raio original do vazio cilíndrico do modelo de McClintock \\
\hline $\log F_{z b}^{f}$ & Máxima deformação suportável pelo vazio de McClintock \\
\hline$\sigma_{e s c}$ & Tensão de escoamento \\
\hline$R$ & Raio instantâneo do vazio esférico do modelo de Rice-Tracey \\
\hline$R_{0}$ & Raio original do vazio esférico do modelo de Rice-Tracey \\
\hline$\Phi$ & Função de escoamento \\
\hline$f_{v}$ & Fração volumétrica de vazios \\
\hline$q_{1}$ & Primeiro parâmetro do modelo de material de Gurson \\
\hline$q_{2}$ & Segundo parâmetro do modelo de material de Gurson \\
\hline
\end{tabular}




\begin{tabular}{|c|c|}
\hline$f_{v}^{*}$ & Fração volumétrica de vazios modificada \\
\hline$f_{v 0}$ & Fração volumétrica de vazios inicial \\
\hline$f_{v c}$ & Fração volumétrica de vazios crítica \\
\hline$f_{v F}$ & Fração volumétrica de falha \\
\hline$d f_{v}$ & Incremento da fração volumétrica de vazios \\
\hline$d f_{v_{-} \text {nucleaşã o }}$ & Incremento da fração volumétrica de nucleação \\
\hline$d f_{v_{-} \text {coalescenncia }}$ & Incremento da fração volumétrica de coalescência \\
\hline$d \varepsilon_{k k}^{p}$ & Taxa de deformação plástica volumétrica \\
\hline$s_{N}$ & Desvio padrão da distribuição de deformações plásticas \\
\hline$\varepsilon_{N}$ & Média da distribuição de deformações plásticas \\
\hline$F_{N}$ & Fração volumétrica total que pode ser nucleada \\
\hline$D^{e}$ & Tensor de elasticidade isotrópico \\
\hline$\varepsilon^{\mathrm{e}}$ & Tensor de deformação elástico \\
\hline$d \gamma$ & Multiplicador plástico \\
\hline$Y$ & Força termodinâmica associada com o dano \\
\hline$s$ & Parâmetro de falha de Lemaître \\
\hline$S$ & Parâmetro de falha de Lemaître \\
\hline$G$ & Módulo cisalhante \\
\hline $\mathrm{K}$ & Módulo volumétrico \\
\hline$A$ & Primeiro parâmetro do modelo de material de von Mises \\
\hline$B$ & Segundo parâmetro do modelo de material de von Mises \\
\hline$n$ & Terceiro parâmetro do modelo de material de von Mises \\
\hline $\mathbf{s}$ & Tensor desviador \\
\hline$\varepsilon^{e}$ & Deformação elástica \\
\hline$\varepsilon^{e, t e n t}$ & Deformação elástica de tentativa \\
\hline $\bar{\varepsilon}^{p, t e n t}$ & Deformação plástica de tentativa \\
\hline$\sigma^{\text {tent }}$ & Tensão de tentativa \\
\hline $\mathbf{S}^{\text {tent }}$ & Tensor desviador de tentativa \\
\hline$p^{\text {tent }}$ & Tensão hidrostática de tentativa \\
\hline$\sigma_{y}^{t e n t}$ & Tensão de escoamento de tentativa \\
\hline
\end{tabular}


$\varepsilon_{v} \quad$ Deformação volumétrica

$\varepsilon_{d} \quad$ Deformação desviadora

$\Delta \gamma \quad$ Multiplicador plástico

$K_{t} \quad$ Módulo tangente 
1 INTRODUÇÃO

2 FUNDAMENTOS TEÓRICOS DO ESTUDO DE FALHA ................24

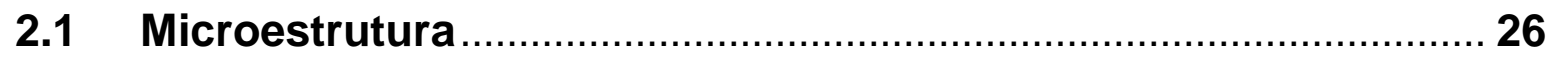

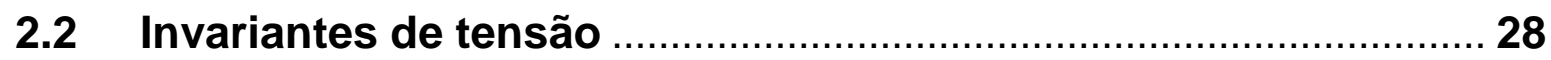

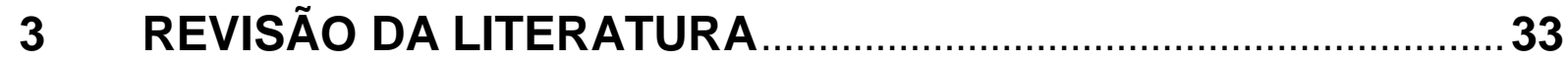

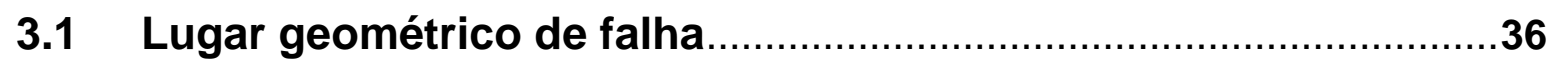

3.2 Mecanismos físicos para ocorrência de falha dúctil .................... 40

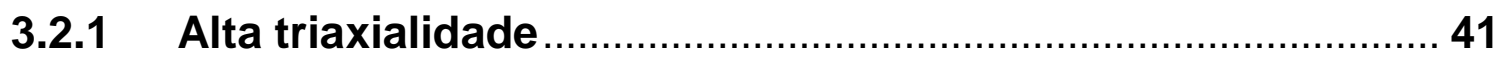

3.2.2 Triaxialidade negativa ….................................................. 42

3.2.3 Falha em triaxialidade intermediária ....................................... 43

3.3 Modelos de falha da mecânica do contínuo …................................ 43

3.3.1 Critério de falha da máxima deformação plástica equivalente

3.3.2 Critério de falha da máxima tensão cisalhante ....................... 45

3.3.3 Critério de falha de Johnson-Cook .......................................... 45

3.3.4 Critério de falha de Wilkins ...................................................... 46

3.3.5 Critério de falha de Cockcroft-Latham .................................. 47

3.3.6 Critério de falha de Bao-Wierzbicki ......................................... 48

3.3.7 Critério de falha de Xue-Wierzbicki ....................................... 49

3.4 Modelos micro-mecânicos …………........................................... 49

3.4.1 Modelo de falha de McClintock …….................................... 50

3.4.2 Modelo de Rice e Tracey …………..................................... 51

3.4.3 Modelo de Gurson-Tvergaard-Needleman .............................. 52

3.5 Modelo de dano de Lemaitre (mecânica do dano contínuo) ........ 55

$4 \quad$ ANÁLISE EXPERIMENTAL ...................................................... 57

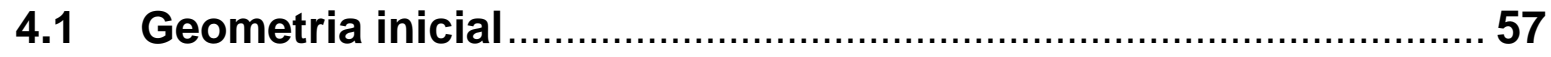

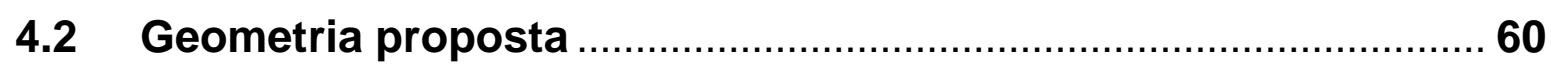

4.2.1 Caracterização do material Alumínio 2024-T351 .................... 62

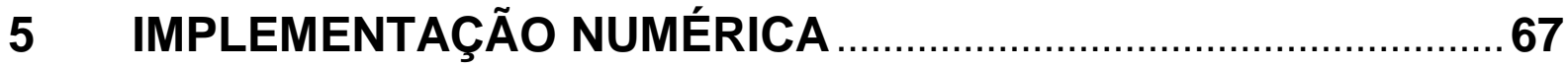


5.1 Implementação de subrotina

5.2 O procedimento de previsão elástica / algoritmo de retorno ......69 6 ESTUDO DE CASO DA APLICAÇÃO DOS CRITÉRIOS DE FALHA 77

6.1 Critério de falha da máxima deformação plástica equivalente $\ldots . .80$

6.2 Critério de falha da máxima tensão cisalhante .............................. 81

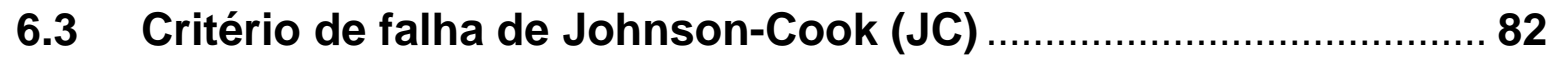

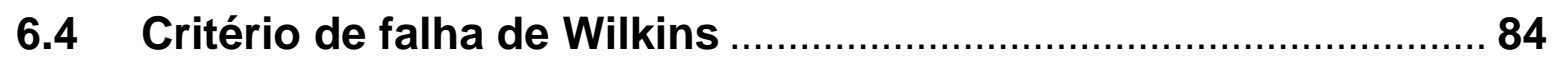

6.5 Critério de falha de Cockcroft Latham …....................................... 86

6.6 Critério de falha de Bao-Wierzbicki .......................................... 88

6.7 Critério de falha de Xue-Wierzbicki .............................................. 90

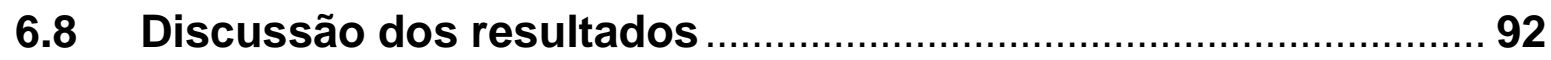

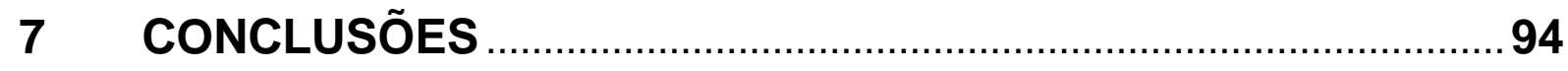

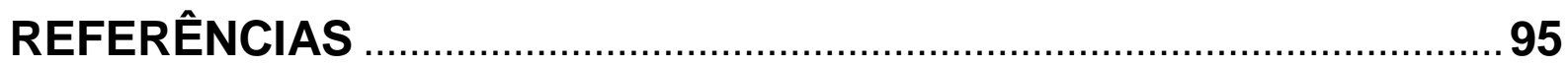

APÊNDICE A - CALIBRAÇÃO DOS CRITÉRIOS DE FALHA DA

MECÂNICA DO CONTÍNUO ...................................................................101

APÊNDICE B - SUBROTINA IMPLEMENTADA NO LS-DYNA ${ }^{\circledR} \ldots \ldots \ldots . .104$ 


\section{INTRODUÇÃO}

A falha corresponde à perda da capacidade de suportar carga por parte de uma estrutura ou componente, e é resultado da acumulação de microdefeitos no material, o que constitui o dano. A falha não resulta necessariamente no colapso global de uma estrutura, podendo também ser considerada como um fenômeno localizado.

O fenômeno de falha está presente no cotidiano das pessoas, em várias situações onde são verificadas rupturas em materiais, por exemplo: um copo de vidro quebrando-se ao cair no chão, uma folha de papel sendo rasgada, uma trinca em uma estrutura metálica ou de concreto, etc. São fenômenos de falha do dia-adia, alguns controlados e outros não.

A falha vem sendo investigada desde os tempos antigos, desde a era das cavernas, quando os ancestrais dos seres humanos utilizavam a falha de pedras para fabricar utensílios, entre eles armas.

A revolução industrial, por sua vez, desencadeou uma longa pesquisa sobre a resistência dos materiais e desenvolvimento de materiais novos. Os metais em particular, passaram a integrar estruturas de engenharia como pontes, veículos terrestres, navios, aeronaves, edifícios, entre outros dispositivos. Assim, o estudo sobre a resistência e ductilidade de metais passou a ser de grande valor na engenharia de estruturas.

Para haver falha dúctil é necessária a ocorrência de grande quantidade de plasticidade, de modo que no cotidiano das pessoas geralmente isso está presente em eventos de impacto como em colisões de navios com obstáculos, impacto de pássaros com aeronaves, perfurações de blindagens com projéteis e crash-tests de veículos.

Dessa forma, o estudo de falha é importante para a solução de problemas que ocorrem em várias áreas da engenharia. A economia de material em estruturas é um exemplo. Na indústria automotiva, na década de 80 , havia um aumento de 20 quilos por ano na massa do veículo e na última década este aumento alcançou ainda uma taxa de 10 quilos por ano. 
Segundo Christlein e Hambrecht (2008), isto ocorre principalmente devido ao aumento dos itens de segurança como o airbag e o antilock braking system (ABS), sendo este responsável por 30\% desse aumento de massa. Melhorias no conforto e acabamento interno são responsáveis por $22 \%$ e 15\%, respectivamente.

Deste modo, devem-se estudar alternativas para reforçar a estrutura do veículo sem comprometer sua massa. Isso leva a indústria em questão a utilizar materiais cada vez mais leves (Picket et al., 2004) - como compósitos, alumínio, magnésio e aços de alta resistência - que apresentam ductilidade menor que os aços comuns, apesar do alto limite de resistência (Yamashita et al, 2003). Assim, a menor ductilidade desses materiais contribui para aumentar a possibilidade de falha.

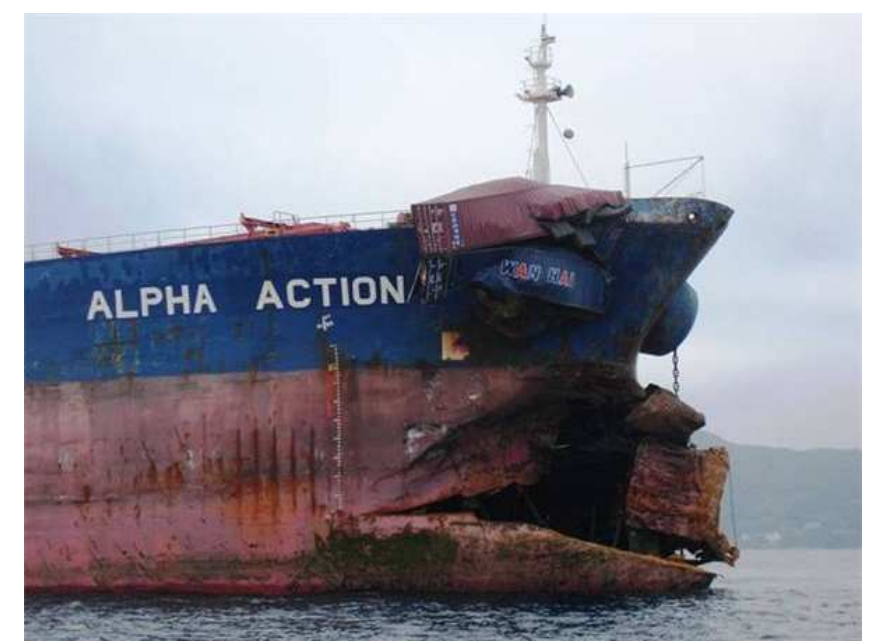

Figura 1. Falha em casco de navio após colisão. Extraído do site http://www.brighthubengineering.com/seafaring/36193-what-is-ship-collision/ em 22/12/2012.

O fenômeno de falha também ocorre em acidentes com navios (Urban, 2003), quando geralmente ocorre ruptura do casco decorrente de colisão. Anualmente nesses acidentes perdem-se cerca de 230 embarcações, a maioria de pequeno porte, e mais de 1000 vidas humanas, além de perdas de vida selvagem, quando ocorrem acidentes com danos ao meio ambiente (Törnqvist, 2003). Entre os acidentes navais onde a falha está presente podem-se citar, por exemplo, o derramamento de óleo, resultante do encalhamento do petroleiro Exxon Valdez, nas águas do Alaska em 1989; o naufrágio do navio cruzeiro Estônia em 1994, este causado pela falha resultante do estresse gerado quando feita navegação a alta velocidade em mar agitado; e o vazamento de combustível do navio maltês Sea Bird em 2008, resultante de uma rachadura no tanque de combustível após colisão com o navio grego Syrus. 
A falha é um fenômeno importante a ser considerado também no projeto de estruturas aeronáuticas. A estrutura de um avião deve ser projetada para resistir ou falhar de forma controlada em eventos de colisões com pássaros e objetos ou com fragmentos de turbina em um evento de blade-off, conforme ilustrado na Figura 2. Segundo Walvekar (2010), estima-se que 30000 colisões de aeronaves com pássaros ocorrem anualmente, resultando em perdas de 3 bilhões de dólares para a aviação mundial.

a)

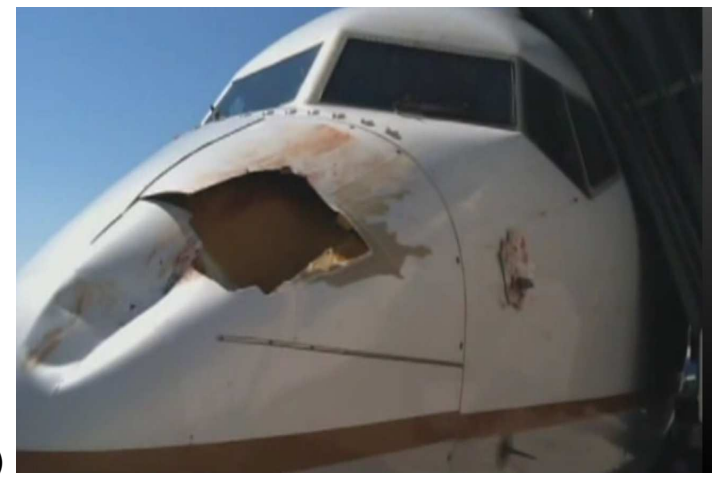

b)

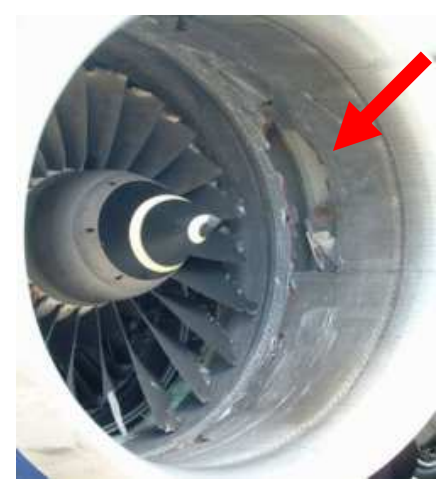

Figura 2. a) Exemplo de falha em fuselagem de avião, resultante de colisão com pássaro. b) Falha no interior de carcaça de motor de avião, em evento de blade-off. Figuras extraídas, respectivamente, dos sites http://gawker.com/5930769/bird-strike-does-terrifying-damage-to-nose-of-united-

airlines-plane em 22/12/2012 e http://www.nasa.gov/centers/glenn/news/AF/2007/ Jan07_printall_prt.htm em 24/12/2012.

Como aplicações militares para o estudo de falha podem ser citadas o projeto de blindagens e estruturas que resistam a explosões.

Ensaios experimentais de protótipos são demorados e custosos. Dessa forma, a competitividade industrial pelo desenvolvimento de produtos mais eficientes leva à crescente necessidade em se reduzir custos e tempo de desenvolvimento de produtos. Nesse contexto, a simulação do comportamento estrutural dos materiais pelo Método dos Elementos Finitos (MEF) tornou-se uma ferramenta de grande valor. Com a constante evolução dos códigos, assim como da capacidade computacional, é possível analisar o comportamento da estrutura desde sua fase elástica até a falha em situações complexas de geometria e carregamento. Exemplos de simulação numérica de falha através do MEF são ilustrados na Figura 3. 
a)

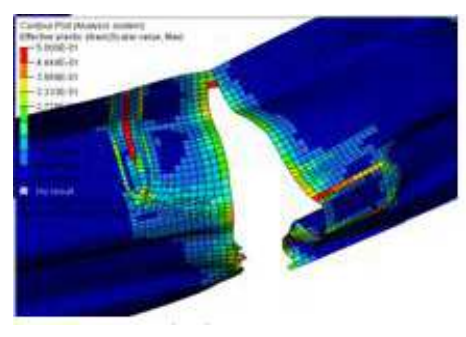

b)

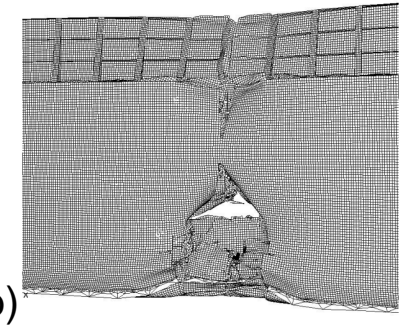

c)

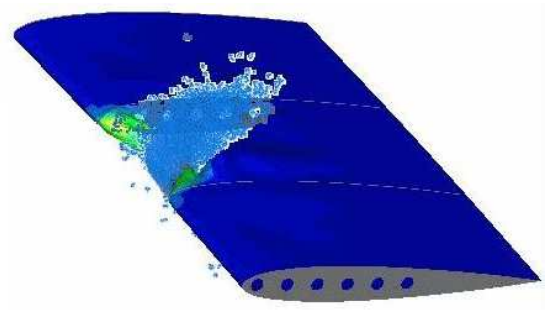

Figura 3. Aplicações da simulação de falha com MEF. a) Impacto em pára-choque. Extraído de Bugelli e Driemeier (2010); b) Impacto em casco de navio. Extraído de Törnqvist (2003); c) Impacto de pássaro em asa de avião. Extraído do site http://www.idacireland.com/autodyn em 22/12/2012.

A Figura 3a mostra a propagação de uma falha em simulação de teste de resistência de pára-choque. Na Figura 3b é simulado um evento de colisão de navio, com ocorrência de falha no casco. Por sua vez, a Figura $3 c$ apresenta a simulação de impacto de ave com asa de avião, na qual verifica-se se a asa falha ou não.

Modelos que mimetizem o comportamento real do material, porém, são essenciais para que os resultados numéricos reflitam o comportamento real da estrutura. Os modelos mais completos disponíveis na literatura estabelecem relações constitutivas e critérios de falha como função de grandes deformações, efeito de taxas de deformação e temperatura, perda de rigidez por danejamento, evolução do dano até surgimento da falha. Porém, ensaios experimentais são sempre muito custosos, e a caracterização de alguns desses modelos exige equipamentos sofisticados e licenças especiais.

Atualmente, portanto, projetos devem minimizar o número de ensaios experimentais, de modo a colher com eficiência dados que caracterizem o modelo de material adequado às condições de estudo. Esses dados, analisados, fornecem o input necessário para simulação numérica do problema. Dessa forma, podem-se racionalizar os investimentos, direcionando novos poucos testes experimentais, em situações reais, para validação da resposta numérica.

O avanço da pesquisa relacionada à área possibilita o desenvolvimento de modelos constitutivos de material, assim como critérios de falha, que apresentam boa acuracidade na representação dos fenômenos físicos modelados. Nota-se inclusive que existe uma forte parceria entre empresas e universidades no estudo e desenvolvimento de novos modelos de material e de falha (Ockewitz et al, 2006). Ainda, ao se analisar a documentação de programas comerciais de elementos finitos, como o LS-Dyna ${ }^{\circledR}$ (2009), verifica-se que necessidades das indústrias (principalmente a automobilística) são atendidas com relação à adaptação e inclusão 
de novas funcionalidades nos códigos de MEF. Em se tratando do LS-Dynaß, como exemplo, pode-se citar o modelo de previsão de falha em pontos de solda desenvolvido pela Toyota e implementado no programa.

Atualmente, existem diferentes critérios de falha disponíveis em programas comerciais de elementos finitos, como $L S-D y n a \AA$, Abaqus $\AA$ e Pam-Crash $\AA$. No entanto, para facilitar a aplicação prática, é desejado que o critério adotado possa ser calibrado com um número razoável de testes experimentais simples, e que o significado físico dos parâmetros que o caracterizam seja conhecido.

Diante do exposto, neste trabalho foram analisados diversos modelos de falha disponíveis na literatura, através do uso do software comercial LS-Dyna®. Esses modelos de falha foram implementados no $L S-D y n a \circledR$ através de uma subrotina. $O$ modelo de material implementado foi o elastoplástico de von Mises tradicional. Para comparação de acuracidade entre os modelos foi utilizado um espécime ad-hoc desenvolvido por Alves e Driemeier (2010), denominado aqui como Bifailure.

O material em estudo é uma chapa de liga de alumínio 2024-T351, de espessura nominal 9,525mm, similar ao utilizado em Wierzbicki et al. (2005). Foram utilizados parâmetros de material disponíveis na literatura em conjunto com valores obtidos de ensaios experimentais de tração uniaxial.

Neste trabalho, o Capítulo 2 trata da fundamentação teórica, com conteúdo necessário ao entendimento sobre falha como invariantes de tensão e microestrutura dos materiais. No Capítulo 3, são explicados diferentes modelos de falha disponíveis na literatura. No Capítulo 4, os testes e resultados experimentais são detalhados. No Capítulo 5 a subrotina de elementos finitos implementada no $L S$ Dyna® é explicada detalhadamente. E no Capítulo 6 os diferentes critérios de falha são aplicados na simulação dos experimentos com o espécime Bifailure, sendo discutidos os resultados numéricos gerados por cada um. 


\section{FUNDAMENTOS TEÓRICOS DO ESTUDO DE FALHA}

A falha estrutural refere-se à perda da capacidade de suportar carga de uma estrutura ou componente. Esta se inicia quando o material atinge seu limite de resistência, causando sua separação em duas ou mais partes. A falha em um material é comumente classificada como sendo frágil ou dúctil, podendo ocorrer um tipo ou outro de falha, ou ambos, de acordo com o tipo de material, o estado de tensão, histórico de carregamento e temperatura. Os modos de falha no momento de ruptura podem variar, entretanto, para materiais dúcteis como aço e alumínio, o fenômeno pode ser ilustrado pela curva tensão-deformação de um ensaio de tração esquematizada na Figura 4.

Percebe-se pela figura que em testes de tração, usados para obter dados relativos ao comportamento mecânico do material, a falha é evidente. Distinguem-se várias etapas do comportamento mecânico do material, em trechos:

OA - comportamento linear, com deformações não permanentes;

$A B$ - plastificação e encruamento, fenômenos associados ao movimento de discordâncias na rede cristalina;

$\mathrm{BC}$ - danejamento, onde se inicia o rompimento de ligações atômicas até a ruptura do material em $\mathrm{C}$.

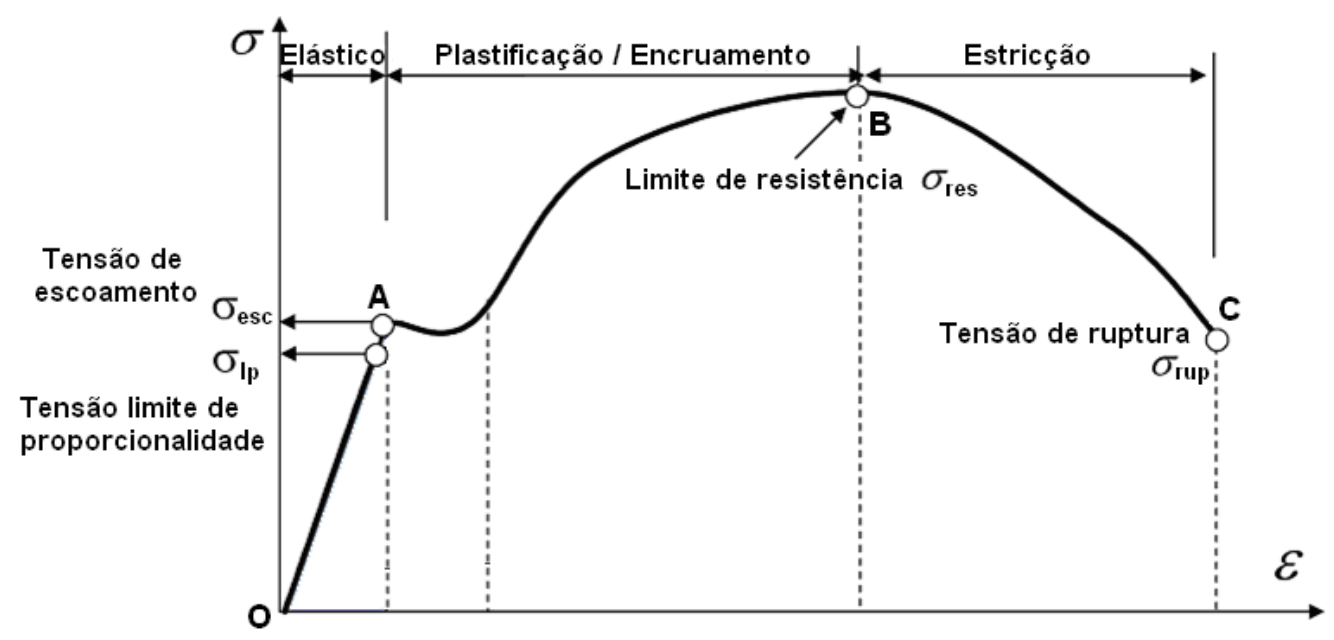

Figura 4. Curva tensão-deformação para material dúctil

O fenômeno de falha em materiais dúcteis envolve desde o comportamento linear de sua fase elástica até, depois de atingido o limite elástico do material, sua 
plastificação e encruamento (fenômenos associados ao movimento de discordâncias na rede cristalina), seguido de dano (onde ocorre o rompimento de ligações atômicas). Como conseqüência da evolução do dano, ocorre localização de deformações e conseqüente estricção do corpo de prova; o material perde resistência e rigidez; ocorre crescimento e coalescência de vazios, levando, finalmente, ao surgimento de uma macrotrinca que se propaga até a falha. É, portanto, um fenômeno complicado da engenharia estrutural.

O corpo de prova de aço inoxidável (austenítico) da Figura 5 foi testado em um ensaio de tração quase-estático. Percebe-se pela figura que há considerável plastificação e estricção em uma pequena região do corpo de prova, onde ocorre a ruptura. Essa estricção está relacionada com o início do danejamento do material e ocorre no ponto B da Figura 5. Nessa região, o estado de tensão não é mais uniaxial, podendo ser medido experimentalmente através de técnicas especiais de tratamento de imagens (como o Digital Image Correlation - DIC) ou, simplesmente, no caso de corpos de prova cilíndricos, através do método de Bridgman (como descrito em Ling, 1996).

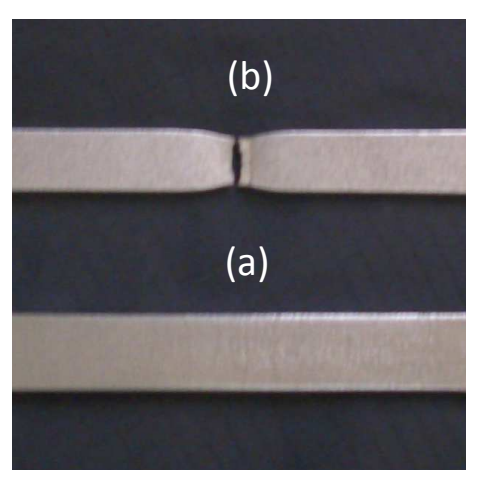

Figura 5. Corpo de prova de aço (a) antes e (b) após ensaio de tração uniaxial. Teste realizado no laboratório do Grupo de Mecânica dos Sólidos e Impacto em Estruturas (GMSIE).

Várias formas de tratar o fenômeno de falha foram desenvolvidas, entre elas modelos de falha abrupta, modelos micromecânicos e mecânica do dano contínuo, que serão explicados neste trabalho.

O fenômeno de falha geralmente envolve não linearidades de material e geométrica, assim torna-se conveniente utilizar métodos numéricos para prever a falha, sendo que com o constante aumento da capacidade de processamento dos computadores, os códigos de elementos finitos podem se tornar capazes de lidar com modelos mais complexos de falha. Por outro lado, a praticidade de calibração 
de um critério de falha é uma prioridade na definição de um critério de falha robusto, que também precisa ser capaz de ser implementado numericamente e prever com boa precisão a falha em diferentes situações a fim de poder ser aplicado com facilidade na indústria.

Para o método numérico ser utilizado corretamente, é necessário conhecer bem o fenômeno estudado, que tem suas explicações na microestrutura. Além disso, é necessário modelar o material e a falha de forma consistente.

De acordo com Wu et al. (2010), o comportamento estrutural de um material depende das propriedades do material, da microestrutura e condições de carregamento (tensões, deformações e temperatura).

\subsection{Microestrutura}

Quando um metal solidifica-se, forma-se uma estrutura policristalina na qual cada cristal é chamado de grão e cada grão possui uma orientação cristalográfica definida. As fronteiras entre os grãos são chamadas de contornos de grão, conforme ilustrado na Figura 6.

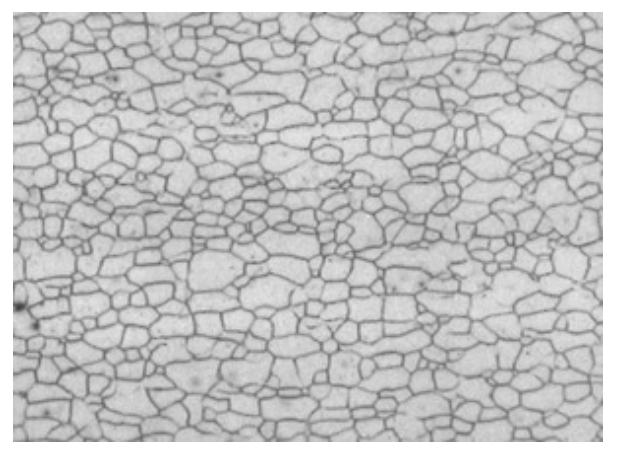

Figura 6. Estrutura granular de aço, mostrando nitidamente os contornos de grão. Extraído do site http://www.arcelormittal.com/automotive/saturnus/sheets/catalogue.pl?id_sheet=I5\&header=\&l anguage $=\mathrm{EN}$ em 30/12/2011.

As propriedades mecânicas da estrutura policristalina são uma média das propriedades mecânicas de cada grão anisotrópico, assim como um todo a estrutura comporta-se como sendo isotrópica. 
A estrutura atômica não é perfeita: nela existem defeitos como lacunas, átomos substitucionais ou intersticiais, discordâncias ou vazios. A plasticidade é embasada no deslocamento de discordâncias na rede cristalina, sendo que uma discordância é um defeito linear ou unidimensional que gera uma distorção local da rede cristalina, conforme Figura 7.

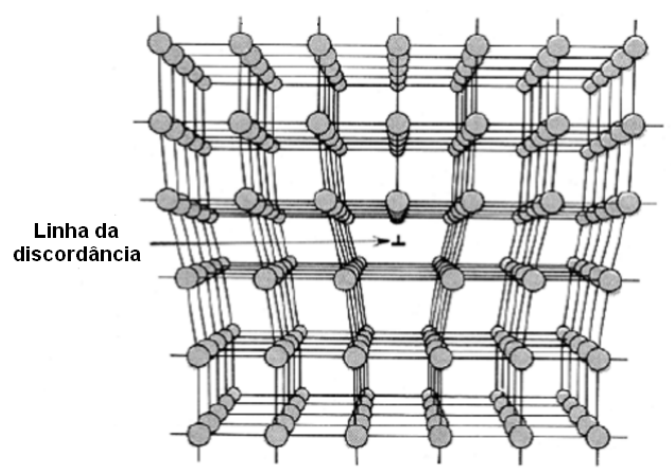

Figura 7. Discordância do tipo aresta, indicada pela seta, gerando distorção na rede cristalina. Adaptado de Callister (2007).

O deslocamento de discordâncias, induzido por tensões cisalhantes, ocorre ao longo de planos cristalográficos chamados de planos de escorregamento.

Quanto maior a dureza e resistência de um material, menor é a facilidade com que as discordâncias conseguem se mover no retículo cristalino. Durante o processo de deformação plástica o número de discordâncias aumenta consideravelmente, geradas pela multiplicação de discordâncias pré-existentes e por concentradores de tensão como contornos de grão e microdefeitos do material. Como a interação entre duas discordâncias é de ordem repulsiva, quando as discordâncias interagem entre si o movimento de uma discordância acaba sendo dificultado pela presença de outras discordâncias, e com isso temos o aumento da resistência mecânica do metal.

Em um ensaio de tração, ao se atingir o limite de resistência à tração do material, a deformação plástica torna-se não homogênea, concentrando-se em uma pequena porção do corpo de prova, e gerando uma zona de estrangulamento da seção conhecida por estricção. A deformação torna-se não homogênea pelo fato de a diminuição da seção transversal ocorrer mais rapidamente que o encruamento. $A$ seguir, ocorre a ruptura (falha) do material.

Em falha dúctil, que é o foco deste trabalho, há considerável deformação plástica antes da ruptura. Geralmente quanto maior a pureza de um material dúctil, 
maior a deformação plástica suportada até a ruptura. O termo "falha dúctil" geralmente está relacionado com a falha por nucleação, crescimento e propagação de vazios (Ballard, 1997).

A influência de temperatura é evidente na definição entre ocorrência de falha mais dúctil ou mais frágil, apesar do comportamento dúctil do material a temperatura ambiente. Quanto maior a temperatura, mais intenso é o movimento de vibração dos átomos. Assim maior é a facilidade de restabelecimento de ligações atômicas quando o material sofre plastificação, pela redução da resistência ao movimento relativo entre átomos. Dessa forma, a falha no material ocorre com presença de grandes deformações plásticas, o que é característico da falha dúctil. Quando a temperatura é reduzida ocorre o efeito inverso: o movimento de átomos ao longo da rede cristalina é dificultado, assim como o restabelecimento de ligações atômicas rompidas. Quando a falha ocorre, a dificuldade de restabelecimento de ligações atômicas dificulta a progressão da deformação plástica, o que caracteriza o modo de falha frágil.

\subsection{Invariantes de tensão}

Considerando-se as componentes do tensor de tensões $\sigma_{i j}$ e as tensões principais $\sigma_{1}, \sigma_{2}$ e $\sigma_{3}$, define-se a tensão hidrostática como:

$$
\sigma_{m}=\frac{1}{3} I_{1}=\frac{1}{3} \sigma_{i i}=\frac{1}{3}\left(\sigma_{1}+\sigma_{2}+\sigma_{3}\right)
$$

onde $I_{1}$ representa o primeiro invariante do tensor de tensões e a notação com índices iguais representa um somatório. Considerando $s_{i j}$ como as componentes do tensor desviador, e $s_{1}, s_{2}$ e $s_{3}$ os seus valores principais, tem-se:

$$
s_{i j}=\sigma_{i j}-\sigma_{m} \delta_{i j}
$$


onde $\delta_{i j}$ é o delta de Kronecker. Em forma matricial, $\delta_{i j}$ corresponderia à matriz identidade. O segundo e o terceiro invariantes do tensor desviador são:

$$
\begin{gathered}
J_{2}=\frac{1}{2} s_{i j} s_{j i}=-\left(s_{1} s_{2}+s_{2} s_{3}+s_{3} s_{1}\right)=\frac{1}{6}\left[\left(\sigma_{1}-\sigma_{2}\right)^{2}+\left(\sigma_{2}-\sigma_{3}\right)^{2}+\left(\sigma_{3}-\sigma_{1}\right)^{2}\right] \\
J_{3}=\operatorname{det}\left(s_{i j}\right)=\frac{1}{3}\left(s_{i j} s_{j k} s_{k i}\right)=s_{1} s_{2} s_{3}=\left(\sigma_{1}-\sigma_{m}\right)\left(\sigma_{2}-\sigma_{m}\right)\left(\sigma_{3}-\sigma_{m}\right)
\end{gathered}
$$

A tensão equivalente de von Mises $(\bar{\sigma})$ pode ser expressa por:

$$
\bar{\sigma}=\sqrt{3 J_{2}}
$$

Considere um volume diferencial submetido ao estado de tensões tridimensional no espaço das tensões principais $\left(\sigma_{1}, \sigma_{2}, \sigma_{3}\right)$. Na Figura 8a, a reta paralela a $\overrightarrow{O N}$, ou reta $\vec{h}$, que passa pela origem com ângulos iguais entre os três eixos é chamada de eixo hidrostático, e cada ponto desse eixo corresponde a um estado hidrostático de tensões. O plano perpendicular à reta $\vec{h}$ que passa pela origem é chamado de plano $\pi$, plano octaédrico, ou ainda plano desviador, e nesse plano a tensão hidrostática é nula. Considerando um ponto $\mathrm{P}$ no espaço de tensões com componentes $\left(\sigma_{1}, \sigma_{2}, \sigma_{3}\right)$, o vetor $\overrightarrow{O P}$ pode ser decomposto em uma componente $\overrightarrow{\mathrm{ON}}$, com norma a, paralela ao eixo $\vec{h}$, relacionada à tensão hidrostática, e em uma componente $\overrightarrow{\mathrm{NP}}$, com norma $r$, perpendicular a $\vec{h}$, relacionada à parte desviadora, tal que:

$$
\begin{gathered}
a=\sqrt{3} \sigma_{m} \\
r=\sqrt{\frac{2}{3}} \bar{\sigma}
\end{gathered}
$$

Desta forma, o fator de triaxialidade é definido como sendo:

$$
\eta=\frac{\sigma_{m}}{\bar{\sigma}}=\frac{\sqrt{2}}{3} \frac{a}{r}
$$




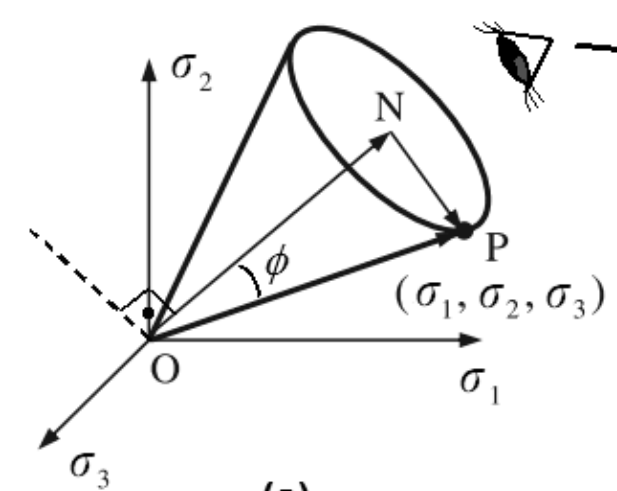

(a)

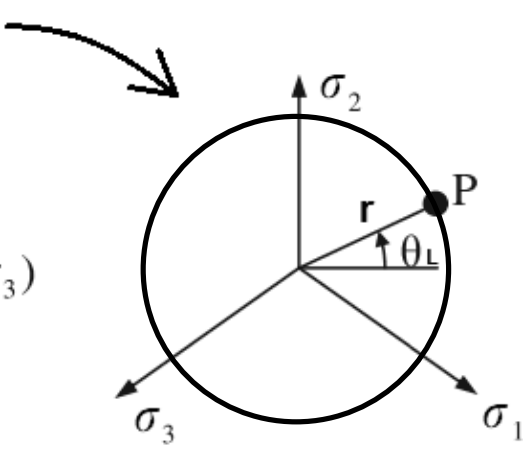

(b)

Figura 8. (a) Cone representativo de um único estado de triaxialidade, (b) Projeção de um estado de tensões no plano $\pi$

A co-tangente do ângulo $\phi$ da Figura 8a é proporcional ao fator de triaxialidade. Portanto demonstra-se que para um determinado fator de triaxialidade existe um infinito número de estados de tensão, representados pela superfície do "cone" da Figura 8a. Ainda, para completar a determinação do estado de tensão é necessária a inclusão do ângulo de Lode, $\theta_{L}$, o qual numericamente representa a magnitude da tensão principal intermediária $\sigma_{2}$ em relação à maior e à menor componente de tensão $\sigma_{1}$ e $\sigma_{3}$, e geometricamente relaciona-se com a posição do ponto $\mathrm{P}$ na circunferência representada na Figura 8b.

As tensões desviadoras podem ser obtidas pela projeção do vetor de tensões OP no plano $\pi$, conforme ilustrado na Figura 8b. Por essa razão que o plano $\pi$ também é chamado de plano desviador.
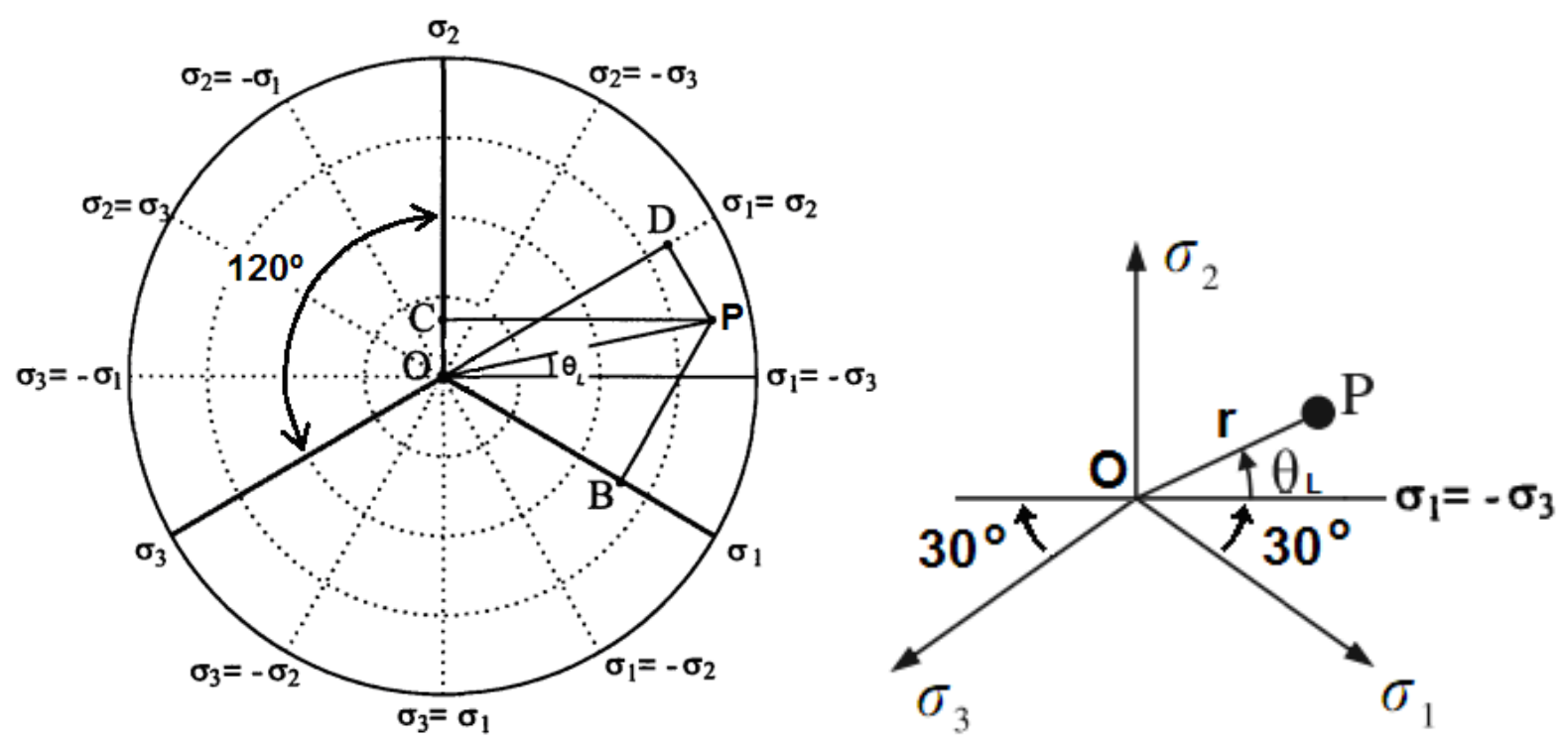

Figura 9. Projeção do vetor de tensões no plano $\pi$. Adaptado de Xue (2007). 
O ângulo de Lode corresponde ao ângulo $\theta_{L}$ da Figura 9. Na Figura 9, além do ângulo de Lode $\theta_{L}$, aparecem as relações entre as tensões principais no plano $\pi$.

O plano $\pi$ aparece esquematizado na Figura 9. Nesse plano, o ângulo entre os eixos das tensões principais é igual a $120^{\circ}$. Desse modo, tem-se que:

$$
\tan \theta_{L}=\frac{\sigma_{2}-\sigma_{1} \operatorname{sen} 30^{\circ}-\sigma_{3} \operatorname{sen} 30^{\circ}}{\sigma_{1} \cos 30^{\circ}-\sigma_{3} \cos 30^{\circ}}
$$

Simplificando, obtém-se a definição do ângulo de Lode $\theta_{L}$ :

$$
\theta_{L}=\tan ^{-1}\left\{\frac{1}{\sqrt{3}} \frac{2 \sigma_{2}-\sigma_{1}-\sigma_{3}}{\sigma_{1}-\sigma_{3}}\right\}
$$

tal que $-\frac{\pi}{6} \leq \theta_{L} \leq \frac{\pi}{6}$. Dessa forma, tem-se que o ângulo de Lode, para alguns estados de tensão mais conhecidos, é definido como:

$$
\begin{aligned}
& \sigma_{1} \neq 0, \sigma_{2}=\sigma_{3}=0 \operatorname{com} \theta_{L}=-\pi / 6 \rightarrow \text { tensão uniaxial } \\
& \sigma_{1}=-\sigma_{3}, \sigma_{2}=0 \operatorname{com} \theta_{L}=0 \rightarrow \text { cisalhamento } \\
& \sigma_{1}=\sigma_{2}, \sigma_{3}<0 \operatorname{com} \theta_{L}=\pi / 6 \rightarrow \text { compressão uniaxial }
\end{aligned}
$$

A relação entre $\theta_{L}$ e o terceiro invariante $J_{3}$ é dada por:

$$
\xi=\frac{27}{2} \frac{J_{3}}{\bar{\sigma}^{3}}=\cos \left(3 \theta_{L}\right)
$$

onde $\xi$ é o terceiro invariante da parte desviadora normalizado, de forma que $-1 \leq \xi \leq 1$. O parâmetro $\xi$ caracteriza a posição (magnitude) da segunda tensão principal $\sigma_{2}$ em relação a primeira e terceira tensões principais $\sigma_{1}$ e $\sigma_{3}$. Quando 
$\xi=-1$, tem-se $\sigma_{1}=\sigma_{2}>\sigma_{3}$; quando $\xi=1$, tem-se $\sigma_{1}>\sigma_{2}=\sigma_{3}$; enquanto que $\xi=0$ para $\sigma_{2}=\left(\sigma_{1}+\sigma_{3}\right) / 2$.

Quando o ângulo de Lode é medido no sentido anti-horário, a partir da linha de $\sigma_{1}$ na Figura 9, variando assim de zero até $\pi / 3$, utiliza-se também a normalização do ângulo de Lode, conhecida como parâmetro de Lode (Bai e Wierzbicki, 2008):

$$
\bar{\theta}=1-\frac{6 \theta_{L}}{\pi}=1-\frac{2}{\pi} a \cos \xi
$$

tal que $-1 \leq \bar{\theta} \leq 1$. Considerando-se o parâmetro de Lode $\bar{\theta}$, tem-se que $\bar{\theta}=1$ corresponde a tração axissimétrica, $\bar{\theta}=0$ corresponde a cisalhamento, e $\bar{\theta}=-1$ corresponde a compressão axissimétrica ou estado de tração equi-biaxial.

O estado plano de tensão $\left(\sigma_{3}=0\right)$ univocamente relaciona $\eta$ com $\xi$ ou $\bar{\theta}$ :

$$
\xi=\cos \left(3 \theta_{L}\right)=\cos \left[\frac{\pi}{2}(1-\bar{\theta})\right]=-\frac{27}{2} \eta\left(\eta^{2}-\frac{1}{3}\right)
$$

A equação anterior apresenta três raízes, uma correspondendo a cisalhamento puro $(\eta=0, \bar{\theta}=0)$ e as outras duas ao estado plano de deformação $(\eta= \pm 1 / \sqrt{3}, \bar{\theta}=0)$.

Em síntese, um estado de tensão representado pelas tensões principais no sistema cartesiano de coordenadas $\left(\sigma_{1}, \sigma_{2}, \sigma_{3}\right)$, também pode ser representado no sistema cilíndrico $\left(\sigma_{m}, \bar{\sigma}, \theta_{L}\right)$ ou no sistema esférico de coordenadas $\left(\bar{\sigma}, \eta, \theta_{L}\right)$.

Outro parâmetro derivado de invariantes e que é utilizado em trabalhos de falha é o produto de triaxialidade:

$$
\sigma_{p}^{*}=\frac{\sigma_{1} \sigma_{2} \sigma_{3}}{\bar{\sigma}^{3}}=\frac{I_{3}}{\bar{\sigma}^{3}}
$$

A maioria dos critérios de falha utiliza os invariantes e parâmetros citados acima na definição de funções de deformação de falha $\varepsilon_{c}$. 


\section{REVISÃO DA LITERATURA}

O fenômeno de falha nos metais é resultado de um processo complexo que ocorre em escala micrométrica. Tal processo envolve a evolução e acumulação de defeitos microscópicos como microvazios e bandas de cisalhamento. Esses defeitos constituem o chamado "dano" do material, afetando as propriedades mecânicas do mesmo.

No passado, várias abordagens foram propostas para o tratamento de falha dúctil, como a mecânica da fratura, modelo de crescimento de vazios, modelo de poroplasticidade, mecânica do dano e vários modelos empíricos. A mecânica de fratura lida com a propagação de uma trinca, o que é diferente do tema tratado nesta dissertação. Assim, por esse motivo, a trinca originada pelo crescimento e propagação de microvazios no material será chamada aqui de falha e não de fratura.

As observações experimentais sobre falha dúctil em geral mostram que (Xue e Wierzbicki, 2008): 1) a aplicação de pressão aumenta a ductilidade do material; 2) a ductilidade do material em estado plano de deformação (ou cisalhamento) é menor do que a ductilidade do mesmo sob o estado de tração ou compressão quando a pressão mantém-se constante; 3) o dano no material se acumula de forma acelerada, inicialmente a uma baixa taxa e posteriormente a uma taxa mais alta à medida que a falha se aproxima; 4) o dano do material afeta a sua resistência mecânica.

A revisão da literatura científica disponível revela grande empenho dos centros de pesquisa no estudo de critérios de falha mais representativos dos fenômenos analisados, considerando a viabilidade de calibração desses critérios através da minimização de testes experimentais. Apesar disso, deve-se ressaltar que a aplicação inadequada desses modelos para diversos estados complexos de deformação pode resultar em previsões errôneas.

Inicialmente, surgiram modelos de falha que consideravam a acumulação de microdefeitos no material. Considerou-se que o surgimento, crescimento e propagação de micro-vazios era responsável pela falha dúctil dos materiais. A primeira análise microscópica de falha foi proposta por McClintock et al. (1966) que assumiu uma distribuição de vazios cilíndricos no material e estudou a evolução do 
crescimento desses vazios. Posteriormente, Rice e Tracey (1969) estudaram o crescimento e mudança de forma de vazios esféricos nos materiais quando sujeitos a carregamento uniaxial. Os autores propuseram que o aumento de volume era mais significativo do que a mudança de forma dos vazios e portanto escreveram a deformação de falha como função do fator de triaxialidade, que é a razão entre a tensão hidrostática e tensão equivalente. No entanto, nos dois modelos anteriores não foi estudada a interação entre microvazios no material. Assim, Leroy et al. (1981) modificou o modelo de Rice e Tracey para incluir o efeito de nucleação e interação entre vazios. Todavia, esses modelos não consideram a plasticidade como acoplada ao dano acumulado pelo material. De acordo com esses modelos, a falha ocorre quando uma variável interna de dano atinge um valor crítico, resultando em uma perda repentina da capacidade de suportar carga do material. Dessa forma, surgiram modelos com acoplamento entre plasticidade e dano, como o proposto por Gurson (1977), que considera o material como sendo um meio poroso, no qual um fator denominado fração volumétrica de vazios controla a ocorrência de falha. Aqui a falha é resultante da coalescência de vazios, e ocorre quando a fração volumétrica de vazios se iguala à unidade. O modelo de Gurson não é realístico, pois, por exemplo, não é capaz de representar a falha sob condições de cisalhamento, onde o mecanismo de crescimento de vazios é inativo. Desse modo, o modelo original de Gurson foi repetidamente modificado para levar em consideração processos adicionais responsáveis pela deterioração do material e conseqüente falha dúctil. Por exemplo, a fim de aprimorar o modelo de Gurson, Tvergaard (1981) e Tvergaard e Needleman (1984) propõem considerar a fração volumétrica de vazios uma função da nucleação de novos vazios e do crescimento de vazios existentes. No entanto, apesar dos aprimoramentos do modelo de Gurson, o grande número de parâmetros do modelo e o fato destes serem fortemente acoplados tornou difícil a calibração e aplicação do modelo. Outro tipo de modelo de falha acoplado, denominado de Mecânica do Dano Contínuo, foi proposto por Lemaitre (1985). Aqui a degradação do material é modelada a partir de uma variável interna de dano enquanto que as equações constitutivas são derivadas da primeira e segunda leis da termodinâmica para meios contínuos.

Para aplicações industriais, são utilizados modelos de falha fenomenológicos empíricos. Apesar de não possuírem embasamento micromecânico, a simplicidade e acuracidade destes modelos os tornam mais aceitos em aplicações de engenharia. 
O critério de falha empírico mais simples é o baseado na máxima deformação plástica equivalente. No entanto, demonstra-se que a deformação equivalente por si só não é suficiente para indicar a ocorrência de falha (Alves e Jones, 1999).

Atualmente, diversos autores confirmam que a falha é fortemente dependente do estado de triaxialidade do material, além do nível de deformação plástica [Alves e Jones (1999), Bao e Wierzbicki (2004), Børvik et al (2004), Wierzbicki et al (2005), Bao e Wierzbicki (2005), Ockewitz et al (2006) e Grytten et al (2009a)]. O modelo de falha de Johnson-Cook (1985), que também é função da triaxialidade, é bastante conhecido por ser o primeiro modelo de falha que também é função da taxa de deformação e temperatura.

Para a calibração dos critérios baseados no fator de triaxialidade é necessário gerar dados experimentais de tensão, triaxialidade e deformação equivalente no instante de falha. Assim, a forma mais comum de se obter diferentes faixas de triaxialidade em experimentos era conduzir testes de tração em espécimes cilíndricos sem e com diferentes entalhes. A seguir, os tensores de tensão e deformação no instante de falha desses espécimes poderiam ser estimados por métodos como o de Bridgman (1956). Porém, métodos como o de Bridgman apenas poderiam gerar dados para altas triaxialidades, limitando assim a calibração e aplicação dos modelos de falha para altas triaxialidades. Desse modo, a posterior introdução das análises pelo Método dos Elementos Finitos foi essencial para prever os valores de tensão e deformação na região de falha, permitindo uma melhor calibração dos modelos de falha.

Kim et al. $(2003,2004,2007)$ e Bai e Wierzbicki (2008) demonstraram que apenas o fator de triaxialidade não é suficiente para caracterizar o estado de tensões de falha, sendo necessário considerar também um novo parâmetro, o ângulo de Lode. Este fato é confirmado pela observação experimental de que em comparação com os testes de tensão e compressão uniaxiais, uma menor ductilidade é observada no teste de torção (Johnson e Cook, 1985). Desse modo, o critério de Xue-Wierzbicki proposto em Wierzbicki et al. (2005) foi criado para incorporar esta observação experimental, possuindo uma superfície de deformação de falha que é função do fator de triaxialidade e parâmetro de Lode. Além disso, investigações numéricas de um vazio esférico contido em uma célula cúbica submetida a tipos diferentes de carregamento triaxial (Gao e Kim, 2006) mostraram que o ângulo de Lode tem uma forte influência na evolução do formato do vazio e no processo de 
coalescência de vazios. E a influência do ângulo de Lode na ductilidade de metais também foi demonstrada experimentalmente por Barsoum e Faleskog (2007), através de ensaios experimentais de um espécime cilíndrico especial sob carregamentos combinados de tração e torção, que produziam valores diferentes de triaxialidade e parâmetro de Lode.

Os trabalhos científicos que estudaram a influência do ângulo de Lode são relativamente recentes, de forma que foi determinada a influência do ângulo de Lode tanto em falha quanto na superfície de escoamento, para diferentes modelos de falha e plasticidade disponíveis na literatura. Por exemplo, em Bardet (1990) foi estudada a influência do ângulo de Lode no formato da superfície de escoamento, e determinado que o modelo de plasticidade de Drucker-Prager assim como os modelos de Tresca e Mohr-Coulomb têm dependência do ângulo de Lode. Além disso, alguns autores sugeriram a inclusão da dependência do ângulo de Lode na formulação de modelos constitutivos tradicionais baseados na superfície de escoamento de von Mises assim como em modelos de evolução de dano. Especificamente, Brünig et al. (2008) e Bai e Wierzbicki (2008) propuseram modelos de plasticidade que incluem a influência dos três invariantes de tensão na superfície de escoamento.

Os modelos de plasticidade baseados na tensão de Von Mises ou critério de Tresca podem prever satisfatoriamente o início do escoamento de materiais dúcteis, no entanto é o ângulo de Lode que permite representar falha em planos inclinados, como ocorre em testes de tração ou compressão uniaxial, ou diferenças entre as curvas de carregamento de testes de tração e cisalhamento de um material (Chocron et al., 2011). Isto decorre pelo fato de que quando a superfície de escoamento é escrita em função do ângulo de Lode, a mesma passa a possuir um formato não convexo, adotando a forma de uma "estrela de seis pontas".

\subsection{Lugar geométrico de falha}

Estudos experimentais sobre falha em diferentes estados de tensões foram conduzidos de forma a se determinar os fatores que influenciam o fenômeno de 
falha, de modo que para os modelos empíricos verificou-se ao longo do tempo que a falha era dependente da tensão hidrostática e tensão de von Mises. Esses dois fatores, que estão ligados aos invariantes de tensão, foram combinados no fator de triaxialidade. A tensão hidrostática positiva acelera o processo de nucleaçãocrescimento-coalescência de vazios e o movimento de bandas de cisalhamento, enquanto que a tensão hidrostática de natureza compressiva tem por efeito mitigar esses processos.

A seguir, verificou-se que a falha não era dependente apenas do fator de triaxialidade, mas também do ângulo de Lode, o qual está relacionado com o terceiro invariante de tensão do tensor desviador. No entanto, a sensibilidade da deformação de falha em relação ao fator de triaxialidade e ao ângulo de Lode é diferente para diferentes materiais. Por exemplo, na Figura 10 aparece esquematizada a superfície de deformação de falha para dois materiais, o alumínio 2024-T351 e o aço 1045, em função do fator de triaxialidade e ângulo de Lode. Percebe-se que a falha do alumínio 2024-T351 é fortemente influenciada tanto pelo fator de triaxialidade quanto pelo ângulo de Lode, enquanto que para o aço 1045 a superfície de falha tem baixa influência do ângulo de Lode.

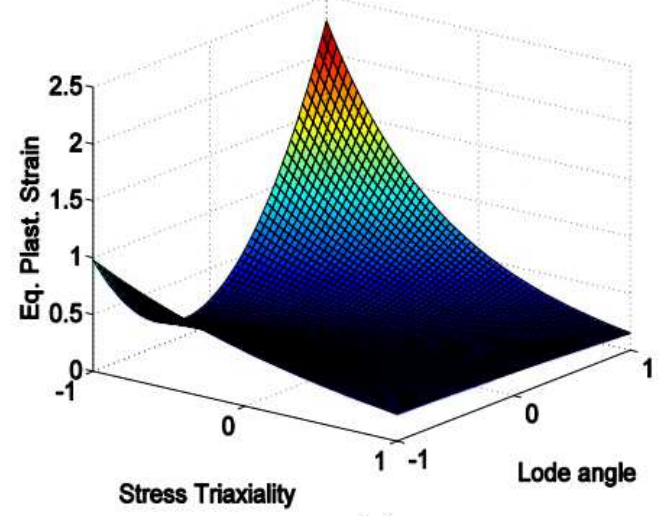

(a)

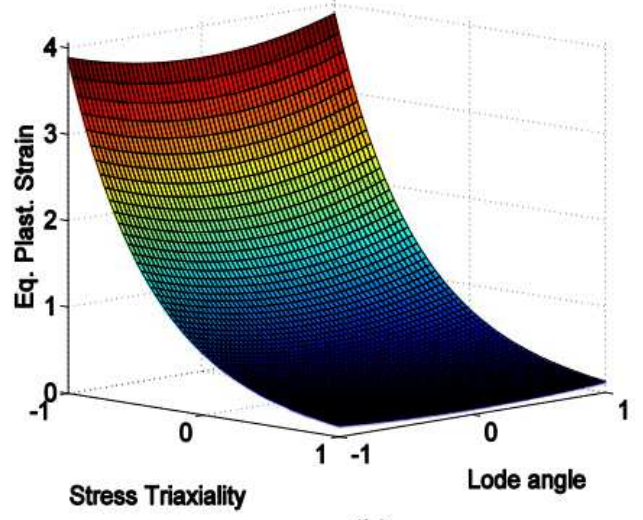

(b)

Figura 10. Deformação de falha em função do fator de triaxialidade e ângulo de Lode para a) alumínio 2024-T351; b) aço 1045 . Extraído de Malcher et al. (2012).

Os mecanismos principais de degradação de material consistem no crescimento de vazios esféricos (influenciado por efeitos de tensão hidrostática) e alongamento de vazios (gerado por efeitos de cisalhamento).

A Figura 11 esquematiza os parâmetros de triaxialidade e ângulo de Lode que podem ser obtidos através de espécimes comumente utilizados em ensaios 
experimentais. Na Figura 11, a área "A" representa a região na qual a maior parte da degradação do material ocorre por efeitos de cisalhamento, onde ambos os valores de triaxialidade e ângulo de Lode estão ao redor de zero, assim o mecanismo principal de degradação consiste no alongamento de vazios. $\mathrm{Na}$ área "B", ainda existe forte influência dos efeitos de cisalhamento, observada em condições de compressão-cisalhamento e tração-cisalhamento, onde tanto ocorrem mecanismos de crescimento de vazios esféricos quanto de alongamento de vazios. Na área "C", os efeitos de cisalhamento são desprezíveis e o mecanismo de degradação predominante consiste no crescimento de vazios esféricos.

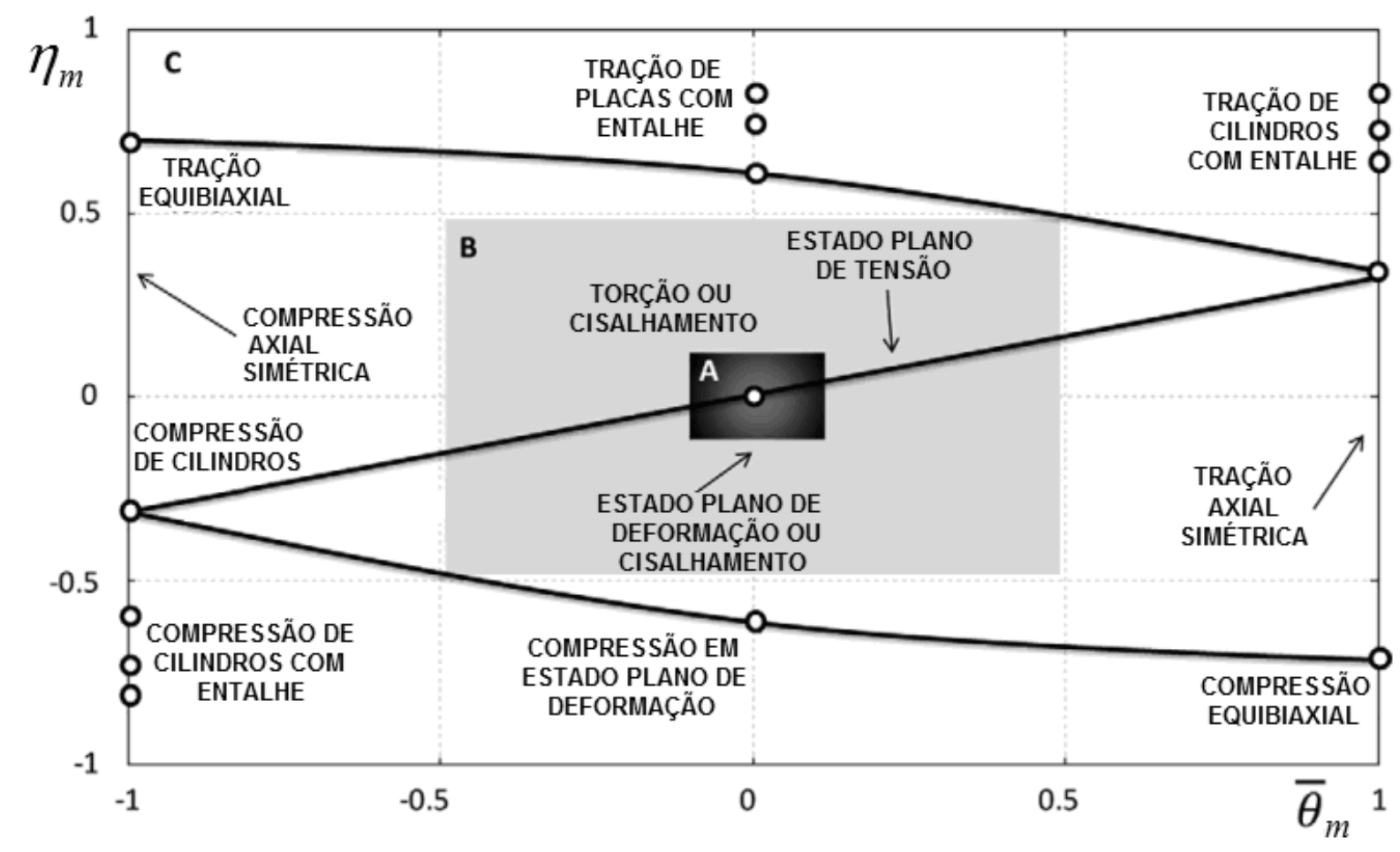

Figura 11. Representação de estados de tensão no espaço de triaxialidade versus parâmetro de Lode. Adaptado de Malcher et al. (2012).

$\mathrm{Na}$ Figura 11, os valores dos eixos correspondem a valores médios do fator de triaxialidade e parâmetro de Lode, dados por:

$$
\begin{aligned}
& \eta_{m}=\frac{1}{\bar{\varepsilon}_{f}} \int_{0}^{\bar{\varepsilon}_{f}} \eta(\bar{\varepsilon}) d \bar{\varepsilon}_{p} \\
& \bar{\theta}_{m}=\frac{1}{\bar{\varepsilon}_{f}} \int_{0}^{\bar{\varepsilon}_{f}} \bar{\theta}(\bar{\varepsilon}) d \bar{\varepsilon}_{p}
\end{aligned}
$$


onde $\bar{\varepsilon}_{f}$ corresponde à deformação plástica equivalente de falha.

A partir de observações experimentais, verifica-se que a falha dúctil compreende três fases: acúmulo de dano, início da falha e propagação de trinca. $O$ início da falha ocorre a partir de acúmulo de dano, de forma que microscopicamente, tal dano é associado com a nucleação, crescimento, e coalescência de microvazios, movimento de bandas de cisalhamento e propagação de microtrincas. Macroscopicamente, o dano no material é verificado pela redução da resistência mecânica e ductilidade do mesmo. Essas mudanças no material são utilizadas para a previsão de falha, através do controle da verificação de valores indicativos instantâneos ou valores indicativos de falha que variam de forma cumulativa com o tempo. Em mecânica do contínuo, uma variável indicativa de danejamento no material comumente utilizada chama-se "dano". Apesar de o dano possuir natureza anisotrópica, por praticidade o mesmo é modelado como sendo isotrópico e como uma grandeza escalar, o que tem produzido bons resultados. Como o dano é uma variável interna do material que não pode ser medida diretamente, é necessário criar uma correlação entre o dano e outras variáveis que podem ser mensuráveis. Deste modo, os modelos de dano criam a correlação necessária para se poder quantificar o dano.

Dois enfoques principais são dados para a modelagem do comportamento mecânico dos materiais: o enfoque macroscópico, em que o material é considerado em forma agregada, e o enfoque microscópico, em que a microestrutura do material é levada em consideração.

Modelos macroscópicos são construídos com base em variáveis de estado mensuráveis, como tensores de tensão e deformação, e às vezes temperatura e taxa de deformação. Demonstra-se experimentalmente que o histórico de carregamento influencia diretamente a ocorrência de falha.

Vários modelos de falha consideram que o dano não possui influência na plasticidade do material, ou seja, são modelos desacoplados. Uma vantagem dessa abordagem é que a evolução do dano e a evolução da plasticidade são desacopladas ao longo do cálculo das tensões no método de integração numérico, reduzindo o processamento computacional necessário. Consequentemente, no processo de verificação de falha, a variável de dano torna-se uma variável de pósprocessamento. Por outro lado, o fato de o modelo de dano estar desacoplado 
resulta em uma queda brusca da curva de carregamento do material quando da ocorrência de falha, resultando em uma representação não realística dos modos de falha, incluindo a falta da perda de resistência do material próximo do momento de falha com a representação de um aumento de resistência nos momentos finais de plasticidade que na verdade não existe.

Em mecânica do dano contínuo, considera-se que o dano possui influência na resistência mecânica do material desde o início do carregamento até a ruptura do material. Esta forma de modelagem por outro lado exige maior capacidade de processamento computacional.

Os modelos de dano cumulativos consideram que a falha ocorre quando a variável de dano excede um valor crítico $D_{C}$. Normalmente a variável de dano é normalizada em relação ao valor crítico $D_{C}$, de forma que o valor crítico de dano a ser atingido passa a ser unitário. A equação que define o incremento do dano cumulativo possui a forma geral:

$$
\frac{d D}{d \bar{\varepsilon}_{p}}=F(\varepsilon, T, \dot{\varepsilon})
$$

onde $d \bar{\varepsilon}_{p}$ é o incremento de deformação plástica ao longo dos ciclos de integração no tempo. O lado direito da equação (17) é função de variáveis de estado como deformação, temperatura e taxa de deformação. Neste trabalho, são estudados critérios de falha que não consideram a influência de temperatura nem da taxa de deformação no lado direito da equação anterior, assim $\mathrm{F}$ torna-se $F=F(\varepsilon)$.

\subsection{Mecanismos físicos para ocorrência de falha dúctil}

Como já discutido anteriormente, além da microestrutura do material e do histórico de tensões e deformações, um dos principais fatores que influenciam a ocorrência de falha dúctil é a triaxialidade. Assim, são apresentados a seguir diferentes formas de falha dúctil, de acordo com a faixa de triaxialidade. 
Seguindo a idéia de Bao e Wierzbicki $(2004,2005)$, ilustrada na Figura 12, é conveniente distinguir três estados que levam a falhas distintas, sendo eles: falha por crescimento de vazios (alta triaxialidade), falha por cisalhamento (baixa ou nula triaxialidade), e a transição entre os dois (triaxialidade média). Bridgman (1956), por exemplo, já havia definido que quando a tensão hidrostática é compressiva, a ocorrência do fenômeno de nucleação-crescimento-coalescência de vazios é dificultada, aumentando assim a ductilidade em metais.

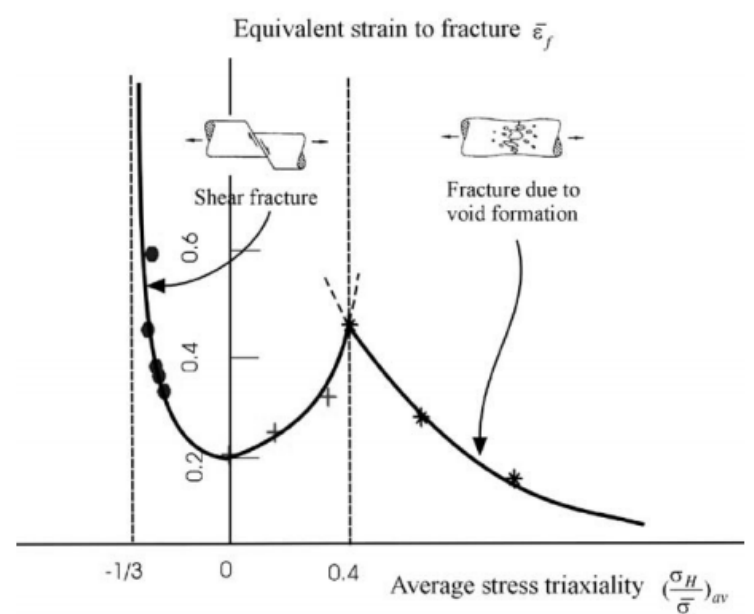

Figura 12. Relação da deformação equivalente de falha com a triaxialidade para alumínio 2024-T351 (Bao e Wierzbicki, 2004)

\subsubsection{Alta triaxialidade}

Este modo de falha se caracteriza por gerar superfícies ásperas e rugosas (com alvéolos). O início do processo ocorre com a nucleação de vazios nas regiões do material com inclusões de maior tamanho (partículas de elementos de liga), grandes defeitos da rede cristalina ou em regiões com bandas de cisalhamento. Um exemplo que ilustra a nucleação em partículas de liga é ilustrado na Figura 13.

Após a nucleação, ocorre o crescimento e propagação do vazio, sendo que a forma de crescimento e mudança de formato de vazios depende do histórico de tensões e deformações do material. 


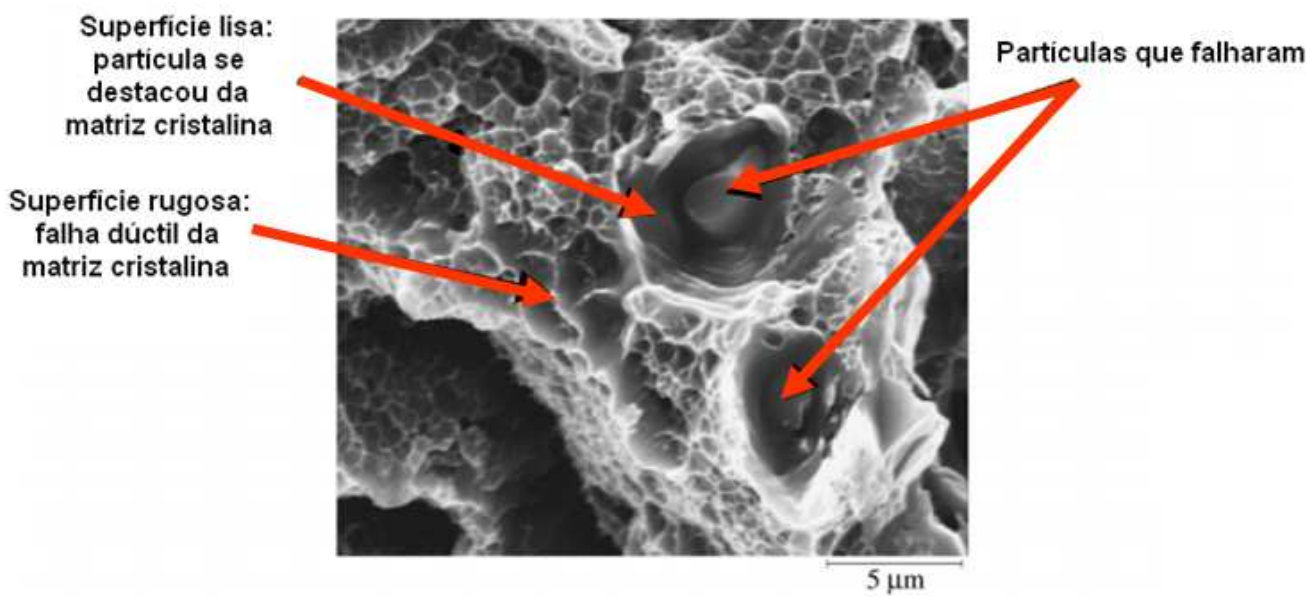

Figura 13. Nucleação de vazios em partículas, e falha dúctil da matriz cristalina para liga de alumínio 2024-T351. Extraído de Bao e Treitler (2004).

Além da nucleação e crescimento de vazios, existem diferentes mecanismos para a propagação dos mesmos. Os vazios podem propagar-se devido à estricção da rede cristalina entre dois vazios (Figura 14a), quando dois vazios entram em contato (Figura 14b), ou pela ligação de microvazios entre dois vazios maiores (Figura 14c).

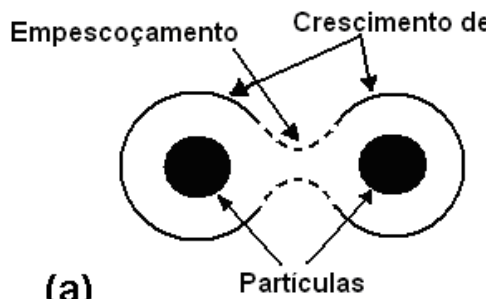

(a)

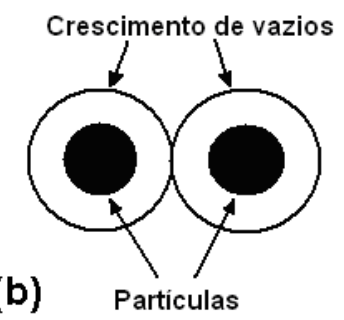

(c)

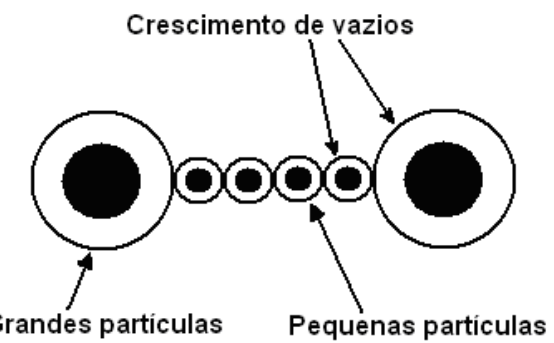

Figura 14. (a) Ligação de vazios por empescoçamento; (b) Ligação de vazios por contato; (c) Ligação de vazios por ligação de microvazios

\subsubsection{Triaxialidade negativa}

Não existem estudos detalhados sobre falha em triaxialidades negativas. No entanto, verifica-se que em testes de compressão de cilindros (nos quais a faixa de triaxialidade está entre $-0,33$ e -0,05) a falha ocorre nos planos de tensão cisalhante máxima (bandas de cisalhamento), a 45ํ da direção de carregamento, gerando uma superfície de falha que é relativamente lisa. Podem-se verificar essas características 
na compressão de cilindros (Bai e Wierzbicki, 2008), de acordo com a Figura 15. No trabalho de Bao e Wierzbicki (2005), inclusive, foi proposto um valor de cut-off de $-1 / 3$ para a triaxialidade, abaixo do qual não há falha.

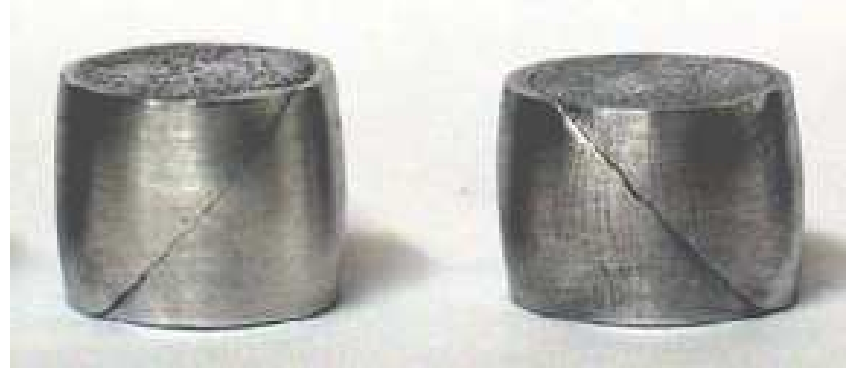

Figura 15. Falha em teste de compressão de cilindros, nos planos de tensão cisalhante máxima. Extraído de Bai e Wierzbicki (2008).

\subsubsection{Falha em triaxialidade intermediária}

French e Weinrich (1975) estudaram a influência da pressão em testes de tração de espécimes de cobre. Foi verificado que sem aplicação de pressão, a superfície de falha mostra que a mesma ocorreu totalmente por nucleação, crescimento e ligação de vazios. Por outro lado, a aplicação de pressão implica na redução da rugosidade da superfície de falha, isto é, ocorre transição gradual para o modo de falha verificado em triaxialidades negativas. Assim, pôde-se concluir que na faixa de triaxialidades intermediárias, o mecanismo de falha é uma combinação de nucleação, crescimento e ligação de vazios e falha nas bandas de cisalhamento.

\subsection{Modelos de falha da mecânica do contínuo}

Vários modelos de falha da mecânica do contínuo consideram o processo de danejamento do material como desacoplado do comportamento plástico do material. Assim, nesses modelos a variável de falha tem por finalidade identificar a sua 
ocorrência, não influenciando na perda gradual de resistência do material até atingir a ruptura. Dessa forma, esses modelos representam uma perda súbita da capacidade do material de transmitir carga no instante de falha. Por outro lado, a mecânica do dano contínuo considera que o danejamento do material afeta sua resistência. Deste modo, o material perde gradativamente sua resistência até a ocorrência de falha. Este é o caso do modelo de dano de Lemaitre.

\subsubsection{Critério de falha da máxima deformação plástica equivalente}

Este critério identifica a falha quando é atingida uma deformação plástica equivalente de ruptura $\bar{\varepsilon}_{f}$.

$$
\bar{\varepsilon}=\bar{\varepsilon}_{f}
$$

Para um material incompressível $\bar{\varepsilon}$ é definido como:

$$
\bar{\varepsilon}=\sqrt{\frac{2}{3}\left(\varepsilon_{1}^{2}+\varepsilon_{2}^{2}+\varepsilon_{3}^{2}\right)}
$$

onde $\varepsilon_{1}, \varepsilon_{2}, \varepsilon_{3}$ são as deformações plásticas principais. Este critério é válido para todos os estados de tensão, de forma que apesar de ter sido um dos primeiros critérios de falha que surgiu, o mesmo é adotado ainda hoje, pela facilidade em identificar a falha na fase de pós-processamento (basta aplicar escalas de cores delimitadas pelo valor crítico de deformação) e pela grande disponibilidade de dados de deformação de ruptura que podem ser encontrados na literatura. 


\subsubsection{Critério de falha da máxima tensão cisalhante}

Existem inúmeras evidências experimentais de que a falha ocorre no plano de tensão cisalhante máxima, como mostrado por Bai e Wierzbicki (2008). A condição de falha é definida como:

$$
\begin{gathered}
\tau_{\text {max }}=\left(\tau_{\max }\right)_{f} \\
\tau_{\max }=\max \left\{\left|\frac{\sigma_{1}-\sigma_{2}}{2}\right|,\left|\frac{\sigma_{2}-\sigma_{3}}{2}\right|,\left|\frac{\sigma_{3}-\sigma_{1}}{2}\right|\right\}
\end{gathered}
$$

onde $\sigma_{1}, \sigma_{2}$ e $\sigma_{3}$ são as tensões principais.

\subsubsection{Critério de falha de Johnson-Cook}

O critério de falha de Johnson-Cook possui uma função de dano cumulativo da forma:

$$
D=\int_{0}^{\bar{\varepsilon}_{f}} \frac{d \bar{\varepsilon}_{p}}{\varepsilon_{c}}
$$

A falha é detectada quando a variável de dano $D$ atinge o valor unitário. A função de deformação de falha, $\varepsilon_{c}$, é dada por:

$$
\varepsilon_{c}=\left[D_{1}+D_{2} \exp \left(D_{3} \eta\right)\right]\left[1+D_{4} \log \frac{\dot{\varepsilon}_{p}}{\dot{\varepsilon}_{0}}\right]\left[1+D_{5}\left(\frac{T-T_{0}}{T_{f}-T_{0}}\right)\right]
$$

onde $\eta$ é o fator de triaxialidade, $\dot{\varepsilon}_{0}$ é a taxa de deformação de referência, $T_{f}$ é a temperatura de fusão do material, e $T_{0}$ é a temperatura de referência. Neste 
trabalho, por praticidade, o critério de falha de Johnson-Cook utilizado possui a fórmula:

$$
\varepsilon_{c}=D_{1}+D_{2} \exp \left(D_{3} \eta\right)
$$

Deste modo, os efeitos da taxa de deformação e temperatura sobre a deformação de falha foram ignorados. Isso porque para o alumínio 2024-T351 os efeitos de taxa de deformação e temperatura sobre a falha são significativos apenas na simulação de impacto a altas velocidades. Conclusões similares também foram tiradas para outros metais, como em Børvik et al. (2001), Børvik et al. (2003) e Hopperstad et al. (2003).

O critério de falha de Johnson-Cook é amplamente utilizado devido ao fato de ser prático de calibrar e de existir na literatura um vasto banco de dados sobre os parâmetros de falha para diversos materiais (Johnson e Holmquist, 1989). Considera-se que este critério é válido para faixas de triaxialidades médias a moderadas. Para triaxialidades baixas ou negativas não é recomendado aplicar este critério, pois a curva inteira de deformação de falha real não pode ser ajustada por apenas uma única função exponencial, de forma que na prática o ajuste de $\varepsilon_{c}$ para o critério de falha de Johnson-Cook é feito para triaxialidades médias a moderadas. Deste modo, este critério é bastante utilizado na avaliação de impacto em estruturas (Grytten et al., 2009a; Dey et al., 2007), e em estudos relacionados a limite balístico (Grytten et al., 2009b).

\subsubsection{Critério de falha de Wilkins}

Este critério é baseado na seguinte variável cumulativa de dano:

$$
D=\int_{0}^{\bar{\varepsilon}_{f}} \frac{1}{\left(1-a \sigma_{m}\right)^{\lambda}}(2-A)^{\mu} d \bar{\varepsilon}_{p}
$$


onde $A=\max \left(\frac{s_{2}}{s_{1}}, \frac{s_{2}}{s_{3}}\right), s_{1}, s_{2}$ e $s_{3}$ são as tensões desviadoras principais, $\sigma_{m}$ é a tensão hidrostática e os parâmetros $a, \lambda$ e $\mu$ são parâmetros do critério de falha. Considera-se que um elemento falhou quando $D \geq D_{\text {crit }}$, e quando estas duas condições forem satisfeitas simultaneamente: $\sigma_{m}<p_{c r}$ e $\bar{\varepsilon}_{p}>0$, onde $p_{c r}$ é uma tensão hidrostática crítica, dada por:

$$
p_{c r}=-\frac{1}{a}
$$

\subsubsection{Critério de falha de Cockcroft-Latham}

Neste critério a falha ocorre quando a seguinte integral atinge um valor crítico $D_{\text {crit }}$ :

$$
D=\int_{0}^{\bar{\varepsilon}_{f}} \frac{\left\langle\sigma_{1}\right\rangle}{\bar{\sigma}} d \bar{\varepsilon}_{p}
$$

onde $\left\langle\sigma_{1}\right\rangle$ é uma função que é igual a $\sigma_{1}$, se $\sigma_{1}>0$, e igual a zero se $\sigma_{1} \leq 0$. Este critério de falha é impreciso, pois não representa com eficácia a falha em altas triaxialidades (Teng e Wierzbicki, 2006) além do valor crítico $D_{\text {crit }}$ variar bastante dependendo do teste utilizado para a calibração (para calibrar este critério é necessário apenas um teste experimental). Para alumínio 2024-T351 o valor $D_{\text {crit }}$ varia de 0,058 até 0,485 segundo Teng e Wierzbicki (2006).

Além disso, o critério de Cockcroft-Latham (Cockcroft e Latham, 1968) foi estudado por Børvik em simulações de limite balístico (Børvik et al., 2009; 2010) e perfuração de placas (Børvik et al., 2011), resultando em boa correlação entre resultados experimentais e numéricos. 


\subsubsection{Critério de falha de Bao-Wierzbicki}

Este critério de falha possibilita uma melhor representação da deformação de falha em função do fator de triaxialidade, pois a função é dividida em subequações de acordo com a faixa de triaxialidade. Este critério é baseado na seguinte variável cumulativa de dano:

$$
D=\int_{0}^{\bar{\varepsilon}_{f}} \frac{d \bar{\varepsilon}_{p}}{\varepsilon_{c}}
$$

onde a função de deformação de falha $\varepsilon_{c}$ para o alumínio 2024-T351 é dada por:

$$
\varepsilon_{c}=\left\{\begin{array}{cc}
\infty & \frac{\sigma_{m}}{\bar{\sigma}} \leq-\frac{1}{3} \\
0,1225\left(\frac{\sigma_{m}}{\bar{\sigma}}+\frac{1}{3}\right)^{-0,46} & -\frac{1}{3}<\frac{\sigma_{m}}{\bar{\sigma}}<0 \\
1,9\left(\frac{\sigma_{m}}{\bar{\sigma}}\right)^{2}-0,18 \frac{\sigma_{m}}{\bar{\sigma}}+0,21 \longrightarrow & 0<\frac{\sigma_{m}}{\bar{\sigma}}<0,4 \\
\exp \left(-1,944 \frac{\sigma_{m}}{\bar{\sigma}}\right) & 0,4<\frac{\sigma_{m}}{\bar{\sigma}}
\end{array}\right.
$$

de forma que $\sigma_{m}$ é a tensão hidrostática e $\bar{\sigma}$ é a tensão equivalente. Uma particularidade deste critério de falha é que para triaxialidades abaixo de $-1 / 3$ não há contribuição para a variável cumulativa de dano. Assim, fica implementado neste critério a observação experimental de que para triaxialidades abaixo de $-1 / 3$ não é possível a ocorrência de falha (Bao e Wierzbicki, 2005). O significado físico dessa afirmação é de que uma trinca nunca poderá surgir em um material submetido à compressão hidrostática com $\sigma_{m} / \bar{\sigma}<-1 / 3$. 


\subsubsection{Critério de falha de Xue-Wierzbicki}

Este critério de falha leva em consideração na sua formulação o ângulo de Lode, além do fator de triaxialidade, o que aumenta consideravelmente sua acuracidade. A função de dano cumulativo para este critério tem o formato:

$$
D=\int_{0}^{\bar{\varepsilon}_{f}} \frac{d \bar{\varepsilon}_{p}}{\varepsilon_{c}}
$$

tal que $\varepsilon_{c}=C_{1} e^{-C_{2} \eta}-\left(C_{1} e^{-C_{2} \eta}-C_{3} e^{-C_{4} \eta}\right)\left(1-\xi^{1 / n}\right)^{n}$ onde $\eta$ é o fator de triaxialidade e $\xi$ é o parâmetro de Lode, dado por:

$$
\xi=\frac{27}{2} \frac{s_{1} s_{2} s_{3}}{\bar{\sigma}^{3}}
$$

Os valores $C_{n}$ são parâmetros do critério de falha, e $n$ é o coeficiente de encruamento do material.

\subsection{Modelos micro-mecânicos}

Nos modelos micromecânicos, o material é considerado como sendo um meio poroso, visto que observações em escala micrométrica indicam que o mecanismo de acúmulo de dano nos materiais dúcteis envolve a nucleação, crescimento e coalescência de vazios. Vários trabalhos científicos abordaram o tema sobre nucleação-crescimento-coalescência de vazios sujeitos a vários estados de tensão. Nesses modelos, o vazio é modelado como uma esfera ou elipsóide rodeado por material sem danejamento, o qual obedece às leis da mecânica do contínuo. Deste modo, a resposta global da porção de material contendo o vazio é considerada como sendo a resposta mecânica macroscópica do material. Devido à enorme combinação 
de formatos e orientações possíveis para os vazios, são necessárias simplificações para tornar o problema matematicamente solúvel. Os trabalhos pioneiros cabem a McClintock (1968) e Rice e Tracey (1969) que analisaram o comportamento de um vazio cilíndrico ou esférico submetido à tensão uniforme. Nesses modelos, o material é considerado como um meio poroso, e a falha ocorre quando é atingido um valor crítico para a fração volumétrica de vazios. Gurson (1977) introduziu o acoplamento entre a influência dos microvazios e a plasticidade do material, e Tvergaard (1981) e Tvergaard e Needleman (1984) estenderam o modelo de Gurson a fim de incluir a aceleração do crescimento de vazios.

\subsubsection{Modelo de falha de McClintock}

Foi McClintock (1968) que realizou uma primeira análise teórica do crescimento de vazios. O material foi considerado como contendo vazios cilíndricos de seção transversal elíptica, de acordo com a Figura 16.
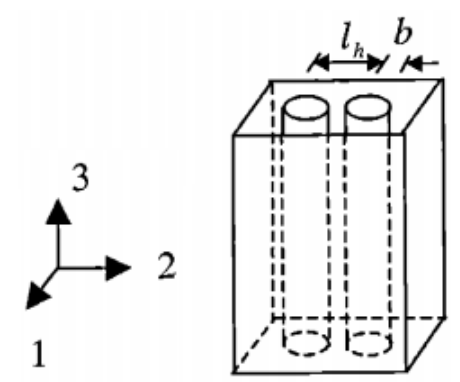

Figura 16. Modelo de crescimento de vazios de McClintock.

McClintock analisou uma longa cavidade cilíndrica em um material tracionado no eixo da cavidade, enquanto o mesmo era submetido a tensões transversais. $O$ crescimento do vazio cilíndrico era governado por:

$$
d \log \frac{b}{b_{0}}=\sqrt{3} \operatorname{senh}\left(\frac{\sqrt{3} \sigma_{r, \mathrm{inf}}}{\sigma_{r, \mathrm{inf}}-\sigma_{z, \mathrm{inf}}}\right) d \varepsilon_{r, \mathrm{inf}}+d \varepsilon_{r, \mathrm{inf}}
$$


onde $z$ é a direção axial, $r$ é a direção radial, inf denota valores distantes, $b_{0}$ é o raio original do cilindro e $b$ é o raio instantâneo do mesmo. $O$ modelo de dano de McClintock pode ser expresso por:

$$
d D=\frac{1}{\log F_{z b}^{f}}\left[\frac{\sqrt{3}}{2(1-n)} \operatorname{senh}\left(\frac{\sqrt{3}(1-n)}{2} \frac{\left(\sigma_{a}-\sigma_{b}\right)}{\bar{\sigma}}\right)+\frac{3}{4} \frac{\sigma_{a}-\sigma_{b}}{\bar{\sigma}}\right] d \bar{\varepsilon}_{p}
$$

onde $\log F_{z b}^{f}$ denota a máxima deformação da célula contendo o microvazio, $\sigma_{a}$ e $\sigma_{b}$ são as tensões transversais, $\bar{\sigma}$ é a tensão equivalente, $\bar{\varepsilon}_{p}$ é a deformação plástica equivalente, $n$ é o coeficiente de encruamento e $D$ é a variável cumulativa de dano. A falha ocorre quando $D$ atinge o valor unitário.

\subsubsection{Modelo de Rice e Tracey}

Rice e Tracey (1969) modelaram o crescimento de um vazio esférico em um material puramente elástico. Um vazio esférico sujeito à tensão uniaxial não somente cresce em tamanho, mas também muda de forma. Rice e Tracey mostraram que quanto maior o fator de triaxialidade, mais significativa é a mudança de tamanho do vazio em comparação com a sua mudança de forma. Essa conclusão está de acordo com a afirmação de que a tensão hidrostática tem por efeito acelerar o processo de nucleação-crescimento-coalescência de vazios. Rice e Tracey obtiveram a taxa de crescimento do raio dos vazios como sendo:

$$
\frac{\dot{R}}{R_{0}}=0,283 \exp \left(\frac{3 \sigma_{m}}{2 \sigma_{e s c}}\right) \dot{\varepsilon}
$$

onde $R_{0}$ é o raio original do vazio, $R$ é o seu valor atual, $\sigma_{m}$ é a tensão hidrostática medida a distância e $\sigma_{\text {esc }}$ é a tensão de escoamento. Segundo os autores, para um 
material sofrendo encruamento sob tensão proporcional, a deformação de falha pode ser expressa por:

$$
\varepsilon_{c}=a \exp \left(-b \frac{\sigma_{m}}{\sigma_{e q}}\right)
$$

onde $a$ e $b$ são dois parâmetros do modelo. Neste modelo, Rice e Tracey não consideraram a interação entre vazios adjacentes.

\subsubsection{Modelo de Gurson-Tvergaard-Needleman}

O modelo de plasticidade com efeito de porosidade é chamado de modelo de Gurson-Tvergaard-Needleman. Ele é baseado no modelo constitutivo poroso de plasticidade, que é dependente da tensão hidrostática e foi desenvolvido por Gurson (1977) considerando nucleação e crescimento de vazios. Considera-se aqui que os vazios estão dispersos em um meio contínuo incompressível. O parâmetro denominado fração volumétrica de vazios $f_{v}$ especifica o início do surgimento de uma trinca, quando o parâmetro atinge um valor crítico.

A função de escoamento proposta por Gurson é dada por:

$$
\Phi=\frac{\bar{\sigma}^{2}}{{\sigma_{e s c}}^{2}}+2 f_{v} \cosh \left(\frac{3}{2} \frac{\sigma_{m}}{\sigma_{e s c}}\right)-1-f_{v}^{2}=0
$$

onde $\bar{\sigma}$ é a tensão equivalente de von Mises, $\sigma_{m}$ é a tensão hidrostática e $\sigma_{e s c}$ é a tensão de escoamento do material. Posteriormente foi realizada uma modificação no modelo de Gurson de forma a introduzir dois novos parâmetros $q_{1}$ e $q_{2}$. Assim, a função de escoamento torna-se:

$$
\Phi=\frac{\bar{\sigma}^{2}}{\sigma_{e s c}{ }^{2}}+2 q_{1} f_{v} \cosh \left(\frac{3 q_{2}}{2} \frac{\sigma_{m}}{\sigma_{e s c}}\right)-1-\left(q_{1} f_{v}\right)^{2}=0
$$


de acordo com a equação (37), o material perde capacidade de transmitir tensão quando os vazios apresentam grande crescimento. A função $f_{v}^{*}\left(f_{v}\right)$ foi criada por Tvergaard e Needleman (1984) para substituir $f_{v}$ na equação anterior, a fim de modelar a perda gradativa de resistência do material:

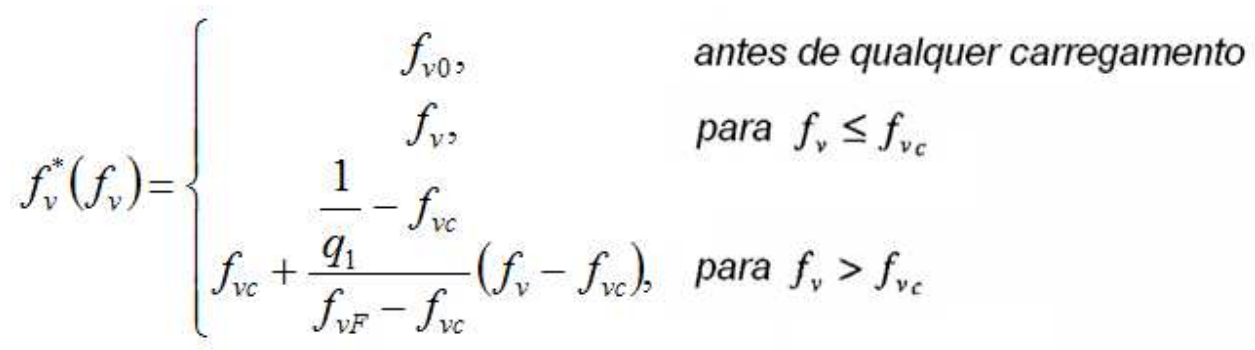

onde $f_{v 0}$ é a fração volumétrica de vazios inicial, $f_{v c}$ é o valor crítico da fração volumétrica de vazios, a partir do qual se forma uma trinca (e a capacidade de transmitir carga cai rapidamente) e $f_{v F}$ é a fração volumétrica de falha na qual ocorre perda completa da resistência do material (ruptura completa gerada por propagação de trinca).

O incremento da variável de fração volumétrica de vazios resulta da nucleação e coalescência de vazios:

$$
d f_{v}=d f_{v_{-} \text {nucleação }}+d f_{v_{-} \text {coalescência }}
$$

Gurson propôs que a taxa do crescimento da fração volumétrica de vazios devido à coalescência é dada por:

$$
d f_{v_{-} \text {coalescência }}=\left(1-f_{v}\right) d \varepsilon_{k k}^{p}
$$

onde $d \varepsilon_{k k}^{p}$ é a taxa de deformação plástica volumétrica. Chu e Needleman (1980) consideraram uma abordagem estatística para a nucleação de vazios. Os autores propuseram uma distribuição normal das nucleações de vazios com relação à deformação plástica: 


$$
\dot{f}_{v_{-} \text {nucleação }}=A_{N} \dot{\varepsilon}_{p}
$$

onde $\varepsilon_{p}$ é a deformação plástica na matriz cristalina e

$$
A_{N}=\frac{F_{N}}{s_{N} \sqrt{2 \pi}} \exp \left\{-\frac{1}{2}\left(\frac{\varepsilon_{p}-\varepsilon_{N}}{s_{N}}\right)^{2}\right\}
$$

onde $s_{N}$ e $\varepsilon_{N}$ são o desvio padrão e a média da distribuição de deformações plásticas e $F_{N}$ é a fração volumétrica total que pode ser nucleada.

Apesar do sucesso dos modelos de nucleação-crescimento-coalescência de vazios na predição de falha em várias aplicações, ainda existem empecilhos com estes tipos de modelo:

- não é tratado o mecanismo de cisalhamento de vazios. O modelo de Gurson falha na simulação de um simples teste de cisalhamento. O modelo original de Gurson foi concebido para representar bem a faixa de alta triaxialidade, onde a pressão influencia diretamente no fenômeno de falha. Assim, recomenda-se cuidado na utilização do modelo de Gurson em baixa triaxialidade.

- no modelo de Gurson o danejamento é restrito à fração volumétrica de vazios. No entanto, o processo de danejamento no material é mais complexo do que a evolução da distribuição de vazios. Por exemplo, uma trinca sem volume na estrutura cristalina do material pode introduzir danejamento ao material ao fazer o mesmo perder resistência mecânica.

- trabalhos posteriores adicionaram novas fórmulas ao modelo de Gurson, no entanto, o modelo ainda não se mostra prático em termos de facilidade de calibração. De fato, com os desenvolvimentos posteriores do modelo, buscando aumentar a sua aplicabilidade, chegou-se a um total de dez parâmetros a serem determinados, sendo que os mesmos estão fortemente acoplados. Por essa razão encontram-se poucos casos de aplicação desse modelo na indústria. 


\subsection{Modelo de dano de Lemaitre (mecânica do dano contínuo)}

Modelos de dano que detectam a deterioração do material desde o início do escoamento inserem uma variável de dano $D$ à lei constitutiva, que varia de 0 a 1 , onde $D=0$ representa material íntegro e $D=1$ representa perda total da capacidade de carga. $O$ dano resulta na perda de rigidez, possibilitando que a falha se inicie na região danificada.

A diferença dos modelos de mecânica do dano contínuo em comparação com os modelos micromecânicos está no fato de o tratamento do crescimento e interação de vazios do primeiro ser tratado fenomenologicamente. Deste modo, parâmetros macroscópicos são utilizados na descrição da resposta mecânica do material.

No modelo de dano de Lemaitre, a lei de elasticidade com dano acoplado é dada por:

$$
\boldsymbol{\sigma}=(1-D) \mathbf{D}^{\mathbf{e}}: \boldsymbol{\varepsilon}^{e}
$$

onde $D$ é a variável de dano, $D^{e}$ é o tensor de elasticidade isotrópico e $\varepsilon^{e}$ é o tensor de deformação elástico. A lei de evolução de dano é dada por:

$$
\dot{D}=\dot{\gamma} \frac{1}{(1-D)}\left(\frac{-Y}{S}\right)^{s}
$$

onde $S$ e $s$ são parâmetros do material, e $\dot{\gamma}$ é o multiplicador plástico, um fator relacionado ao incremento de plasticidade, calculado a cada ciclo de integração no tempo (ver capítulo 5). A variável $-Y$, que representa a força termodinâmica associada com o dano, é igual a:

$$
-Y=\frac{\bar{\sigma}^{2}}{6 G(1-D)^{2}}+\frac{p^{2}}{2 K(1-D)^{2}}
$$


onde $\bar{\sigma}$ é a tensão equivalente de von Mises, $p$ é a pressão hidrostática, $G$ é o módulo cisalhante e $K$ é o módulo volumétrico.

Como exemplo adicional, a variável de dano da mecânica do dano contínuo também pode ser introduzida em modelos constitutivos, de forma acoplada, como por exemplo no modelo de plasticidade de Johnson e Cook (1985):

$$
\bar{\sigma}=\left(1-\beta_{b} D\right)\left[A+B \cdot \bar{\varepsilon}_{p}^{n}\left[1+C \ln \frac{\dot{\varepsilon}_{p}}{\dot{\varepsilon}_{0}}\right]\left[1-\left(\frac{T-T_{0}}{T_{f}-T_{0}}\right)^{q}\right]\right.
$$

onde $\mathrm{D}$ é a variável de dano cumulativo do critério de falha de Johnson-Cook e $\beta_{b}$ é um parâmetro de material. 


\section{ANÁLISE EXPERIMENTAL}

Neste trabalho propõe-se o projeto da geometria de um corpo de prova especial que falhe em diferentes níveis de triaxialidade, especificamente alta triaxialidade (falha por nucleação, crescimento e propagação de vazios) e triaxialidade próxima de zero (falha nas bandas de cisalhamento).

\subsection{Geometria inicial}

A geometria inicial do corpo de prova foi proposta por Alves e Driemeier (2010), conforme Figuras 17 e 18.

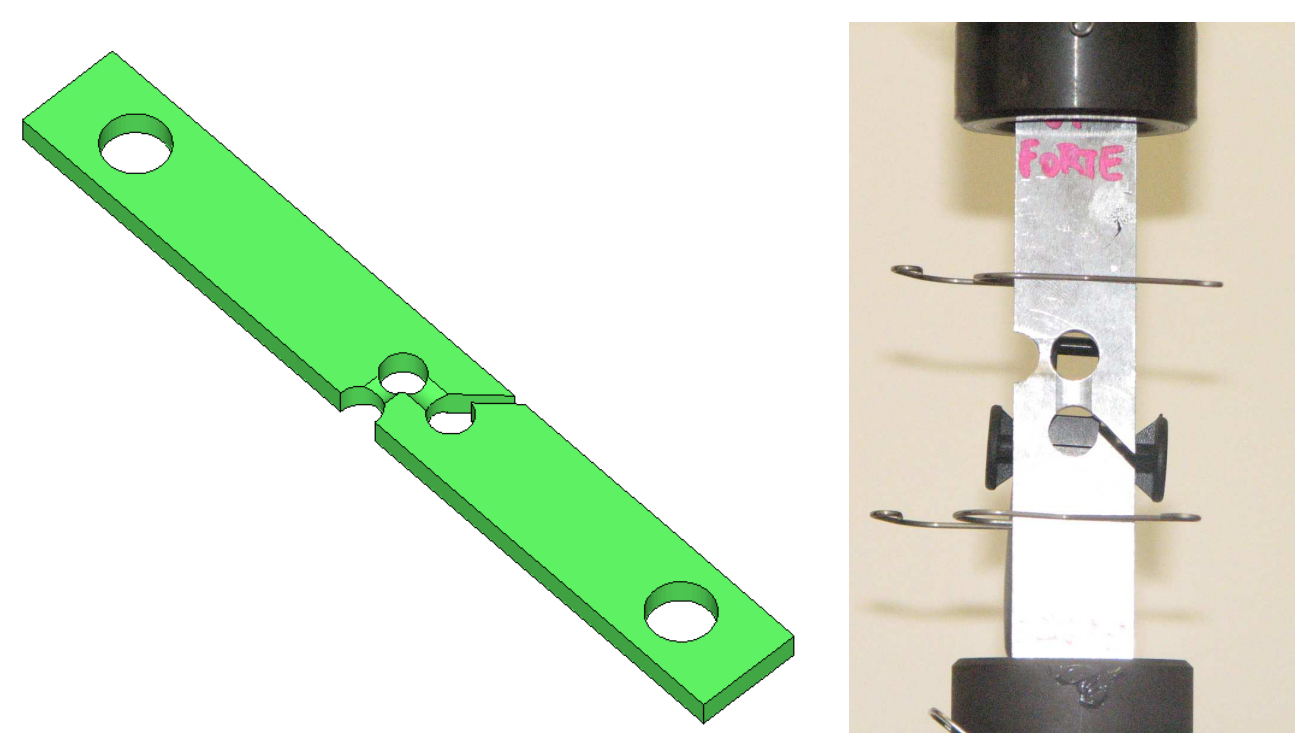

Figura 17. Primeira geometria do espécime Bifailure, e corpo de prova na máquina de tração. 


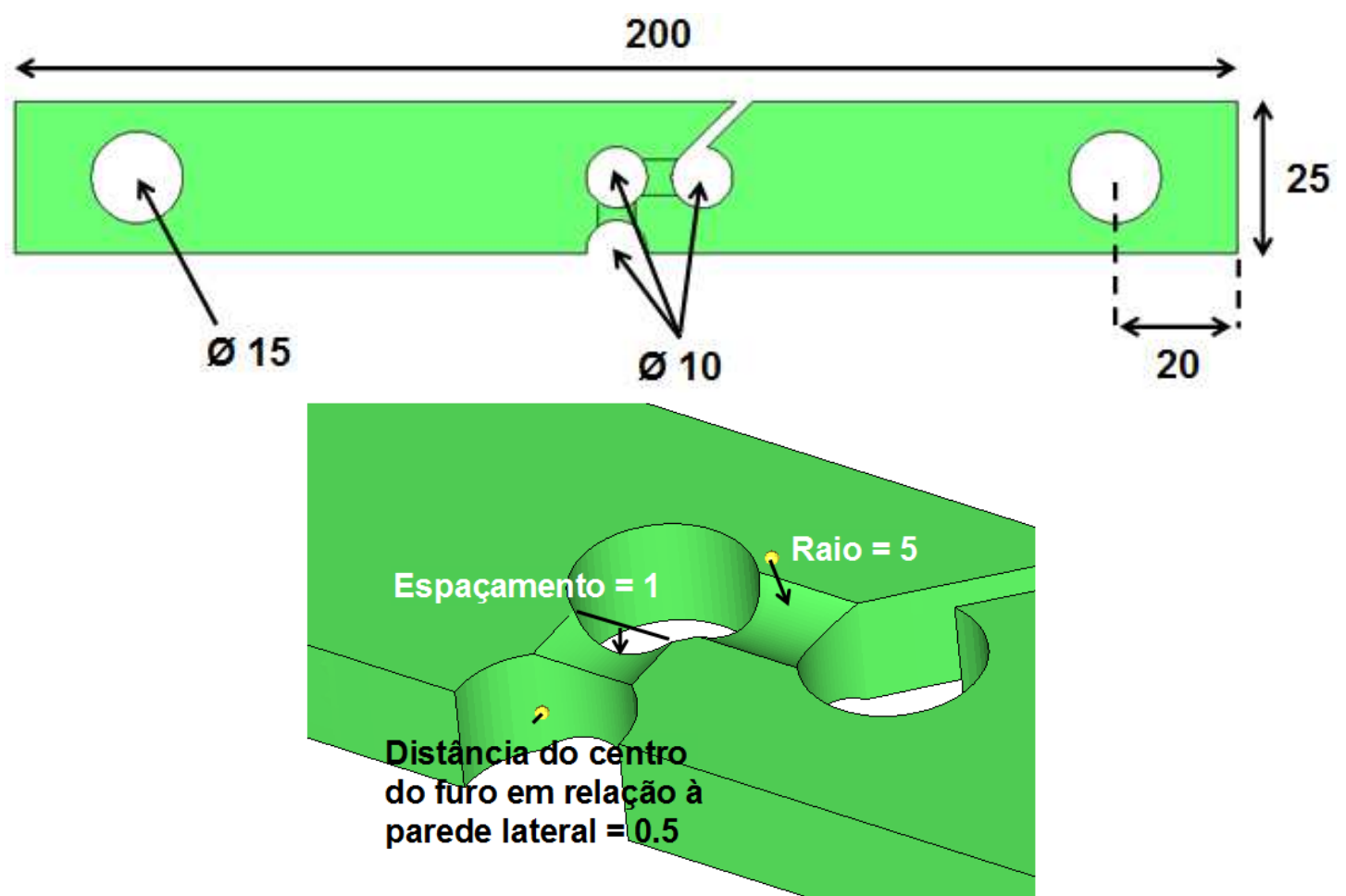

Figura 18. Medidas da primeira geometria do espécime Bifailure

Para a primeira geometria do Bifailure foi testado o material alumínio aeronáutico, disponível em chapas de $6,35 \mathrm{~mm}$ de espessura, com características dadas na Tabela 1.

Tabela 1 - Propriedades do material alumínio aeronáutico

\begin{tabular}{ccc}
\hline $\begin{array}{c}\text { Densidade } \\
\text { ton } / \mathrm{mm}^{3} \text { ) }\end{array}$ & $\begin{array}{c}\text { Módulo de } \\
\text { elasticidade }(\mathrm{MPa})\end{array}$ & Coef. de Poisson \\
\hline $2,78 \times 10^{-9}$ & 67100 & 0,33 \\
\hline
\end{tabular}

A Figura 19 ilustra a seqüência de instantes do ensaio da primeira geometria do espécime. Percebe-se que, após a primeira ruptura no entalhe menor (região de alta triaxialidade), houve grande rotação da região central do espécime, afastando a falha na região central da condição desejável de cisalhamento puro. 

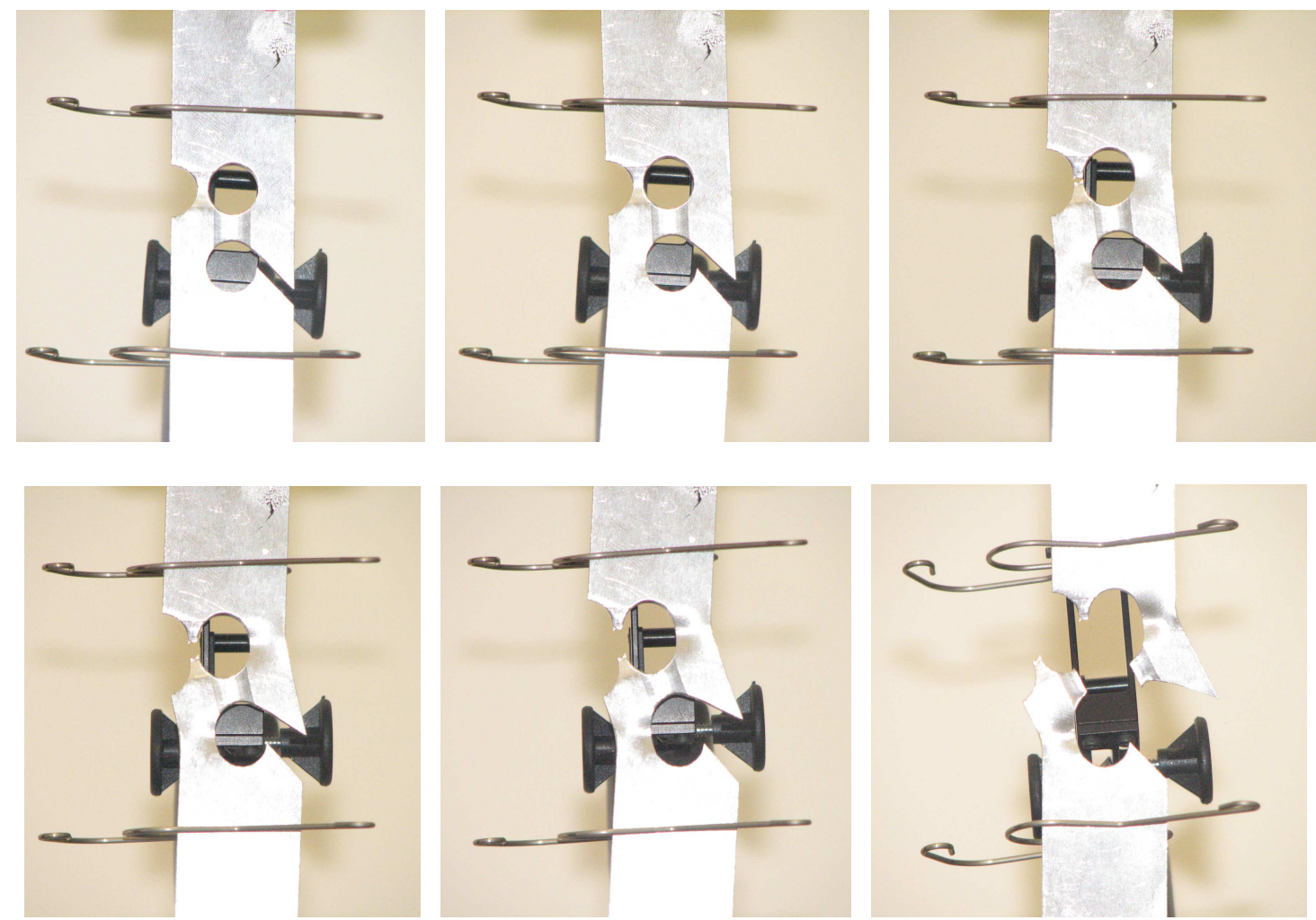

Figura 19. Resultados experimentais para a primeira geometria do Bifailure, em alumínio

A Figura 20 mostra claramente a plastificação considerável de regiões fora da região de ruptura, ocasionadas, principalmente, pelo desequilíbrio do espécime e rotação do mesmo após a primeira falha.

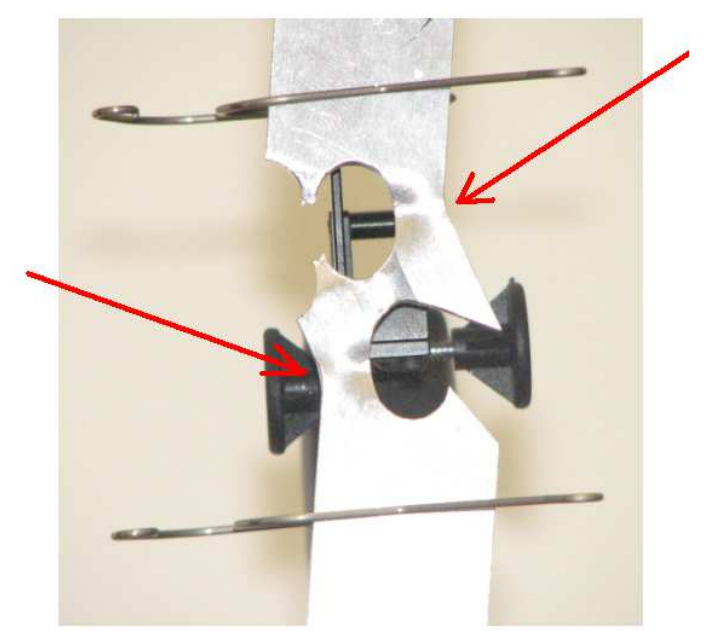

Figura 20. A grande deformação das regiões destacadas dificulta a obtenção de cisalhamento puro na região central do espécime. 


\subsection{Geometria proposta}

Como solução para o problema de rotação do espécime, foi proposta uma nova geometria para o espécime Bifailure, com dois entalhes menores, conforme ilustra a Figura 21. A geometria do espécime foi projetada para que a deformação de falha dos entalhes menores fosse pequena e, portanto, não houvesse rotação significativa do espécime. As medidas do espécime são apresentadas nas Figuras 22 e 23. Este espécime com as dimensões mostradas a seguir foi o espécime utilizado neste trabalho.

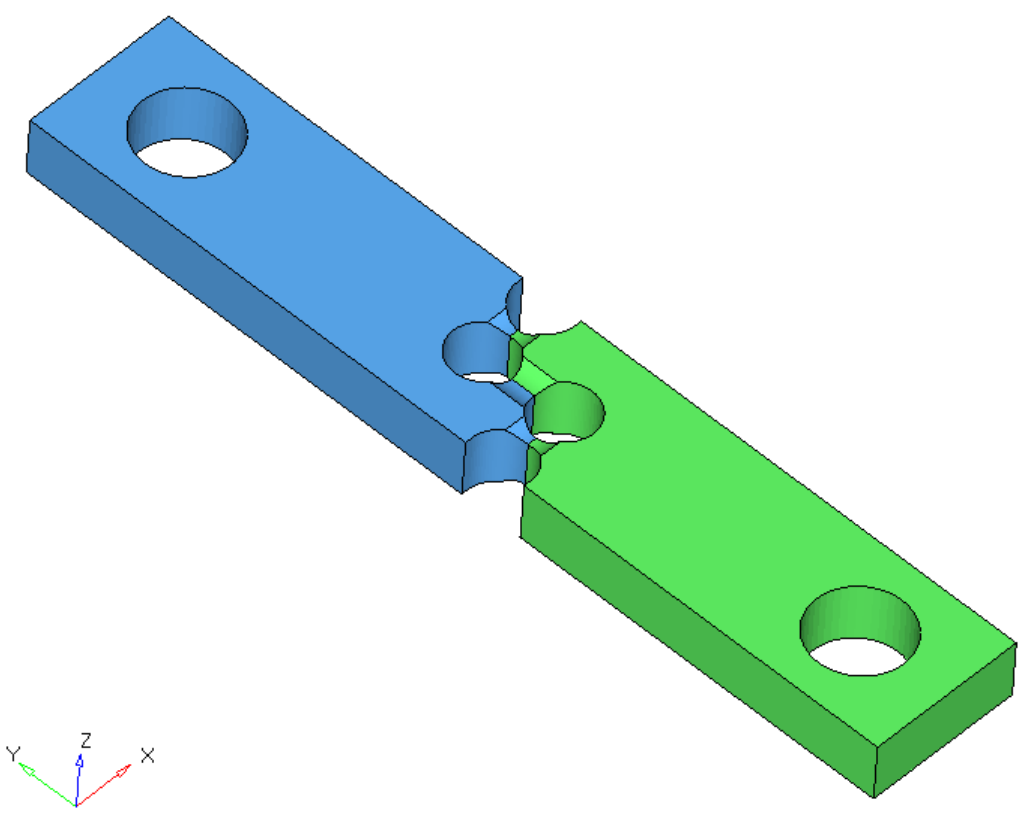

Figura 21. Segunda proposta do espécime Bifailure

145

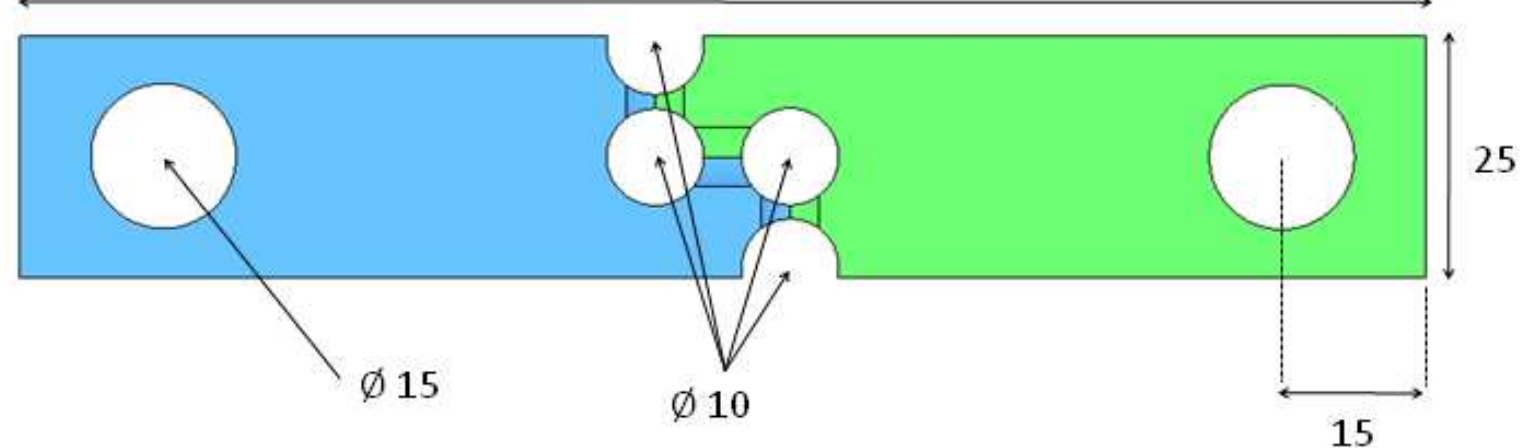

Figura 22. Medidas da segunda proposta do espécime Bifailure 
a)

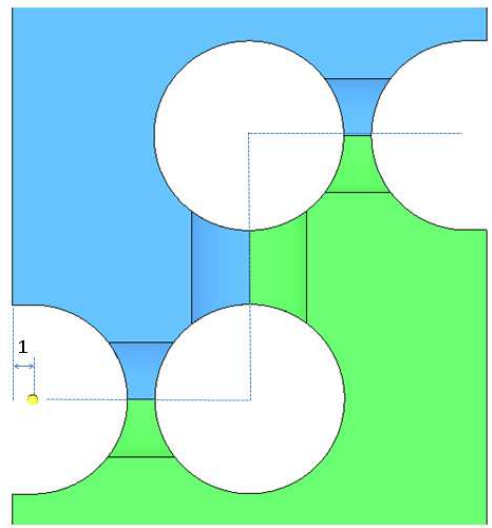

b)

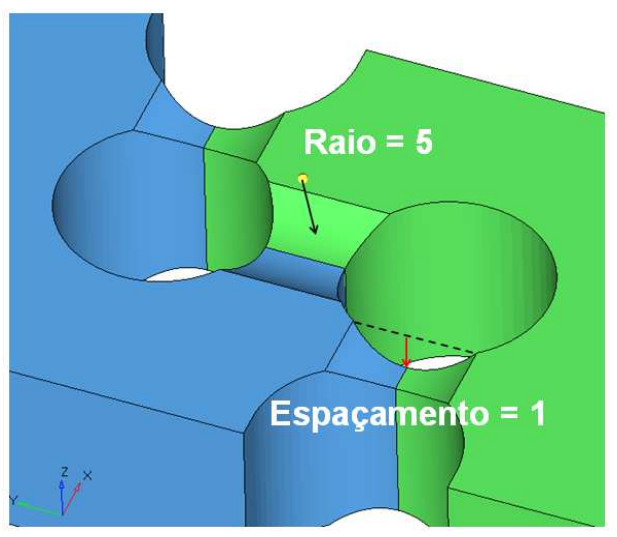

Figura 23. Em a), distanciamento do centro dos furos dos entalhes menores em relação à parede lateral do espécime; em b), indicação de raio e espaçamento máximo da curvatura dos entalhes em relação à face superior.

Os ensaios de tração foram realizados na máquina de tração Instron do Laboratório de Impacto do GMSIE, conforme ilustrado na Figura 24.

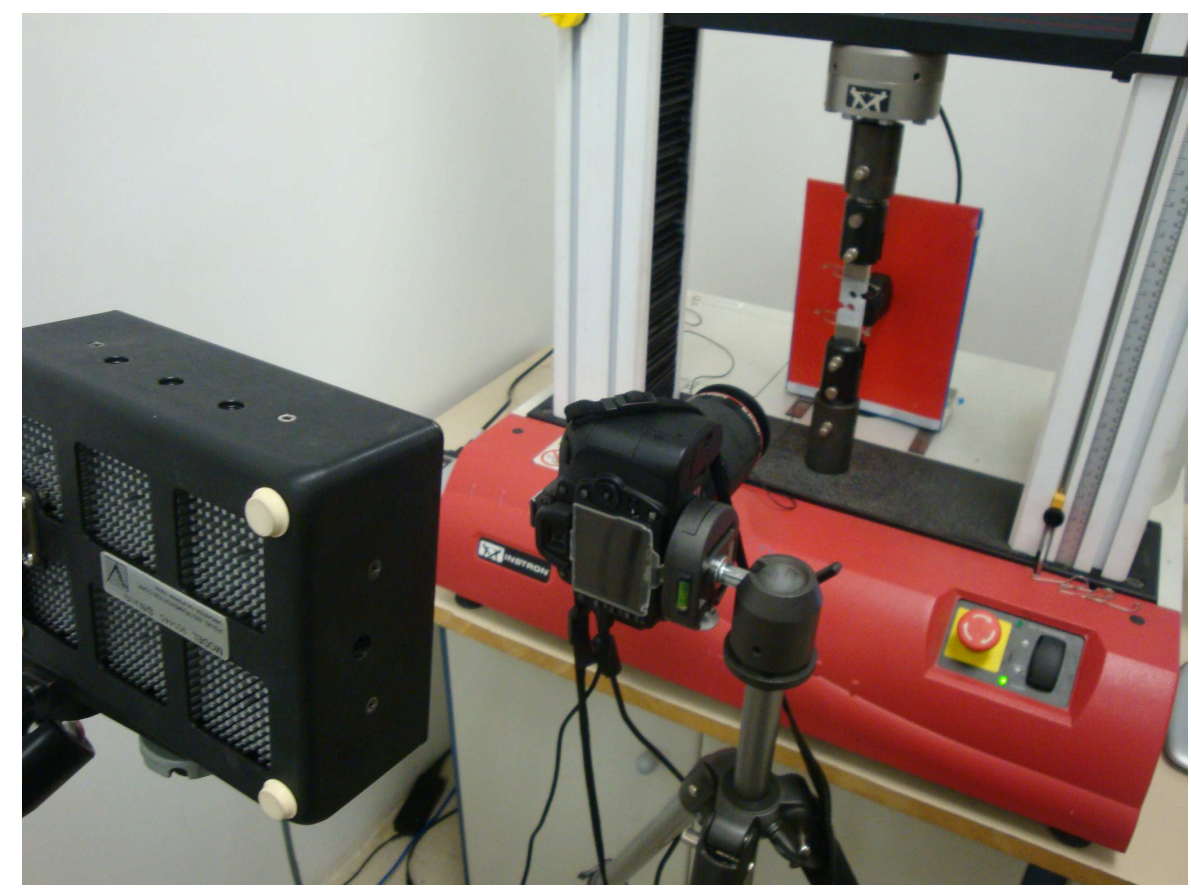

Figura 24. Corpo de prova montado na máquina de tração

Para os testes foi utilizado um extensômetro para medição de deformação, ilustrado na Figura 25. 


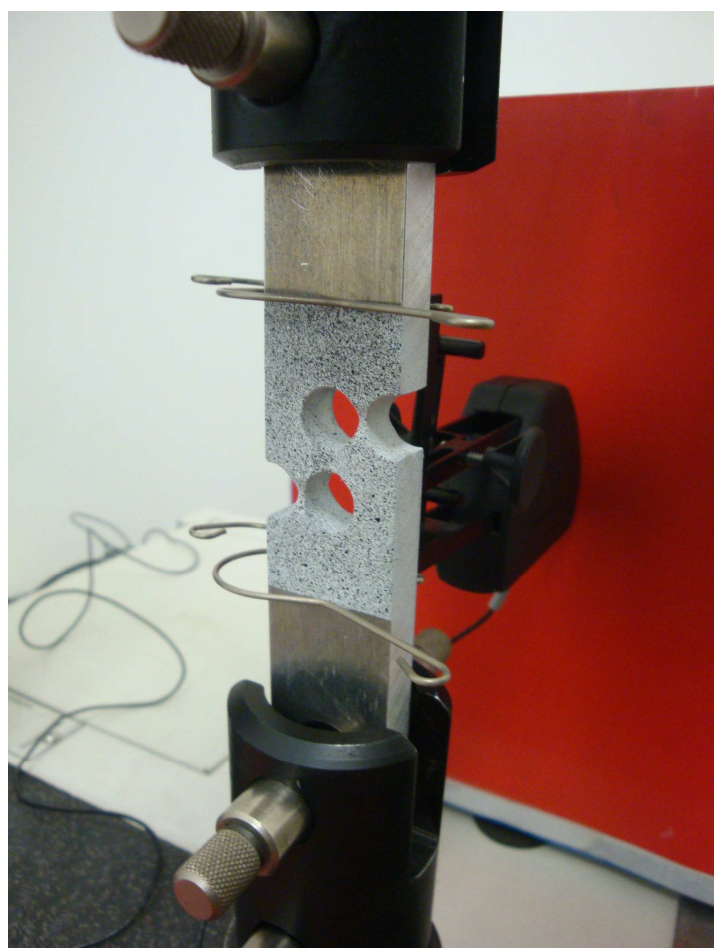

Figura 25. Corpo de prova Bifailure montado na máquina de tração com extensômetro

\subsubsection{Caracterização do material Alumínio 2024-T351}

O material utilizado neste trabalho foi a liga de alumínio 2024-T351, de forma que os corpos de prova foram fabricados a partir de uma chapa com 9,5 mm de espessura do referido material. As propriedades desse material são listadas na Tabela 2.

Tabela 2 - Propriedades do material Alumínio 2024-T351

\begin{tabular}{ccc}
\hline $\begin{array}{c}\text { Densidade } \\
\left.\text { (ton } / \mathrm{mm}^{3}\right)\end{array}$ & $\begin{array}{c}\text { Módulo de } \\
\text { elasticidade }(\mathrm{MPa})\end{array}$ & Coef. de Poisson \\
\hline $2,7 \times 10^{-9}$ & 74660 & 0,3 \\
\hline
\end{tabular}

Foram realizados testes de tração uniaxial de corpo de prova padrão para esse tipo de ensaio, com dimensões dadas pela Figura 26. 


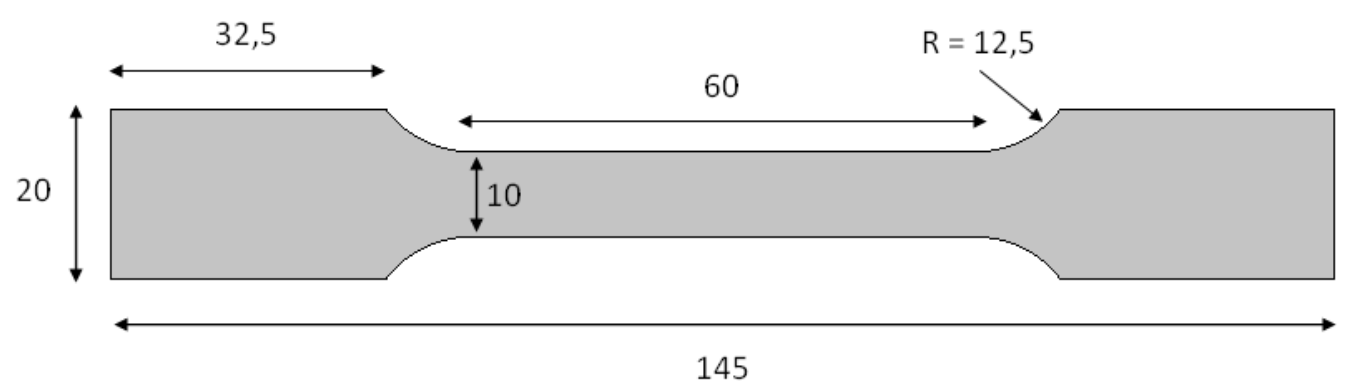

Figura 26. Medidas do corpo de prova para ensaio de tração

O ensaio de tração padrão consiste em tracionar o corpo de prova até a ruptura. O corpo de prova utilizado é ilustrado na Figura 27.

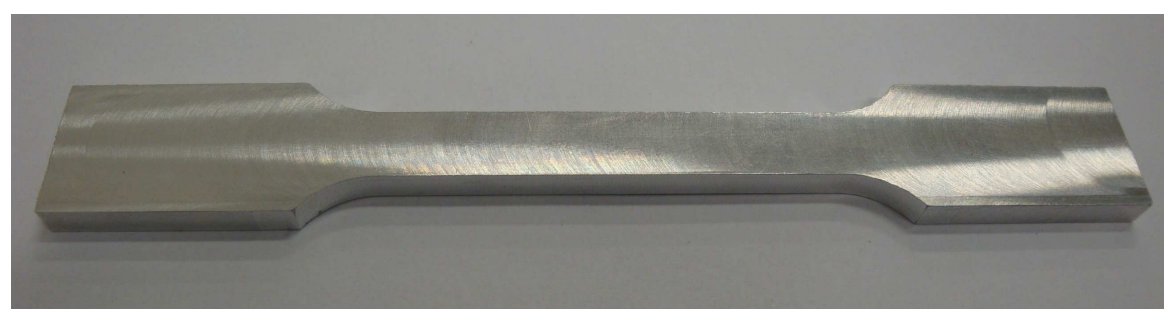

Figura 27. Corpo de prova padrão utilizado para ensaio de tração

A curva tensão-deformação de engenharia obtida para o alumínio 2024-T351 é ilustrada na Figura 28. Verifica-se na curva o instante de ruptura do espécime, evidenciado pela queda da magnitude da curva no final do teste.

A opção pelo estudo da liga de alumínio 2024-T351 foi pelo fato de os parâmetros que definem as propriedades do material estarem disponíveis na literatura científica. Trabalhos como o de Wierzbicki et al. (2005) e Malcher et al. (2012) apresentam um extensivo estudo sobre modelos de falha aplicados ao alumínio 2024-T351 e portanto fornecem tabelas com os parâmetros dos modelos de falha utilizados neste trabalho. 


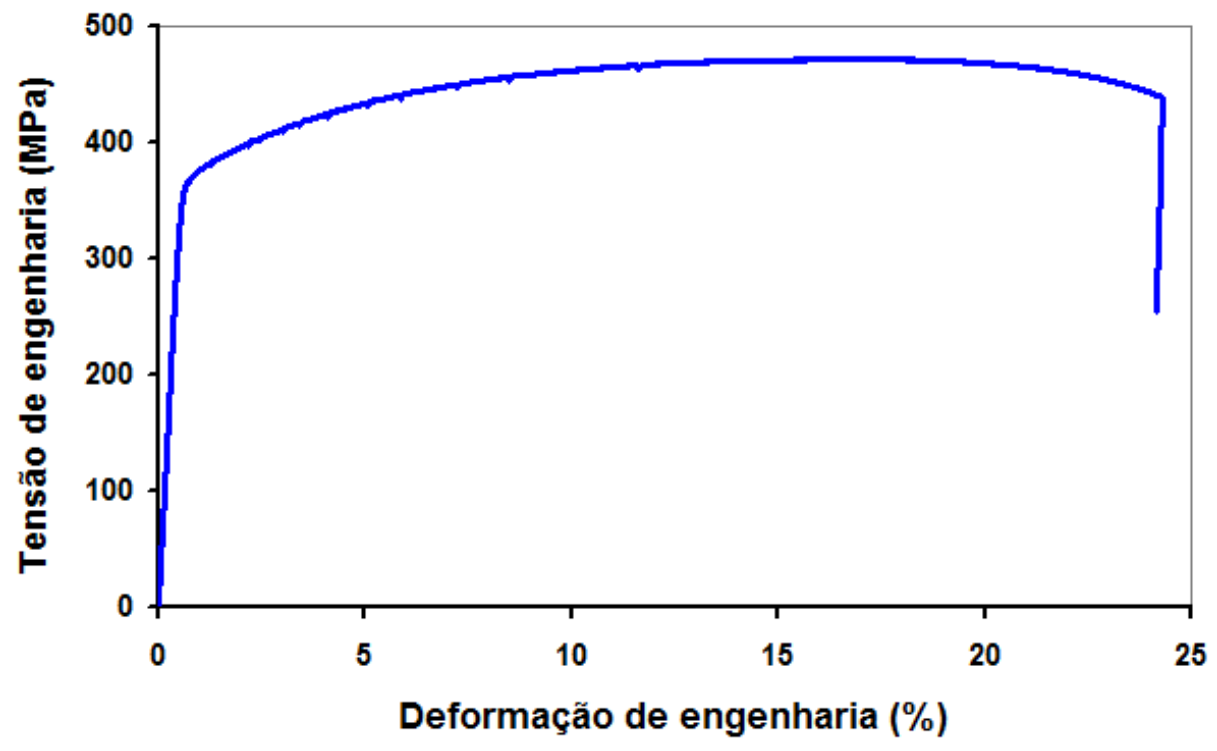

Figura 28. Curva tensão-deformação de engenharia para alumínio 2024-T351

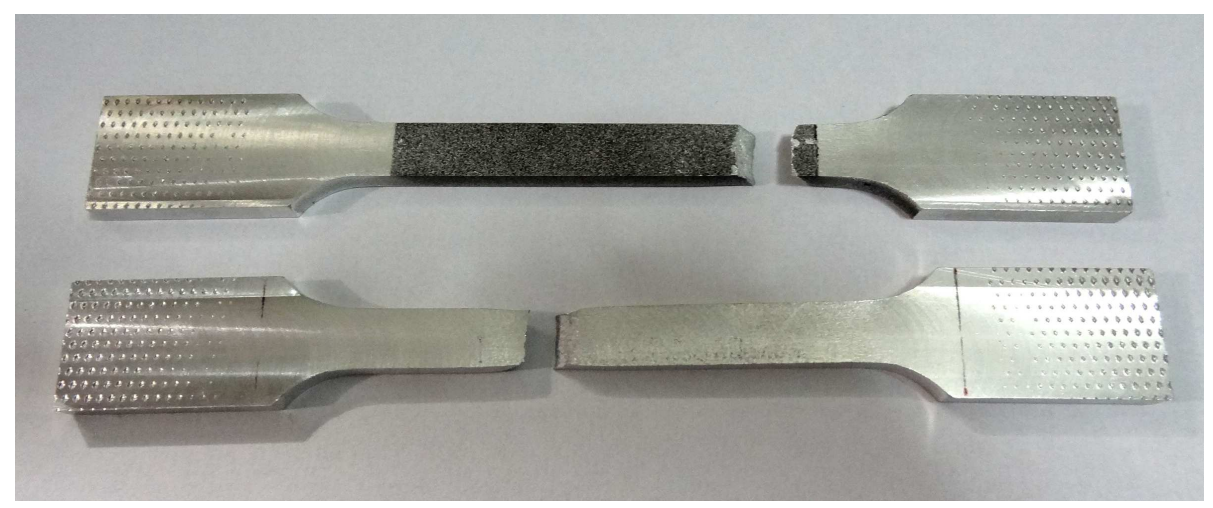

Figura 29. Resultado experimental dos testes de tração padrão

Posteriormente foram realizados testes de tração do espécime Bifailure (segunda proposta), obtendo-se o resultado mostrado na Figura 30. Na mesma figura aparece também o indicativo da região de falha correspondente a cada queda da curva de força do gráfico. Desse modo, obtém-se que a primeira queda da curva de força está ligada à ruptura dos entalhes laterais menores, enquanto que a queda final da curva de força está ligada à ruptura do entalhe central. 


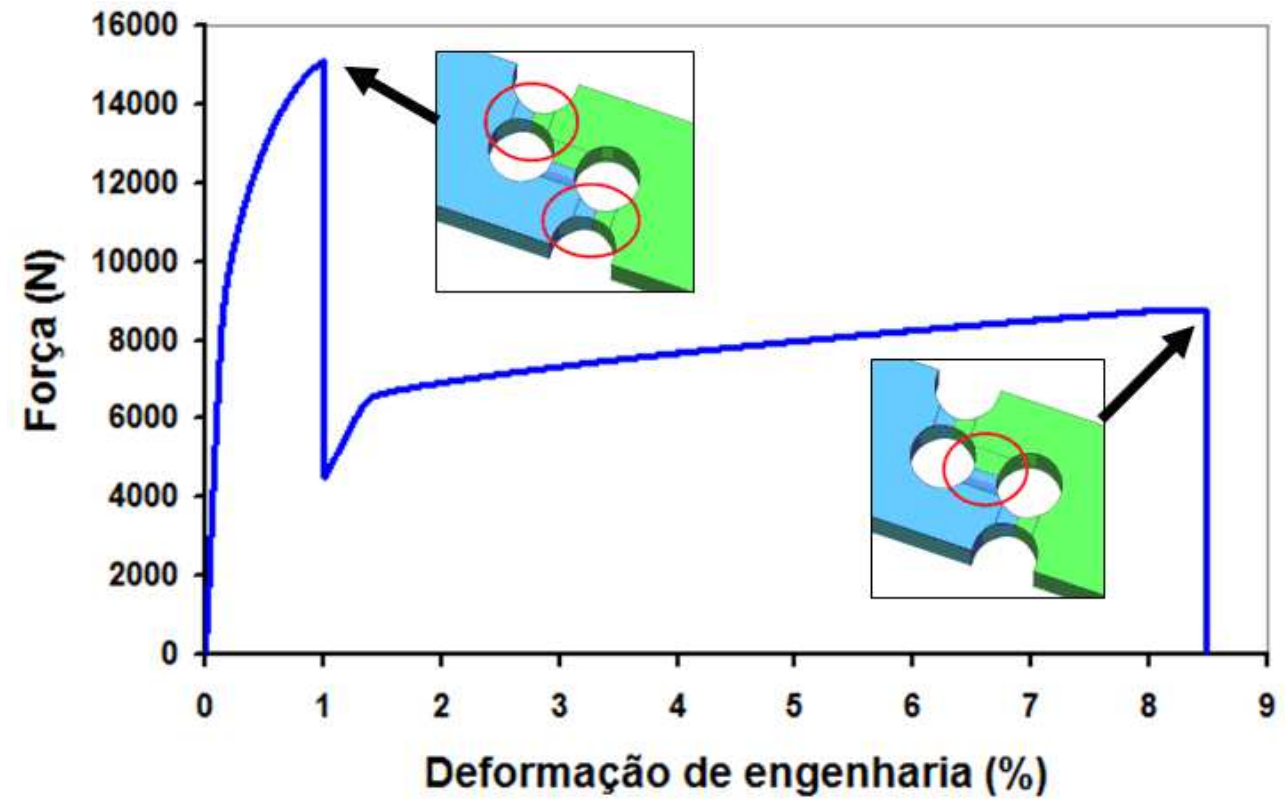

Figura 30. Curva força-deformação para espécime Bifailure

Obteve-se ruptura do espécime Bifailure sem grande rotação da região central, de acordo com a Figura 31, o que favoreceu a obtenção de medidas mais precisas com o extensômetro.

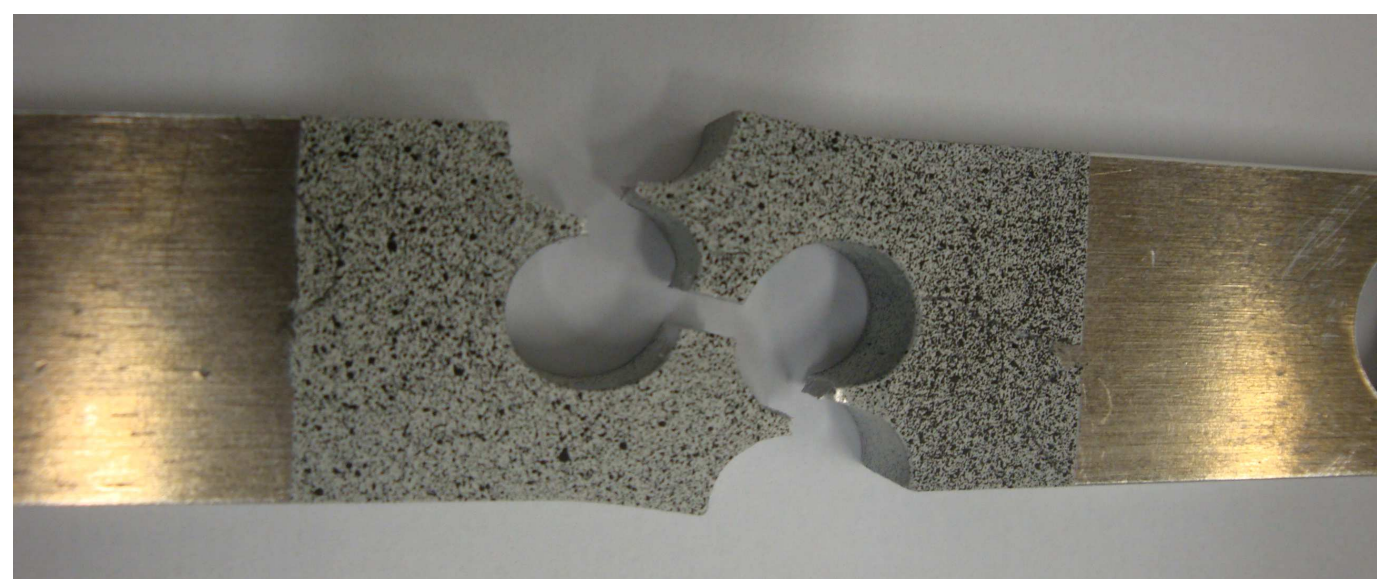

Figura 31. Região central do espécime Bifailure após o ensaio de tração

Em síntese, as propriedades do alumínio 2024-T351 utilizadas neste trabalho são listadas na Tabela 3. 
Tabela 3 - Propriedades para alumínio 2024-T351

\begin{tabular}{cccc}
\hline Descrição & Símbolo & Valor & Referência \\
\hline Densidade & $\rho$ & $2700 \mathrm{~kg} / \mathrm{m}^{3}$ & Teng et al. 2005 \\
Módulo elástico & $E$ & $74660 \mathrm{MPa}$ & Teng et al. 2005 \\
Coef. Poisson & $V$ & 0,3 & Teng et al. 2005 \\
Parâmetro de JC & $A$ & $352 \mathrm{MPa}$ & Teng et al. 2005 \\
Parâmetro de JC & $B$ & $440 \mathrm{MPa}$ & Teng et al. 2005 \\
Parâmetro de JC & $n$ & 0,42 & Teng et al. 2005 \\
Max. def. plást. equiv. de falha & $\bar{\varepsilon}_{f}$ & 0,21 & Teng e Wierzbicki, 2006 \\
Max. tensão cisalhante de falha & $\tau_{\text {max }}$ & $380 \mathrm{MPa}$ & Teng e Wierzbicki, 2006 \\
Parâmetro de falha de JC & $D_{1}$ & 0,13 & Teng et al. 2005 \\
Parâmetro de falha de JC & $D_{2}$ & 0,13 & Teng et al. 2005 \\
Parâmetro de falha de JC & $D_{3}$ & $-1,5$ & Teng et al. 2005 \\
Parâmetro de falha de Wilkins & $a$ & $0,0012 \mathrm{MPa}{ }^{-1}$ & Wierzbicki et al. 2005 \\
Parâmetro de falha de Wilkins & $\lambda$ & 2,15 & Wierzbicki et al. 2005 \\
Parâmetro de falha de Wilkins & $\mu$ & 2,18 & Wierzbicki et al. 2005 \\
Parâmetro de falha de Wilkins & $D_{c}$ & 0,93 & Wierzbicki et al. 2005 \\
Valor crítico superior de falha de & $D_{\text {crit }}$ & 0,485 & Teng e Wierzbicki, 2006 \\
Cockcroft-Latham & $D_{\text {crit }}$ & 0,058 & Teng e Wierzbicki, 2006 \\
Valor crítico inferior de falha de & & & \\
Cockcroft-Latham & $C_{1}$ & 0,87 & Wierzbicki et al. 2005 \\
Parâmetro de falha de Xue-Wierzbicki & $C_{2}$ & 1,77 & Wierzbicki et al. 2005 \\
Parâmetro de falha de Xue-Wierzbicki & $C_{3}$ & 0,21 & Wierzbicki et al. 2005 \\
Parâmetro de falha de Xue-Wierzbicki & $C_{4}$ & 0,01 & Wierzbicki et al. 2005 \\
Parâmetro de falha de Xue-Wierzbicki & $C_{4}$ & 0,153 & Wierzbicki et al. 2005 \\
Coeficiente de encruamento & $n$ & &
\end{tabular}




\section{IMPLEMENTAÇÃO NUMÉRICA}

\subsection{Implementação de subrotina}

A fim de se obter maior controle sobre o algoritmo numérico de solução e para ser possível a utilização de critérios de falha que não estão originalmente disponíveis no programa comercial de elementos finitos, foi desenvolvida uma subrotina de material para o software $L S-D y n a \AA$. A subrotina consiste na implementação do modelo constitutivo de material e dos critérios de falha que foram tratados neste trabalho. $O$ modelo de material que foi implementado foi o de von Mises, para lidar com elementos sólidos.

A subrotina é escrita na linguagem de programação Fortran, a qual é também utilizada originalmente na compilação do programa de elementos finitos $L S$-Dyna®.

A subrotina completa está disponível no Apêndice $B$, sendo que aqui serão explicados os pontos mais importantes sobre o seu funcionamento.

O modelo de plasticidade de von Mises é composto por:

1) Uma lei linear elástica:

$$
\sigma=\mathbf{D}^{\mathrm{e}}: \varepsilon^{e}
$$

onde $\mathbf{D}^{\mathrm{e}}$ é o tensor de elasticidade isotrópico e $\boldsymbol{\varepsilon}^{e}$ é o tensor de deformações.

2) Uma função de escoamento na forma:

$$
\Phi\left(\sigma, \sigma_{y}\right)=\sqrt{3 J_{2}(\mathbf{s})}-\sigma_{y}=\bar{\sigma}(\mathbf{s})-\sigma_{y}
$$

onde $\boldsymbol{s}$ é o tensor desviador, $\bar{\sigma}$ é a tensão equivalente e $\sigma_{y}$ é a tensão de escoamento, que é tomada como uma função da deformação plástica acumulada, 
ou função do modelo constitutivo, de forma que neste trabalho é igual a $\sigma_{y}=A+B \bar{\varepsilon}_{p}^{n}$ (modelo constitutivo de von Mises).

3) Uma lei de escoamento:

$$
\dot{\varepsilon}^{p}=\dot{\gamma} N=\dot{\gamma} \frac{\partial \Phi}{\partial \sigma}=\dot{\gamma} \sqrt{\frac{3}{2}} \frac{\boldsymbol{s}}{\|\boldsymbol{s}\|}
$$

tal que $\dot{\gamma}$ é chamado de multiplicador plástico.

4) E uma lei de encruamento, com a equação de evolução para a variável interna de encruamento:

$$
\dot{\bar{\varepsilon}}^{p}=\sqrt{\frac{2}{3}}\left\|\dot{\mathcal{\varepsilon}}^{p}\right\|=\dot{\gamma}
$$

O processo de retorno aplicado ao estado de previsão elástica descrito na próxima seção é necessário para se determinar quanto do incremento de deformação total que ocorre a cada passo de integração é de natureza elástica e quanto é de natureza plástica. O fluxograma da Figura 32 ilustra o que se explicou aqui. Nesse fluxograma, o índice $n$ indica o passo atual e 0 índice $n+1$ indica 0 próximo passo no processo de integração. 


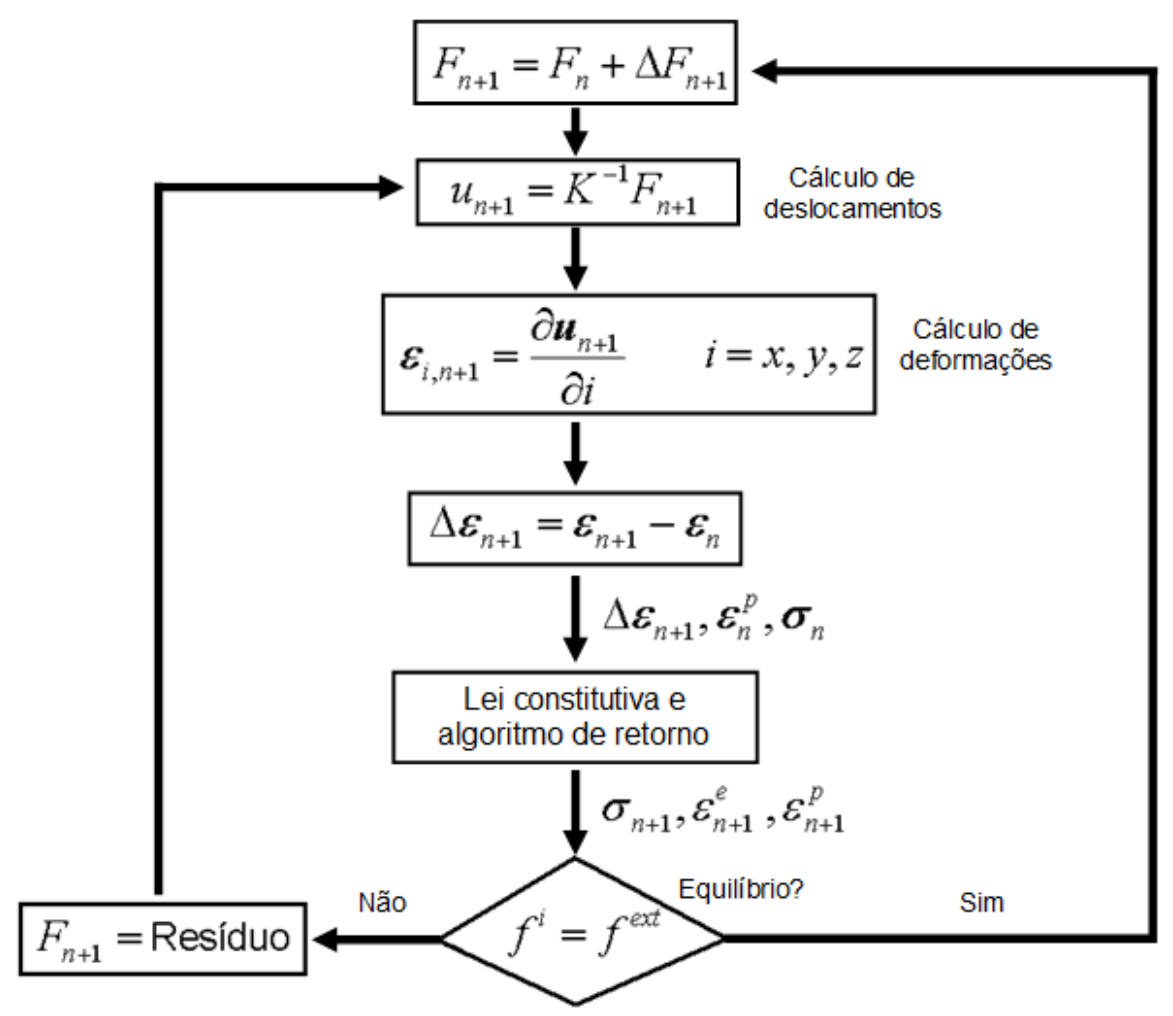

Figura 32. Fluxograma representando o funcionamento da solução numérica de elementos finitos

\subsection{O procedimento de previsão elástica / algoritmo de retorno}

Dado o incremento de deformação total:

$$
\Delta \boldsymbol{\varepsilon}_{n+1}=\boldsymbol{\varepsilon}_{n+1}-\boldsymbol{\varepsilon}_{n}
$$

correspondente a um pseudo incremento de tempo $\left[\mathrm{t}_{\mathrm{n}}, \mathrm{t}_{\mathrm{n}+1}\right]$ e dadas as variáveis de estado $\left\{\varepsilon_{\mathrm{n}}^{\mathrm{e}}, \bar{\varepsilon}_{\mathrm{n}}^{\mathrm{p}}\right\}$ em $\mathrm{t}_{\mathrm{n}}$, a fim de ser possível determinar quanto do incremento de deformação total é elástico e quanto é plástico considera-se inicialmente que esse incremento de deformação total é elástico. Desse modo, a deformação elástica de tentativa e a deformação plástica acumulada de tentativa são dadas por:

$$
\begin{gathered}
\varepsilon_{\mathrm{n}+1}^{\mathrm{e}, \text { tent }}=\varepsilon_{\mathrm{n}}^{\mathrm{e}}+\Delta \varepsilon \\
\bar{\varepsilon}_{\mathrm{n}+1}^{\mathrm{p}, \text { tent }}=\bar{\varepsilon}_{\mathrm{n}}^{\mathrm{p}}
\end{gathered}
$$


A correspondente tensão de tentativa é calculada por:

$$
\sigma_{\mathrm{n}+1}^{\mathrm{tent}}=\mathbf{D}^{\mathrm{e}}: \boldsymbol{\varepsilon}_{\mathrm{n}+1}^{\mathrm{e}, \text { tent }}
$$

Ou, de forma equivalente, decompondo nas partes hidrostática e desviadora:

$$
\begin{aligned}
& \mathbf{s}_{\mathrm{n}+1}^{\text {tent }}=2 \mathrm{G} \boldsymbol{\varepsilon}_{\mathrm{d}, \mathrm{n}+1}^{\mathrm{e}, \text { tent }} \\
& \boldsymbol{p}_{\mathrm{n}+1}^{\text {tent }}=\mathrm{K} \boldsymbol{\varepsilon}_{\mathrm{v}, \mathrm{n}+1}^{\mathrm{e} \text {,ent }}
\end{aligned}
$$

onde $s$ e $p$ denotam, respectivamente, os tensores desviador e hidrostático, G e K são respectivamente os módulos cisalhante e volumétrico $\mathrm{e}$ os índices $d \mathrm{e} v$ representam, respectivamente, os componentes desviador e volumétrico.

Depois de calcular o estado elástico de tentativa, o próximo passo no algoritmo é verificar se $\sigma_{\mathrm{n}+1}^{\text {tent }}$ se situa dentro ou fora da superfície de escoamento de tentativa:

- Se $\sigma_{\mathrm{n}+1}^{\text {tent }}$ se situar dentro da superfície de escoamento de tentativa, isto é, se:

$$
\Phi\left(\sigma_{n+1}^{\text {tent }}, \sigma_{y, n}\right)=\bar{\sigma}\left(s_{n+1}^{\text {tent }}\right)-\sigma_{y, n} \leq 0
$$

então o processo no intervalo $\left[\mathrm{t}_{\mathrm{n}}, \mathrm{t}_{\mathrm{n}+1}\right]$ é puramente elástico e o próprio estado elástico é a solução do problema de integração. Desse modo, se atualiza:

$$
\begin{gathered}
\varepsilon_{n+1}^{e}=\varepsilon_{n+1}^{e, t e n t} \\
\sigma_{n+1}=\sigma_{n+1}^{\text {tent }} \\
\bar{\varepsilon}_{n+1}^{p}=\bar{\varepsilon}_{n}^{p} \\
\sigma_{y, n+1}=\sigma_{y, n}
\end{gathered}
$$

- Caso contrário, o processo é elasto-plástico no intervalo $\left[\mathrm{t}_{\mathrm{n}}, \mathrm{t}_{\mathrm{n}+1}\right]$ e o algoritmo de retorno descrito a seguir precisa ser aplicado. A Figura 33 ilustra este caso, mostrando o processo de previsão elástica e algoritmo de retorno à superfície de escoamento. 


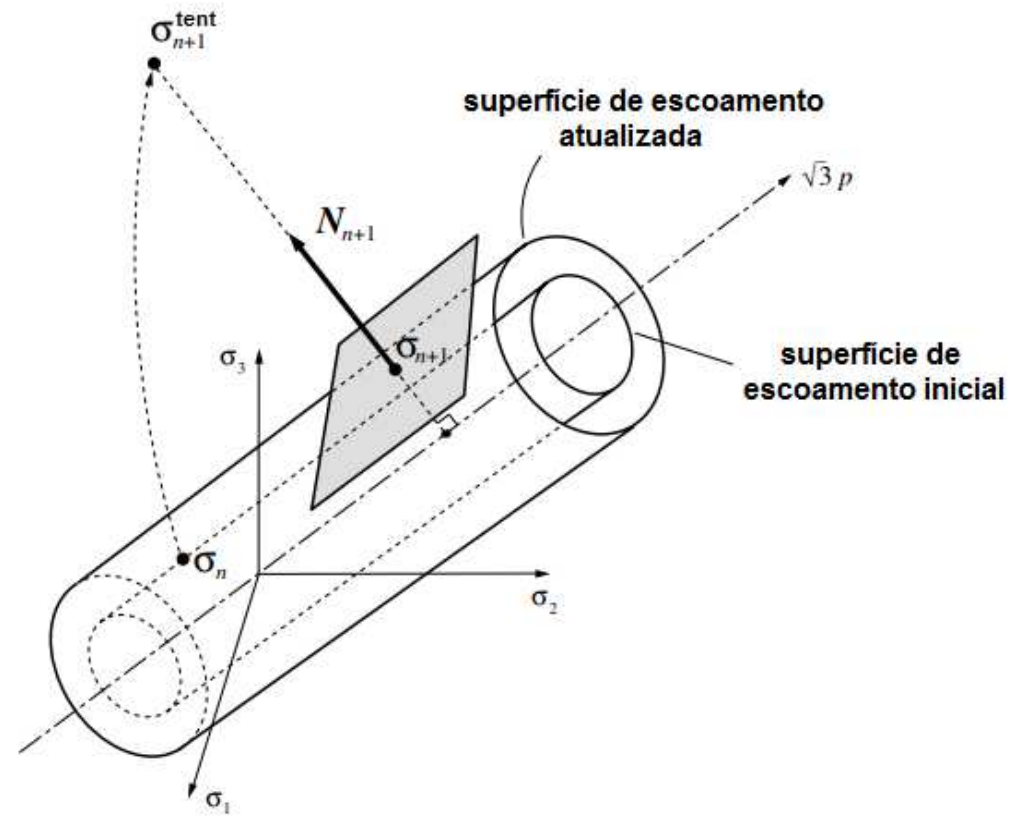

Figura 33. Representação esquemática da predição elástica / algoritmo de retorno para o modelo de von Mises. Extraído de Souza Neto et al. (2008).

Deve-se destacar que o algoritmo de retorno consiste em resolver o sistema de equações não lineares a seguir:

$$
\begin{gathered}
\varepsilon_{n+1}^{e}=\varepsilon_{n+1}^{e, \text { tent }}-\Delta \gamma \sqrt{\frac{3}{2}} \frac{s_{n+1}}{\left\|s_{n+1}\right\|} \\
\bar{\varepsilon}_{n+1}^{p}=\bar{\varepsilon}_{n}^{p}+\Delta \gamma \\
\sqrt{3 J_{2}\left(s_{n+1}\right)}-\sigma_{y}\left(\bar{\varepsilon}_{n+1}^{p}\right)=0
\end{gathered}
$$

Que precisa ser resolvido para $\varepsilon_{n+1}^{e}, \bar{\varepsilon}_{n+1}^{p}$ e $\Delta \gamma$, onde:

$$
\boldsymbol{s}_{n+1}=\boldsymbol{s}_{n+1}\left(\boldsymbol{\varepsilon}_{n+1}^{e}\right)=2 \mathrm{G} \varepsilon_{\mathrm{d}, \mathrm{n}+1}^{\mathrm{e}}
$$

Depois de resolver o sistema de equações (59), o tensor de deformações plásticas pode ser atualizado de acordo com a seguinte fórmula:

$$
\boldsymbol{\varepsilon}_{n+1}^{p}=\boldsymbol{\varepsilon}_{n}^{p}+\Delta \gamma \sqrt{\frac{3}{2}} \frac{\boldsymbol{s}_{n+1}}{\left\|\boldsymbol{s}_{n+1}\right\|}
$$


O sistema de equações (59) pode ser simplificado em uma única equação não-linear em função do multiplicador plástico $\Delta \gamma$. Esta redução no número de equações é fundamental para tornar o processo de atualização de tensões mais eficiente computacionalmente. Pela simplificação do sistema de equações (59), nota-se que a plasticidade afeta apenas a parte desviadora e não a volumétrica dos tensores. A separação em partes desviadora e volumétrica das deformações fornece:

$$
\begin{gathered}
\varepsilon_{v, n+1}^{e}=\varepsilon_{v, n+1}^{e, \text { tent }} \\
\boldsymbol{\varepsilon}_{d, n+1}^{e}=\boldsymbol{\varepsilon}_{d, n+1}^{e \text { etent }}-\Delta \gamma \sqrt{\frac{3}{2}} \frac{\boldsymbol{s}_{n+1}}{\left\|\boldsymbol{s}_{n+1}\right\|}
\end{gathered}
$$

De forma equivalente, em termos de tensões temos:

$$
\begin{gathered}
p_{n+1}=p_{n+1}^{\text {tent }} \\
\boldsymbol{s}_{n+1}=\boldsymbol{s}_{n+1}^{\text {tent }}-\Delta \gamma 2 G \sqrt{\frac{3}{2}} \frac{\boldsymbol{s}_{n+1}}{\left\|\boldsymbol{s}_{n+1}\right\|}
\end{gathered}
$$

Assim, o processo de retorno afeta somente o componente desviador de tensão. A componente hidrostática, $\boldsymbol{p}_{n+1}$, tem seu valor calculado na fase de previsão elástica e pode, portanto, ser eliminada do sistema de equações. Uma maior simplificação é alcançada rearranjando a equação (65):

$$
\left(1+\sqrt{\frac{3}{2}} \frac{\Delta \gamma 2 G}{\left\|s_{n+1}\right\|}\right) \boldsymbol{s}_{n+1}=\boldsymbol{s}_{n+1}^{\text {tent }}
$$

ou seja, as tensões desviadora de tentativa e atualizada são colineares. Isso implica que:

$$
\frac{\boldsymbol{s}_{n+1}}{\left\|\boldsymbol{s}_{n+1}\right\|}=\frac{\boldsymbol{s}_{n+1}^{\text {tent }}}{\left\|\boldsymbol{s}_{n+1}^{\text {tent }}\right\|}
$$


A substituição da equação (67) na equação (65) conduz a uma fórmula mais simples para a atualização de tensões desviadoras:

$$
\boldsymbol{s}_{n+1}=\left(1-\sqrt{\frac{3}{2}} \frac{\Delta \gamma 2 G}{\left\|\boldsymbol{s}_{n+1}^{\text {tent }}\right\|}\right) \boldsymbol{s}_{n+1}^{\text {tent }}=\left(1-\frac{\Delta \gamma 3 G}{\bar{\sigma}_{n+1}^{\text {tent }}}\right) \boldsymbol{s}_{n+1}^{\text {tent }}
$$

onde $\bar{\sigma}_{n+1}^{\text {tent }} \equiv \sqrt{3 J_{2}\left(\boldsymbol{s}_{n+1}^{\text {tent }}\right)}$ é a tensão elástica de tentativa de von Mises. Observa-se que sendo $\boldsymbol{s}_{n+1}^{\text {tent }}$ um tensor constante no processo de retorno, a tensão desviadora $\boldsymbol{s}_{n+1}$ é uma função linear de $\Delta \gamma$ somente na equação de atualização (68). Temos que a equação (68) indica que a tensão desviadora atualizada é obtida aplicando-se o fator de escala $1-\Delta \gamma 3 G / \bar{\sigma}_{n+1}^{\text {tent }}$ à tensão desviadora de tentativa.

Finalmente, com a substituição das equações (68) e $(59)_{2}$ na equação $(59)_{3}$, obtém-se que o sistema de equações (59) é reduzido à seguinte equação escalar (e não linear) que é função do multiplicador plástico $\Delta \gamma$ :

$$
\widetilde{\Phi}(\Delta \gamma) \equiv \bar{\sigma}_{n+1}^{\text {tent }}-3 G \Delta \gamma-\sigma_{y}\left(\bar{\varepsilon}_{n}^{p}+\Delta \gamma\right)=0
$$

A equação (69) é resolvida pelo método de Newton-Raphson, e com a solução $\Delta \gamma$, as variáveis de estado são atualizadas de acordo com:

$$
\begin{gathered}
\boldsymbol{s}_{n+1}=\left(1-\frac{\Delta \gamma 3 G}{\bar{\sigma}_{n+1}^{\text {tent }}}\right) \boldsymbol{s}_{n+1}^{\text {tent }} \\
\boldsymbol{\sigma}_{n+1}=\boldsymbol{s}_{n+1}+p_{n+1}^{\text {tent }} \boldsymbol{I} \\
\boldsymbol{\varepsilon}_{\mathrm{n}+1}^{\mathrm{e}}=\left[\mathbf{D}^{\mathrm{e}}\right]^{-1}: \boldsymbol{\sigma}_{\mathrm{n}+1}=\frac{1}{2 \mathrm{G}} \mathbf{s}_{\mathrm{n}+1}+\frac{1}{3} \boldsymbol{\varepsilon}_{\mathrm{v}, \mathrm{n}+1}^{\mathrm{e} \text { ent }} \\
\overline{\boldsymbol{\varepsilon}}_{\mathrm{n}+1}^{\mathrm{p}}=\overline{\boldsymbol{\varepsilon}}_{\mathrm{n}}^{\mathrm{p}}+\Delta \gamma
\end{gathered}
$$

O procedimento de estado elástico de tentativa e algoritmo de retorno está resumido nos esquemas das Figuras 34 e 35 ao final deste capítulo.

Os critérios de falha implementados na subrotina são os mesmos descritos na seção 3.3, ou critérios de falha empíricos baseados na mecânica do dano. Vale 
ressaltar que os critérios de falha implementados produzem leves diferenças de resultados em comparação com os mesmos critérios já disponíveis no programa de elementos finitos, como o critério da máxima deformação plástica equivalente, ou critério de falha de Johnson-Cook. Acredita-se que essas diferenças ocorrem pelo critério de ativação de falha nos elementos. Na subrotina, conhece-se que a falha é ativada quando o valor crítico de falha é atingido em pelo menos um ponto de integração do elemento. 


\section{Algoritmo de previsão elástica e retorno}

(i) Previsão elástica. Dado $\Delta \boldsymbol{\varepsilon}$ e as variáveis de estado em $\mathrm{t}_{\mathrm{n}}$, avaliar o estado elástico de tentativa:

$\boldsymbol{\varepsilon}_{\mathrm{n}+1}^{\mathrm{e}, \text { tent }}:=\boldsymbol{\varepsilon}_{\mathrm{n}}^{\mathrm{e}}+\Delta \boldsymbol{\varepsilon}$

$\bar{\varepsilon}_{\mathrm{n}+1}^{\mathrm{p}, \text { tent }}:=\bar{\varepsilon}_{\mathrm{n}}^{\mathrm{p}}$

$p_{n+1}^{\text {tent }}:=K \varepsilon_{v, n+1}^{\text {,tent }} ; \quad \boldsymbol{s}_{n+1}^{\text {tent }}:=2 G \varepsilon_{d, n+1}^{\text {etent }}$

$\bar{\sigma}_{n+1}^{\text {tent }}:=\sqrt{\frac{3}{2} \boldsymbol{s}_{n+1}^{\text {tent }}: \boldsymbol{s}_{n+1}^{\text {tent }}}$

(ii) Verificar ocorrência de plasticidade:

SE $\bar{\sigma}_{n+1}^{\text {tent }}-\sigma_{y}\left(\bar{\varepsilon}_{n+1}^{p, t e n t}\right) \leq 0$

ENTÃO ajuste $(.)_{n+1}:=(.)_{n+1}^{\text {tent }} \quad$ e SAIA da subrotina

(iii) Procedimento de retorno. Resolver a equação:

$\widetilde{\Phi}(\Delta \gamma) \equiv \bar{\sigma}_{n+1}^{t e n t}-3 G \Delta \gamma-\sigma_{y}\left(\bar{\varepsilon}_{n}^{p}+\Delta \gamma\right)=0$

para $\Delta \gamma$ usando o método de Newton-Raphson (ir para esquema da Figura 35) e atualizar as variáveis de estado:

$p_{n+1}:=p_{n+1}^{\text {tent }} ; \quad \boldsymbol{s}_{n+1}:=\left(1-\frac{\Delta \gamma 3 G}{\bar{\sigma}_{n+1}^{\text {tent }}}\right) \boldsymbol{s}_{n+1}^{\text {tent }}$

$\boldsymbol{\sigma}_{n+1}:=\boldsymbol{s}_{n+1}+p_{n+1} \boldsymbol{I}$

$\boldsymbol{\varepsilon}_{n+1}^{e}=\frac{1}{2 G} \boldsymbol{s}_{n+1}+\frac{1}{3} \varepsilon_{v, n+1}^{e, \text { tent }} \boldsymbol{I}$

$\bar{\varepsilon}_{n+1}^{p}:=\bar{\varepsilon}_{n}^{p}+\Delta \gamma$

(iv) SAIR

Figura 34. Esquema do algoritmo de previsão elástica e retorno. Extraído de Souza Neto et al. (2008). 


\section{Algoritmo de Newton-Raphson}

(i) Ajuste um valor inicial para $\Delta \gamma$

$\Delta \gamma^{(0)}:=0$

e o correspondente residual (valor da função de escoamento):

$\tilde{\Phi}:=\bar{\sigma}_{n+1}^{\text {tent }}-\sigma_{y}\left(\bar{\varepsilon}_{n}^{p}\right)$

(ii) Executar iteração de Newton-Raphson

$H:=\left.\frac{d \sigma_{y}}{d \bar{\varepsilon}^{p}}\right|_{\bar{\varepsilon}_{n}^{p}+\Delta \gamma} \quad$ (inclinação)

$d:=\frac{d \widetilde{\Phi}}{d \Delta \gamma}=-3 G-H \quad$ (derivada residual)

$\Delta \gamma:=\Delta \gamma-\frac{\tilde{\Phi}}{d} \quad$ (novo valor para $\left.\Delta \gamma\right)$

(iii) Verificar convergência

$\tilde{\Phi}:=\bar{\sigma}_{n+1}^{\text {tent }}-3 G \Delta \gamma-\sigma_{y}\left(\bar{\varepsilon}_{n}^{p}+\Delta \gamma\right)$

SE $|\tilde{\Phi}| \leq \varepsilon_{\text {tol }} \quad$ ENTÃO RETORNAR ao esquema da Figura 34

(iv) IR PARA (ii)

Figura 35. Esquema do algoritmo de Newton-Raphson. Extraído de Souza Neto et al. (2008). 


\section{ESTUDO DE CASO DA APLICAÇÃO DOS CRITÉRIOS DE FALHA}

Conforme explicado anteriormente, a fim de simular numericamente os ensaios experimentais, foi utilizado o programa comercial de elementos finitos $L S$ Dyna® e o modelo constitutivo de von Mises:

$$
\bar{\sigma}=A+B \bar{\varepsilon}_{p}^{n}
$$

onde $A, B$ e $n$ são constantes do material que precisam ser determinadas experimentalmente. Neste trabalho esses parâmetros foram extraídos do modelo constitutivo de Johnson-Cook, sem considerar os efeitos da taxa de deformação e temperatura, a partir do trabalho de Teng et al. (2005).

Tabela 4 - Parâmetros do modelo de von Mises para alumínio 2024-T351

\begin{tabular}{ccc}
\hline$A(\mathrm{MPa})$ & $B(\mathrm{MPa})$ & $n$ \\
\hline 352 & 440 & 0,42 \\
\hline
\end{tabular}

Inicialmente foi realizada a simulação do teste de tração com espécime comum, utilizando a malha de elementos finitos mostrada na Figura 36.

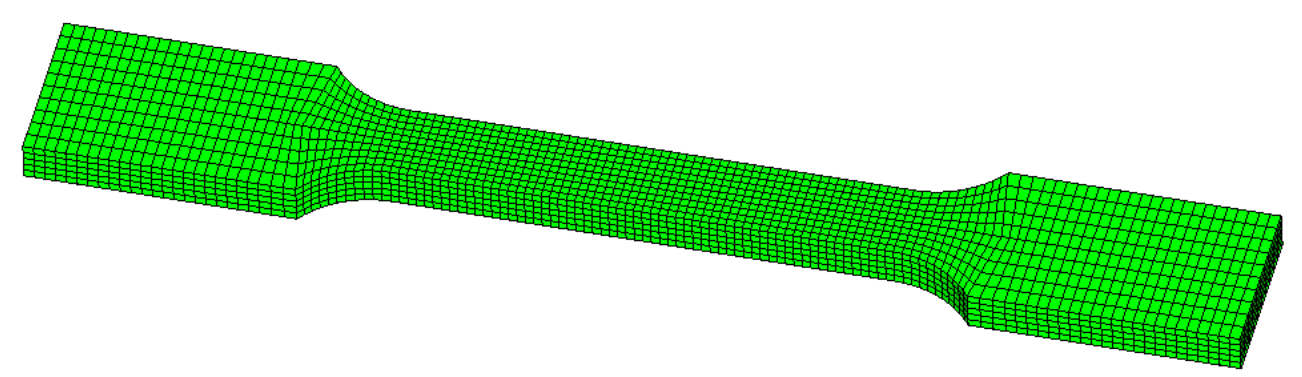

Figura 36. Malha de elementos finitos utilizada na simulação do teste de tração comum

A simulação do teste de tração comum foi feita a fim de verificar a correlação entre as curvas tensão-deformação experimental e numérica. Nesta comparação foi incluída também a curva do alumínio 2024-T351 utilizada por Wierzbicki et al. (2005). 


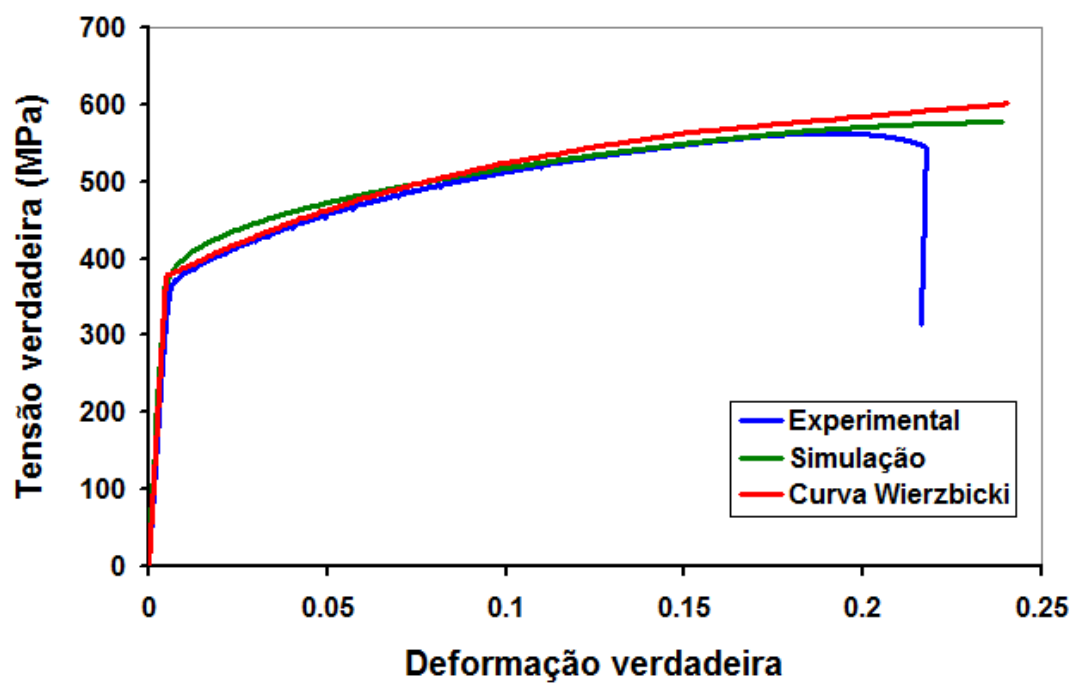

Figura 37. Curva tensão-deformação para teste de tração comum, com a curva extraída da simulação e curva do material utilizado por Wierzbicki et al. (2005)

Verifica-se na Figura 37 boa correlação entre resultados experimentais e numéricos, com relação ao comportamento plástico do material.

Como ocorreu a validação dos parâmetros de material adotados, os mesmos foram utilizados na simulação do espécime Bifailure, no teste de diferentes critérios de falha. A malha do espécime Bifailure é apresentada nas Figuras 38 e 39 . Os pinos que tracionam o espécime foram modelados como superfícies analíticas (cilindros), sendo aplicado um deslocamento imposto no pino de uma extremidade enquanto que o outro pino é mantido fixo. Os valores de deformação de engenharia obtidos são tomados a partir da distância entre dois nós que corresponderiam aos pontos de apoio das pinças do extensômetro com o corpo de prova. Por simplificação, os entalhes que rompem a alta triaxialidade serão chamados de 1 e 2 , e o entalhe central, que rompe a triaxialidade próxima a zero será chamado de entalhe 3.

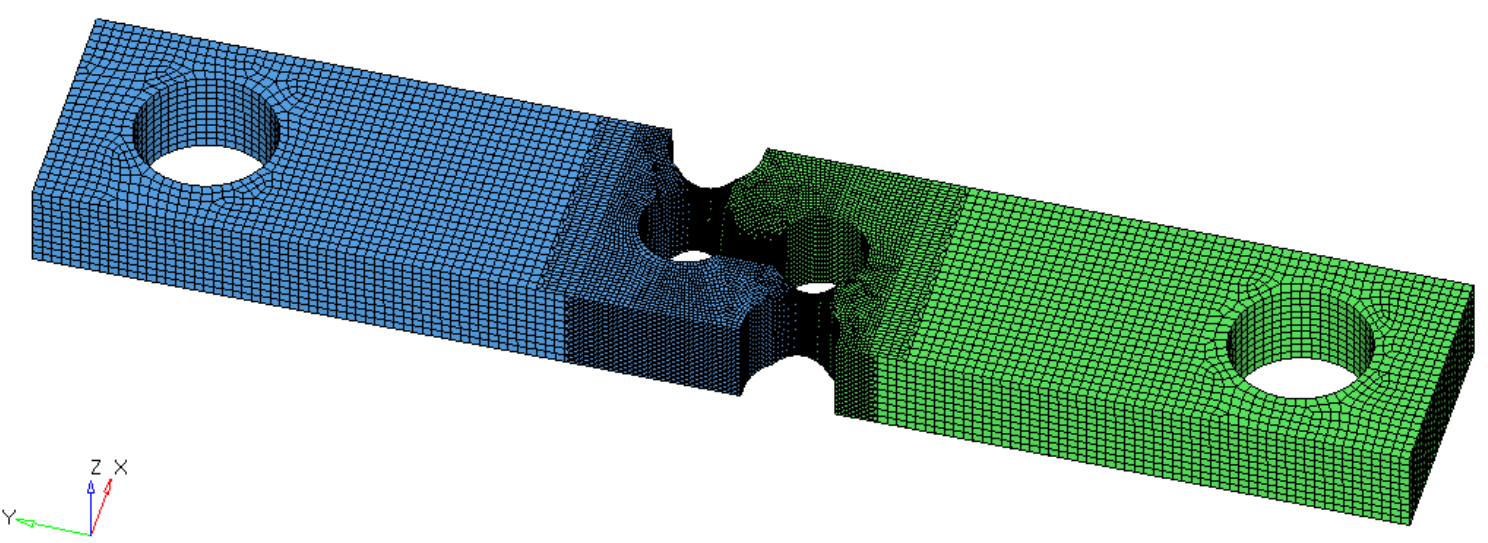

Figura 38. Malha do corpo de prova Bifailure, composta de 152220 elementos 


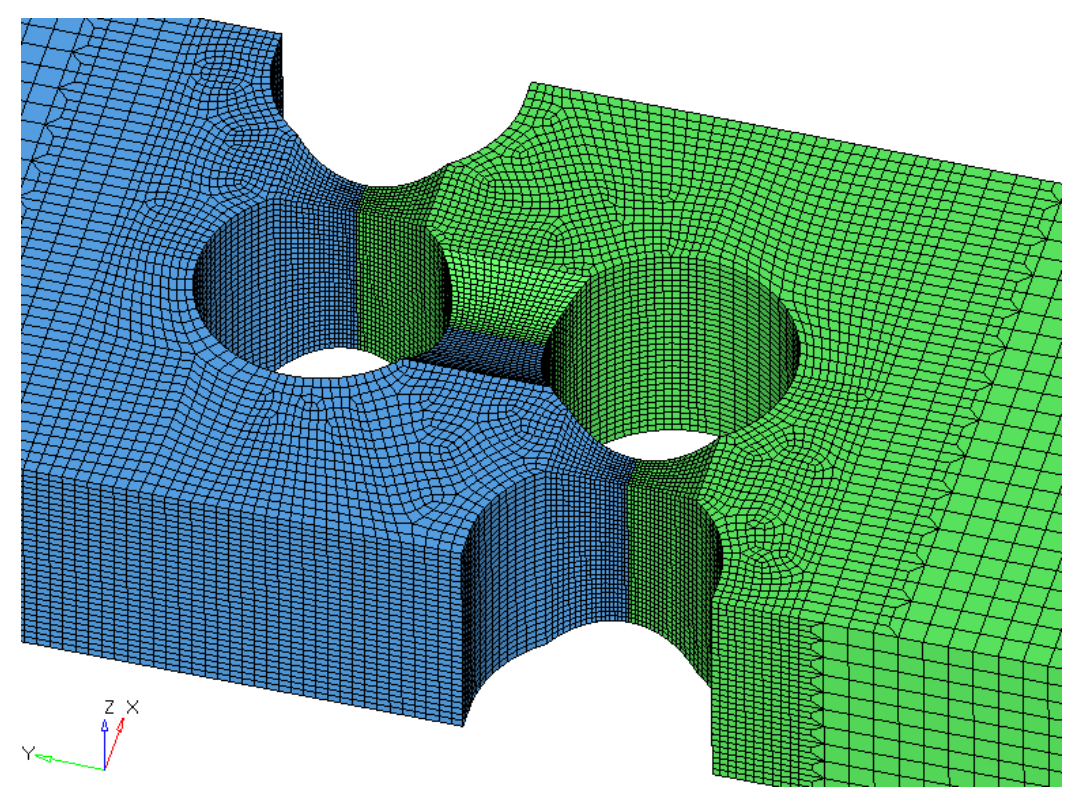

Figura 39. Detalhe da malha do espécime Bifailure, na região dos entalhes

Através de simulação foram medidas as triaxialidades para os entalhes $1,2 \mathrm{e}$ 3, que estão ilustradas na Figura 40. O valor médio de triaxialidade obtido para os entalhes 1 e 2 é de 0,629 e para o entalhe 3 é de 0,016.

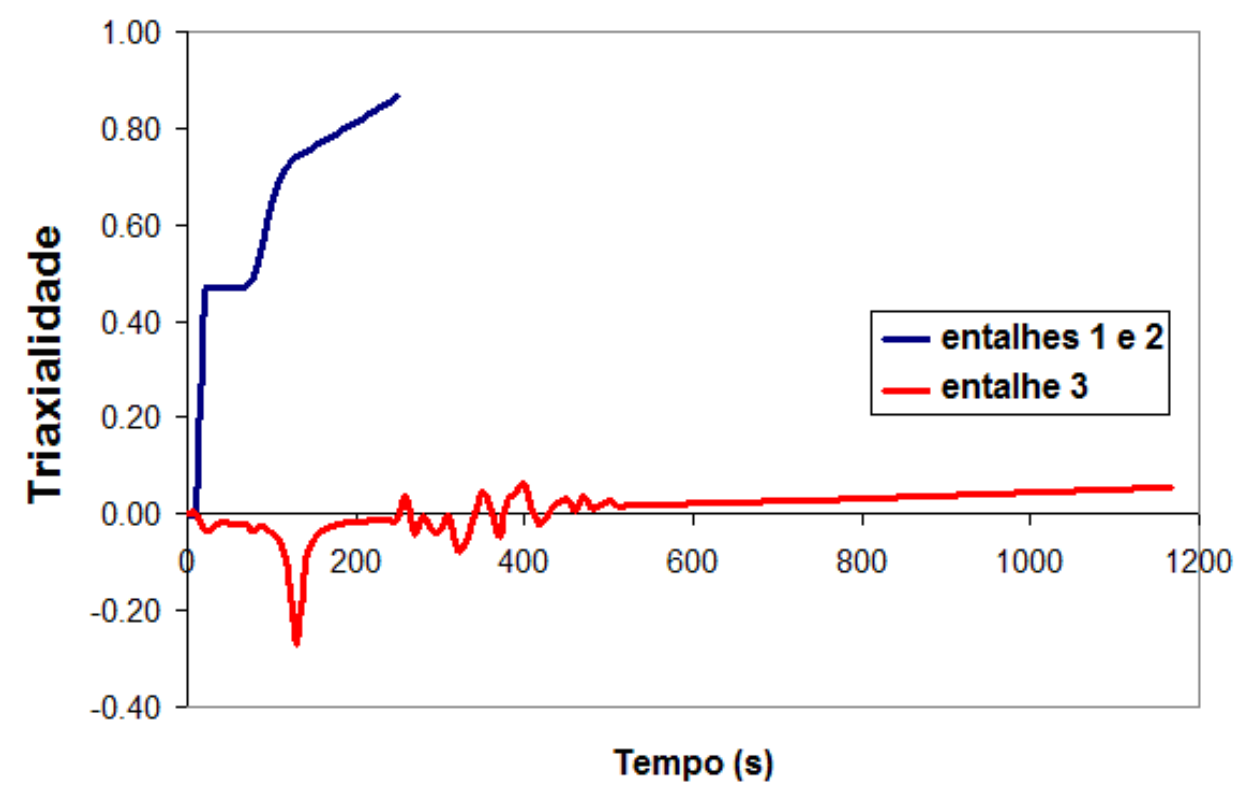

Figura 40. Variação da triaxialidade para os entalhes do espécime Bifailure

A seguir são discutidos os resultados numéricos dos critérios de falha implementados na subrotina de elementos finitos. 


\subsection{Critério de falha da máxima deformação plástica equivalente}

Para este critério foi utilizado o valor de deformação de falha de 0,21 , extraído do trabalho de Teng e Wierzbicki (2006). O resultado da simulação é apresentado na Figura 41.

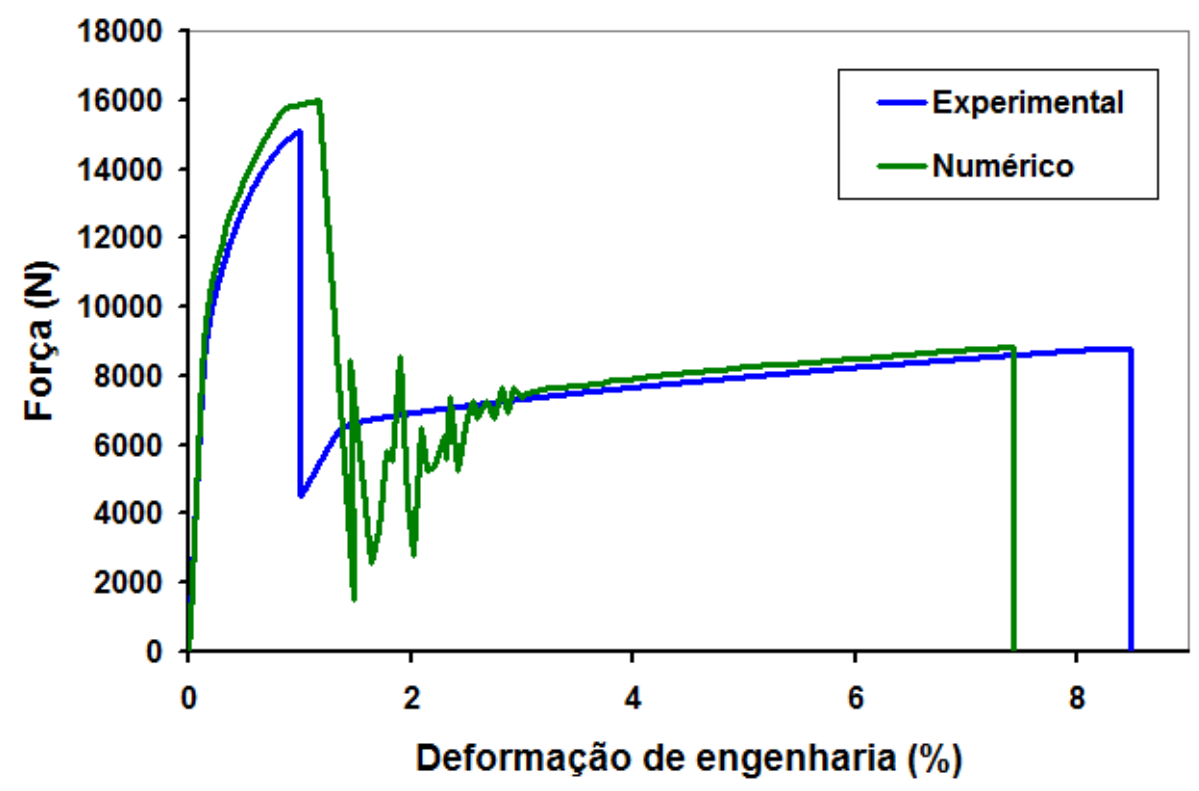

Figura 41. Curvas experimental e numérica da simulação com critério de falha da máxima deformação plástica equivalente

Verifica-se correlação razoável entre resultados experimentais e numéricos, apesar do critério embasado apenas em deformação ser relativamente simples. Após a ruptura dos entalhes 1 e 2 , verifica-se na curva numérica um comportamento oscilatório do espécime. Isso ocorre pelo fato de não haver amortecimento nas simulações.

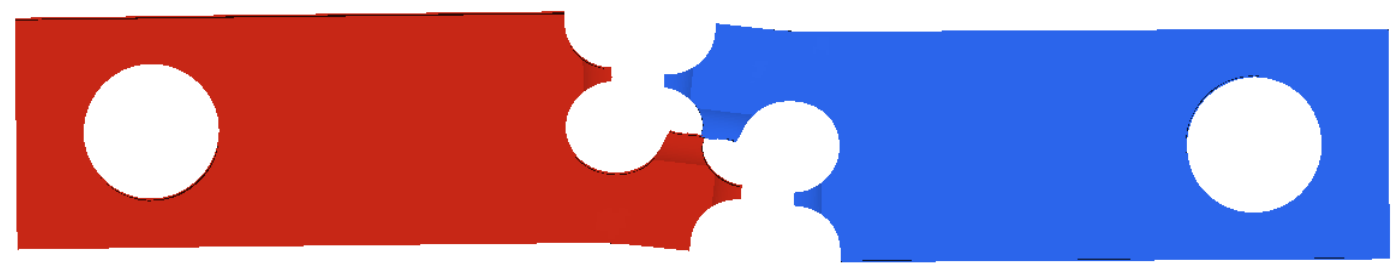

Figura 42. Resultado da simulação com critério de falha da máxima deformação plástica equivalente 
Verifica-se que a acuracidade deste critério depende do valor utilizado para a calibração do mesmo. Pelo fato de ser necessário apenas um teste para a calibração do critério da máxima deformação plástica equivalente, em Wierzbicki et al. (2005) foi adotado um valor que produzisse uma melhor correlação com os testes experimentais analisados nesse trabalho. $O$ valor utilizado para a calibração não foi baseado no teste de tração uniaxial, o qual produziria um valor crítico muito maior $\left(\bar{\varepsilon}_{f}=0,45\right)$.

\subsection{Critério de falha da máxima tensão cisalhante}

Para este critério foi utilizado o valor de tensão cisalhante de falha de 380 MPa, extraído do trabalho de Teng e Wierzbicki (2006). O resultado da simulação é apresentado na Figura 43. Verifica-se que o critério da máxima tensão cisalhante superestimou a ruptura do espécime, resultando em grande rotação da parte central do mesmo, evidenciada na Figura 44, que ilustra o momento imediatamente após a falha.

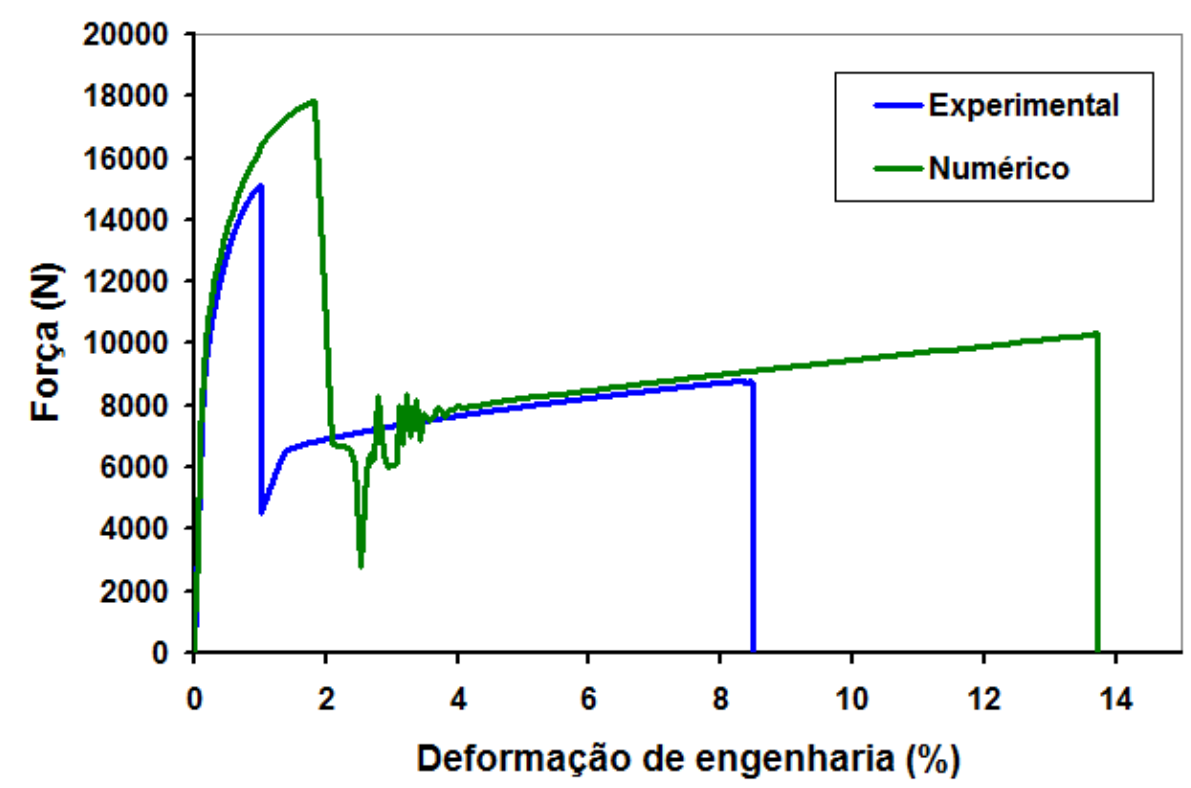

Figura 43. Curvas experimental e numérica da simulação com critério de falha da máxima tensão cisalhante 


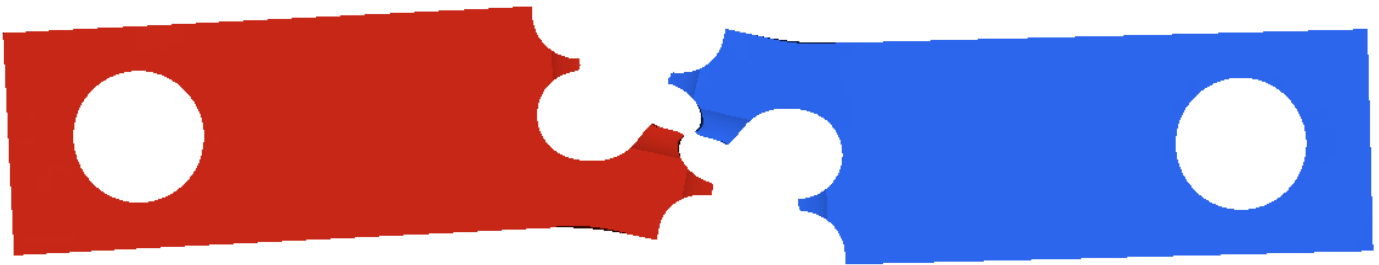

Figura 44. Resultado da simulação com critério de falha da máxima tensão cisalhante

Este critério precisa apenas de um teste experimental para ser calibrado, por essa razão o valor utilizado para a calibração deve ser o mais representativo possível da ruptura dos espécimes ensaiados. Uma implementação do critério da máxima tensão cisalhante foi feita no espaço das deformações principais em Wierzbicki et al. (2005), chegando-se a bons resultados.

\subsection{Critério de falha de Johnson-Cook (JC)}

Para este critério, a deformação de falha tem o seguinte formato:

$$
\varepsilon_{c}=D_{1}+D_{2} \exp \left(D_{3} \eta\right)
$$

Desta forma, neste trabalho foram adotados os valores de Teng et al. (2005), que aparecem na Tabela 5. A relação fator de triaxialidade $x$ deformação de falha está mostrada na Figura 45.

Tabela 5 - Parâmetros do critério de falha de Johnson-Cook para alumínio 2024-T351

\begin{tabular}{ccc}
\hline$D_{1}$ & $D_{2}$ & $D_{3}$ \\
\hline 0,13 & 0,13 & $-1,5$ \\
\hline
\end{tabular}




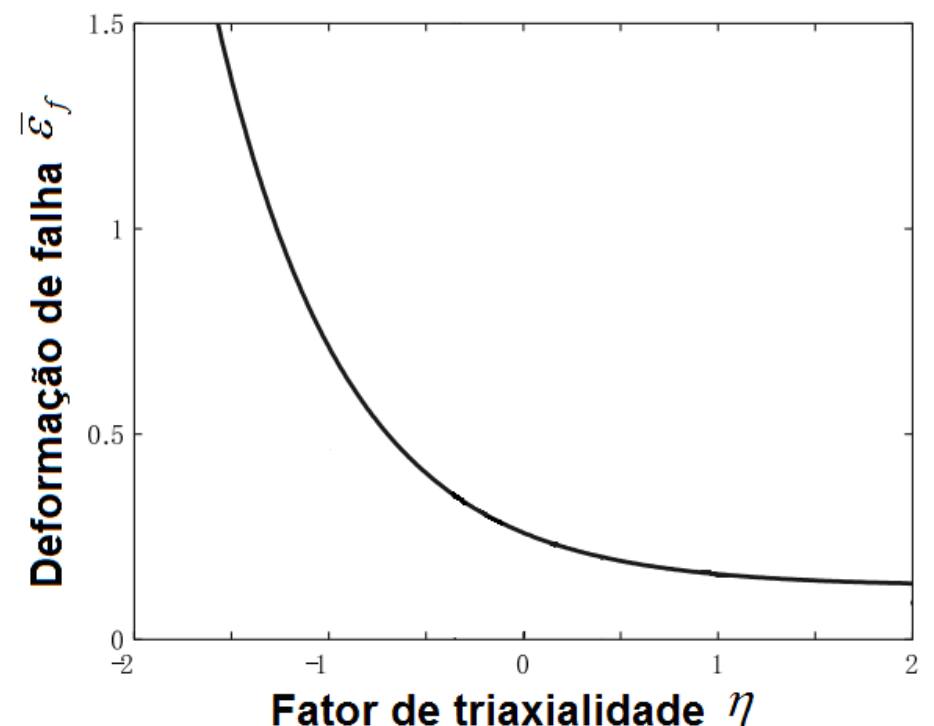

Figura 45. Lugar geométrico de falha para o critério de falha de Johnson-Cook

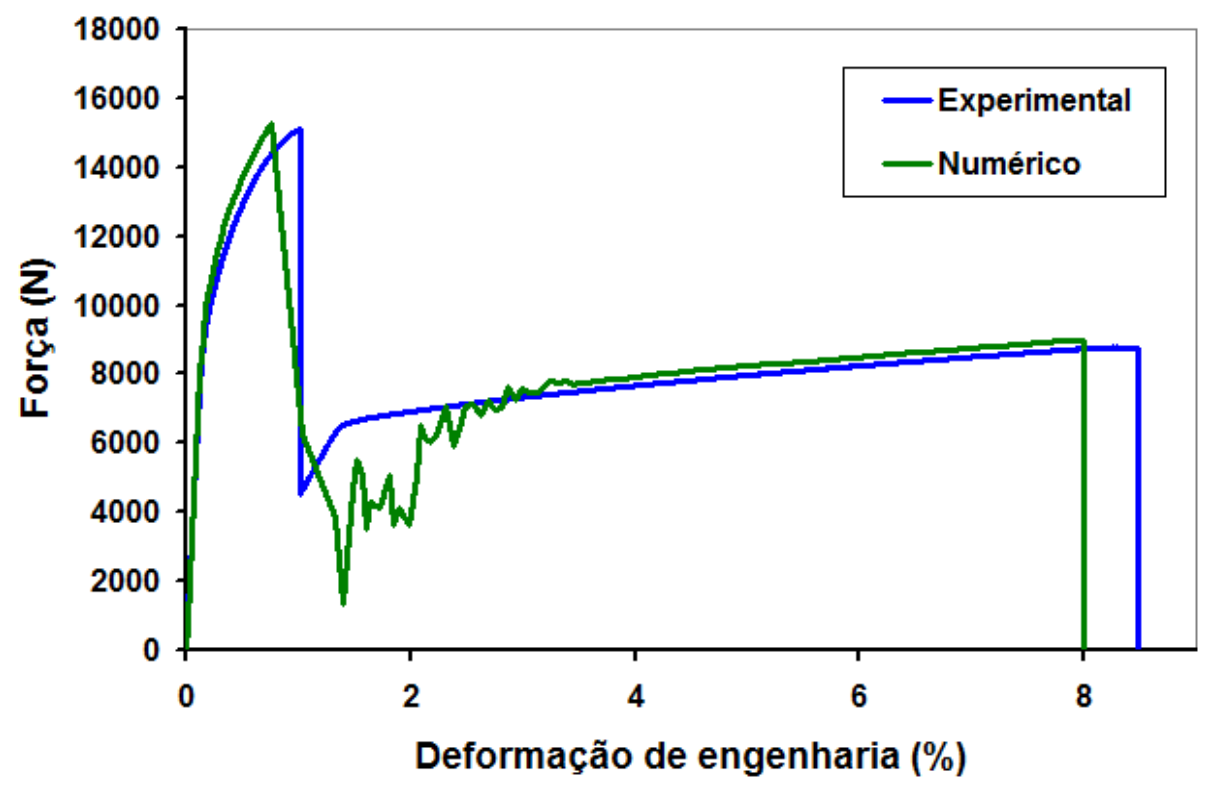

Figura 46. Resultado da simulação com critério de falha de Johnson-Cook

De acordo com a Figura 46, verifica-se boa correlação entre resultado experimental e numérico, apesar de o critério de falha de Johnson-Cook considerar apenas o fator de triaxialidade em sua formulação. Três testes experimentais são necessários para a calibração do critério de falha de JC. Desse modo, da mesma forma que ocorre com os dois critérios anteriores, o critério de JC também necessita de uma calibração que satisfaça a maior parte dos ensaios experimentais analisados. Por esse motivo encontra-se disponível na literatura mais de um 
conjunto de parâmetros de JC para alumínio 2024-T351. A Figura 47 ilustra o espécime logo após a falha.

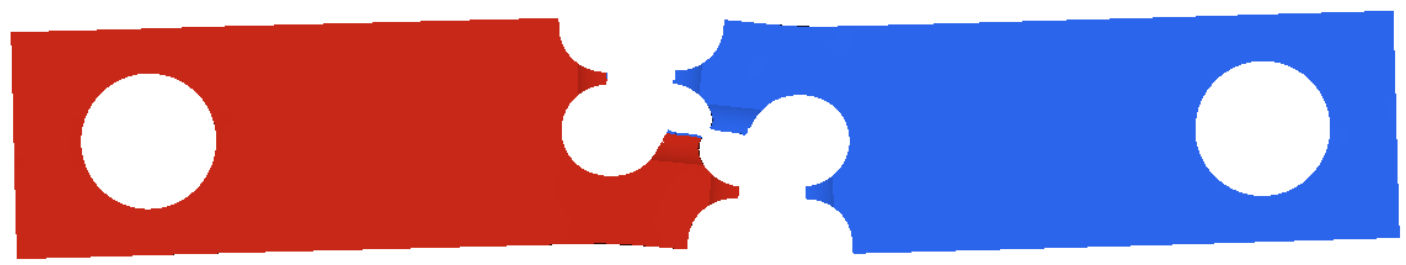

Figura 47. Resultado da simulação com critério de falha de Johnson-Cook

Um ponto interessante a ser considerado é que nesta simulação a falha do entalhe 3 não ocorreu exatamente no centro, mas sim de forma assimétrica. Outro ponto importante foi uma representação razoável da ruptura no entalhe 3 . O critério de Johnson-Cook foi originalmente proposto para a representação de falha em altas triaxialidades. Assim, pode-se dizer que a representação de falha no entalhe 3 foi razoável apesar do fato de a ruptura próxima a cisalhamento puro implicar em altos valores de deformação de falha pelo critério de JC.

\subsection{Critério de falha de Wilkins}

O critério de falha de Wilkins implementado aqui foi calibrado de acordo com Wierzbicki et al. (2005). Os parâmetros utilizados aparecem na Tabela 6.

Tabela 6 - Parâmetros do critério de falha de Wilkins para alumínio 2024-T351

\begin{tabular}{cccc}
\hline$a$ & $\lambda$ & $\mu$ & $D_{\text {crit }}$ \\
\hline $1,2 \cdot 10^{-3} \mathrm{MPa}^{-1}$ & 2,15 & 2,18 & 0,93 \\
\hline
\end{tabular}




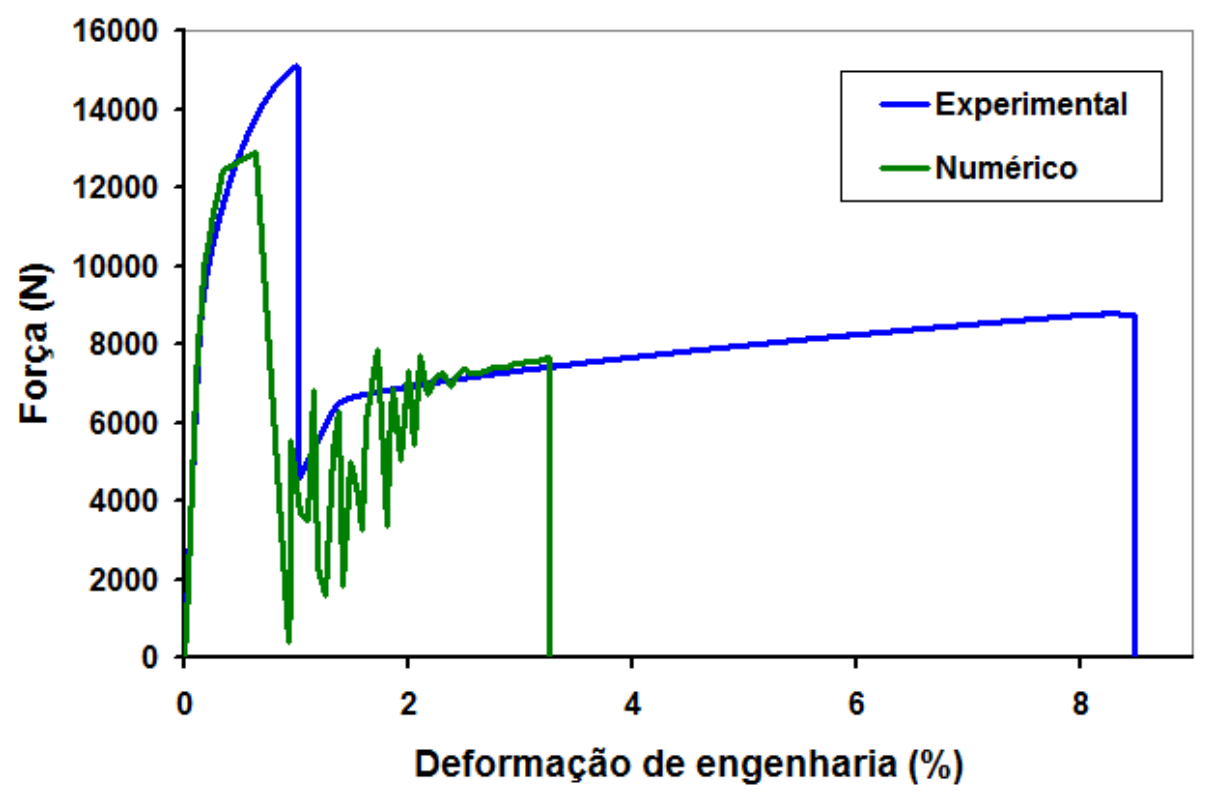

Figura 48. Resultado da simulação com critério de falha de Wilkins.

Pelos resultados apresentados, na Figura 48 percebe-se que o critério de falha de Wilkins subestimou a ocorrência de ruptura em alta triaxialidade (entalhes laterais menores) e gerou uma péssima previsão da falha em cisalhamento (entalhe central). Apesar de serem necessários no mínimo 4 testes experimentais para a sua calibração, este critério de falha não apresentou bons resultados no presente trabalho. De acordo com Wierzbicki et al. (2005) este critério produziria bons resultados na faixa de triaxialidade $-1 / 3<\eta<1 / 3$ enquanto que subestimaria resultados na faixa de triaxialidade $1 / 3<\eta<2 / 3$.

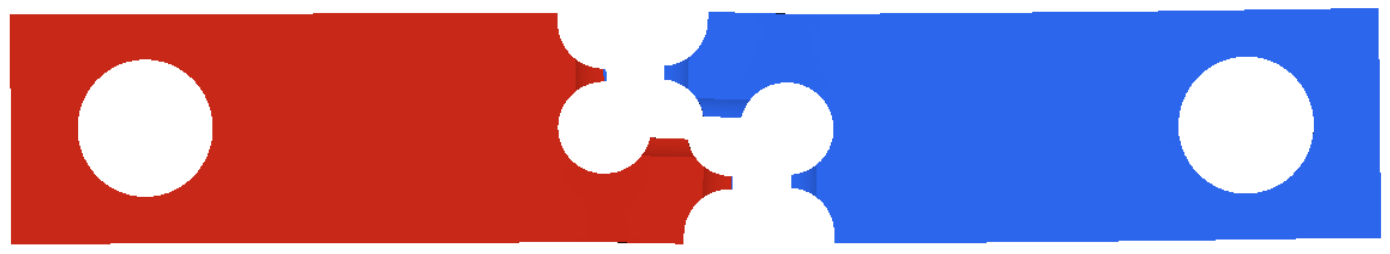

Figura 49. Resultado da simulação com critério de falha de Wilkins. 


\subsection{Critério de falha de Cockcroft Latham}

Este critério de falha é baseado em uma energia de deformação de ruptura na definição do valor crítico de falha. Desse modo, apenas um teste experimental é necessário para a sua calibração. No entanto, da mesma forma que para os critérios baseados na máxima deformação plástica equivalente e no critério da máxima tensão cisalhante, é necessário calibrar este critério com o valor que melhor representa na média os fenômenos de falha analisados. De acordo com Teng e Wierzbicki (2006) os valores críticos deste critério para o alumínio 2024-T351 variam de 0,058 até 0,485 . Dessa forma, aqui foram feitas simulações com esses dois valores extremos.

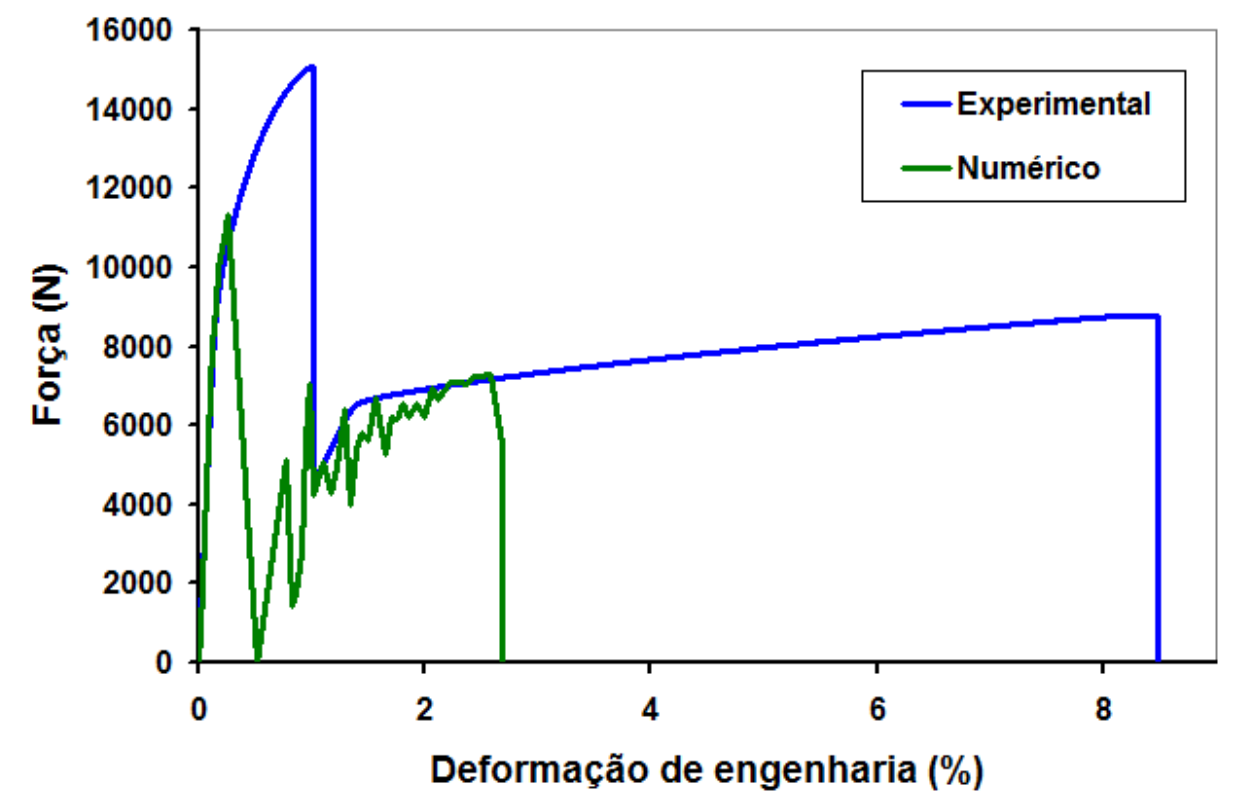

Figura 50. Resultado da simulação com critério de falha de Cockcroft-Latham e valor crítico de 0,058 


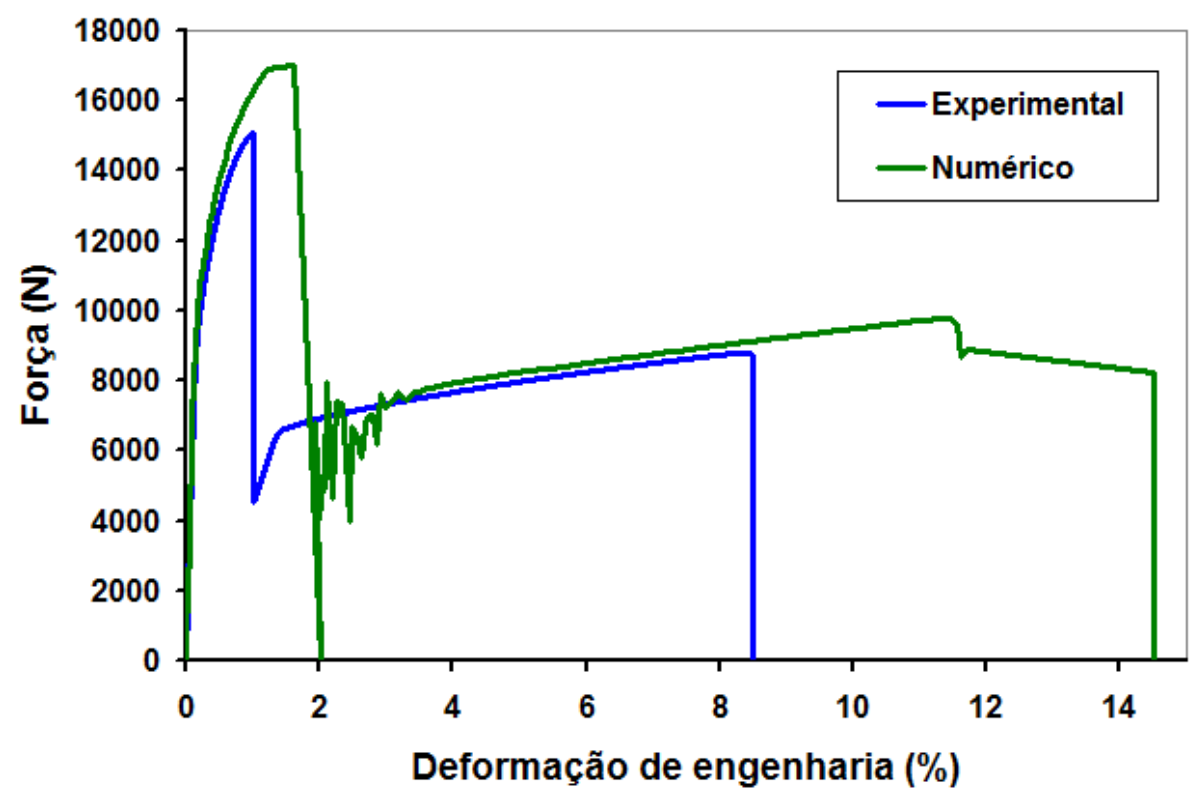

Figura 51. Resultado da simulação com critério de falha de Cockcroft-Latham e valor crítico de 0,485

Verifica-se que os valores extremos de calibração deste critério não geraram bons resultados para a simulação do espécime Bifailure. A fim de se representar melhor a simulação do Bifailure, um melhor valor crítico poderia ser escolhido para a simulação. De acordo com Teng e Wierzbicki (2006), a calibração deste critério a partir de ensaios de compressão de cilindros oferecem valores consistentes, enquanto que a calibração feita a partir de ensaios de tração uniaxial de espécimes com e sem entalhe geram valores que se espalham em uma longa faixa.

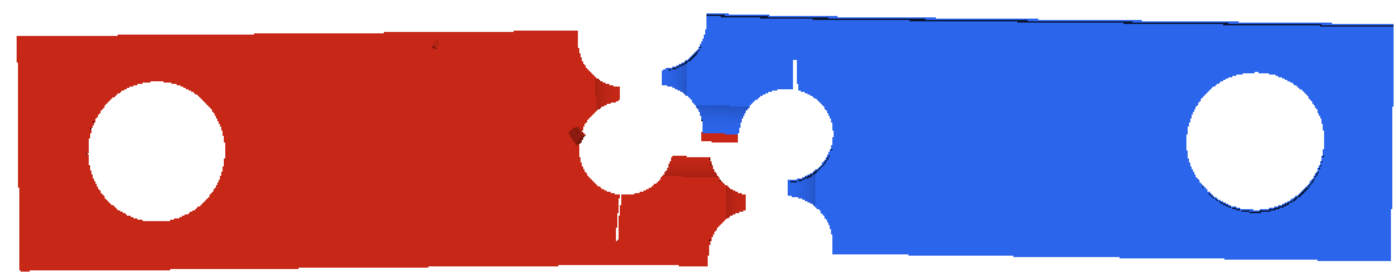

Figura 52. Resultado da simulação com critério de falha de Cockcroft-Latham e valor crítico de 0,058

É interessante notar na Figura 52 que a utilização de um valor crítico baixo resultou em duas pequenas trincas, uma de cada lado ao redor do entalhe 3 , antes da ocorrência da ruptura. Nas Figuras 52 e 53, percebe-se que houve ruptura não simétrica em relação ao entalhe 3, sendo que na Figura 54 verifica-se a existência de duas microtrincas de modo que uma delas irá originar a ruptura final do entalhe 3 (microtrinca do lado vermelho). 


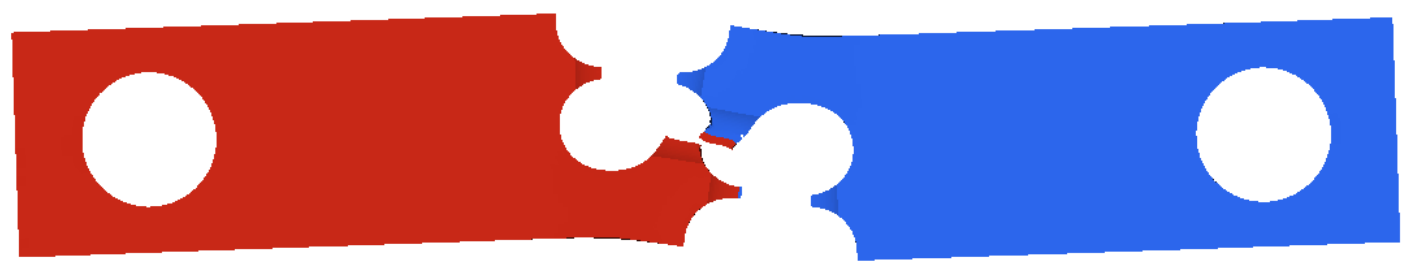

Figura 53. Resultado da simulação com critério de falha de Cockcroft-Latham e valor crítico de 0,485

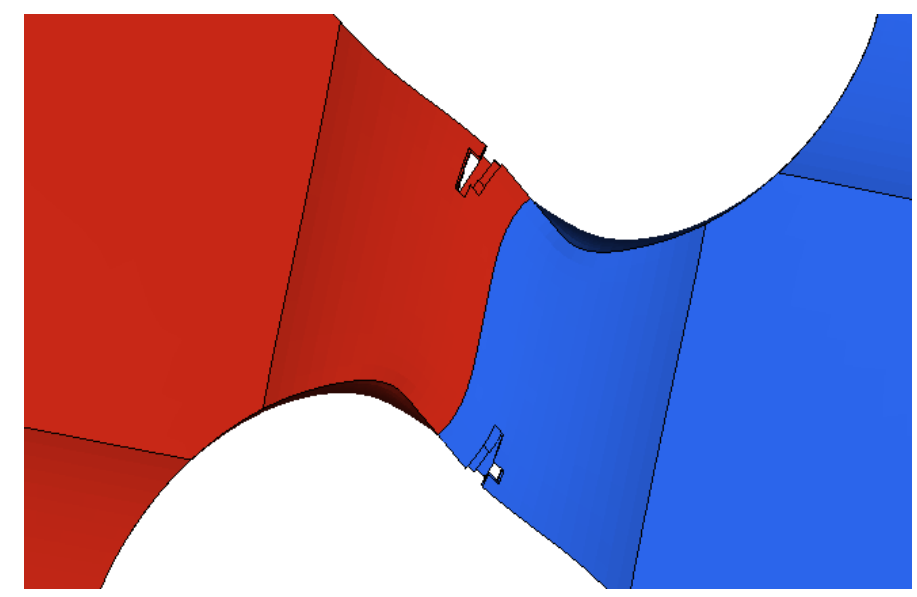

Figura 54. Trincas ao redor do entalhe 3, para critério de falha de Cockcroft-Latham com valor crítico de 0,485

\subsection{Critério de falha de Bao-Wierzbicki}

O critério de falha de Bao-Wierzbicki é função apenas do fator de triaxialidade, mas é representado por quatro funções diferentes de acordo com a faixa de triaxialidade. Este critério de falha foi desenvolvido por Bao e Wierzbicki (2004) através da construção do lugar geométrico de falha (fracture locus) pela realização e simulação de vários testes experimentais incluindo testes em cisalhamento puro e testes uniaxiais de espécimes em forma de cilindro com e sem entalhe, para o alumínio 2024-T351. A função de deformação de falha aparece esquematizada na seção 3.3.6 para o alumínio 2024-T351, sendo que a mesma é ilustrada na Figura 55. 


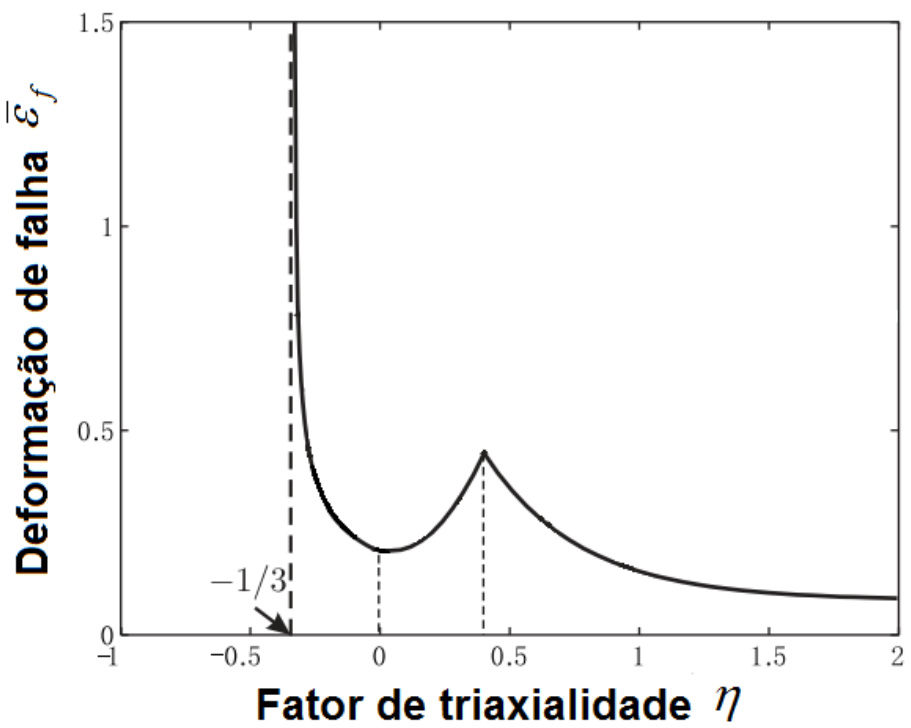

Figura 55. Deformação de falha para o critério de Bao-Wierzbicki

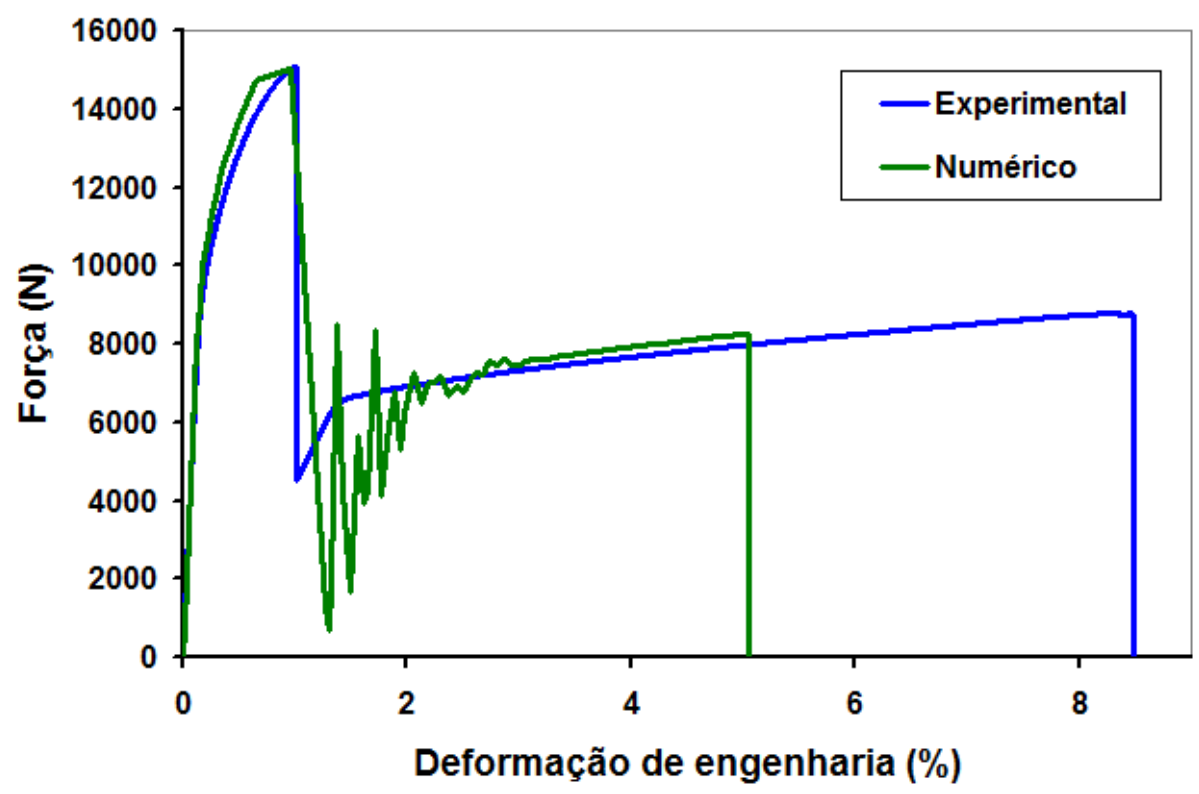

Figura 56. Resultado da simulação com critério de falha de Bao-Wierzbicki

Apesar da formulação deste critério possuir uma melhor representação da deformação de falha para praticamente toda a faixa de triaxialidades, não foi constatado um bom resultado numérico para a falha sob cisalhamento. Além disso, uma grande oscilação da curva de força numérica foi verificada, conforme Figura 56.

Apesar do resultado ruim para a previsão de falha por cisalhamento por parte deste critério, em contrapartida pode-se dizer que o mesmo já foi empregado com sucesso em simulações de impacto com falha, como em simulações de testes de Taylor com a verificação de diferentes modos de falha do espécime (Teng et al., 2005). 


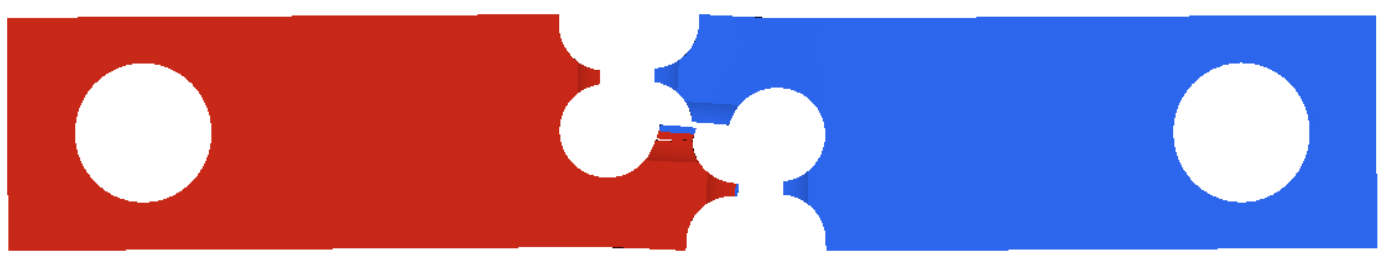

Figura 57. Resultado da simulação com critério de falha de Bao-Wierzbicki

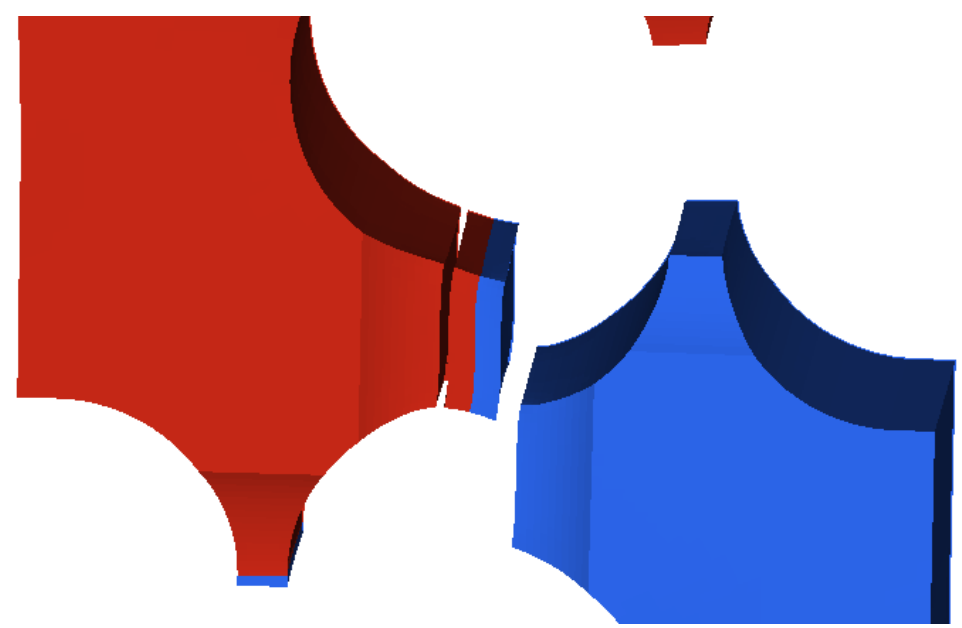

Figura 58. Para o critério de falha de Bao-Wierzbicki, duas trincas foram geradas na região do entalhe central

\subsection{Critério de falha de Xue-Wierzbicki}

Este critério considera o fator de triaxialidade e o ângulo de Lode em sua formulação, possuindo cinco parâmetros para a sua calibração, os quais estão listados na Tabela 7.

Tabela 7 - Parâmetros do critério de falha de Xue-Wierzbicki para alumínio 2024-T351

\begin{tabular}{ccccc}
\hline$C_{1}$ & $C_{2}$ & $C_{3}$ & $C_{4}$ & $n$ \\
\hline 0,87 & 1,77 & 0,21 & 0,01 & 0,153 \\
\hline
\end{tabular}

Na Tabela 7, né o coeficiente de encruamento do material, extraído do ajuste da curva tensão-deformação equivalente do material à função:

$$
\bar{\sigma}=K_{t} \bar{\varepsilon}_{p}^{n}
$$


onde $\bar{\sigma}$ é a tensão equivalente, $K_{t}$ é o módulo tangente e $\bar{\varepsilon}_{p}$ é a deformação plástica equivalente. A superfície de deformação de falha em função do fator de triaxialidade e ângulo de Lode para este critério é mostrada na Figura 59.

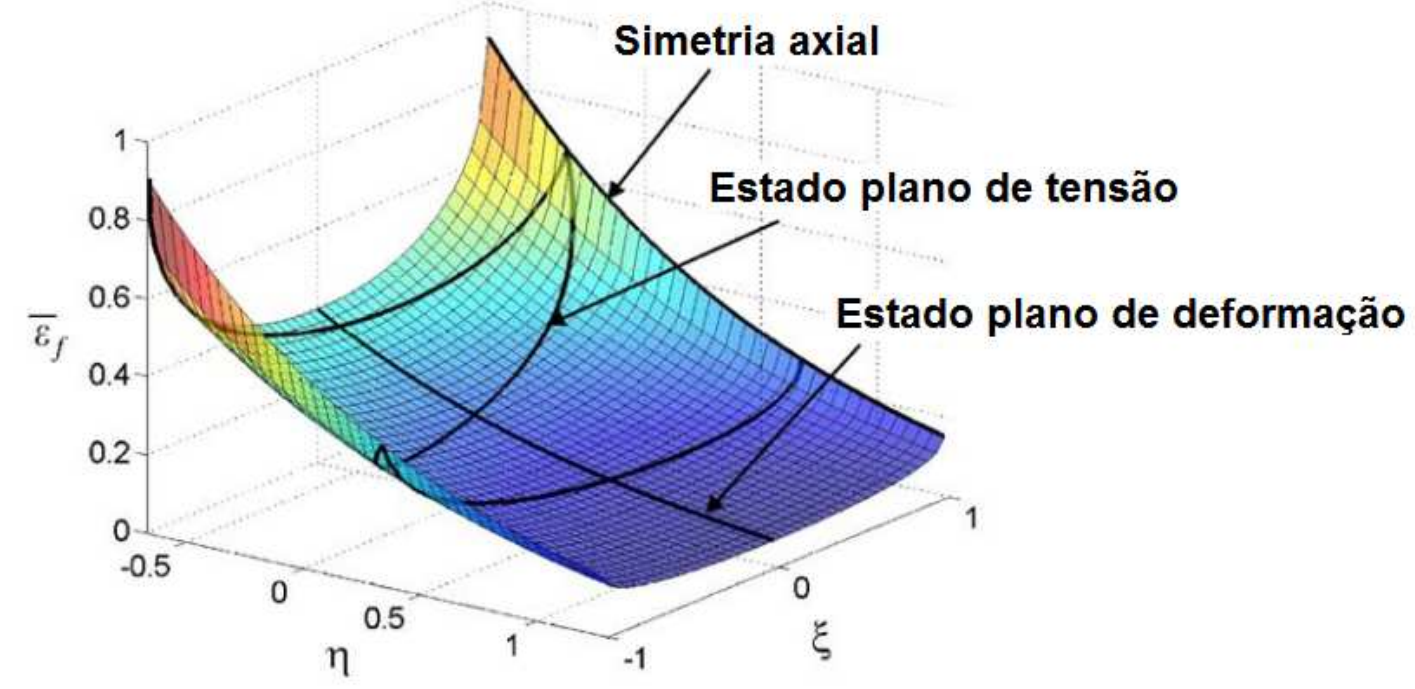

Figura 59. Superfície de deformação de falha para o critério de falha de Xue-Wierzbicki. Extraído de Wierzbicki et al. (2005)

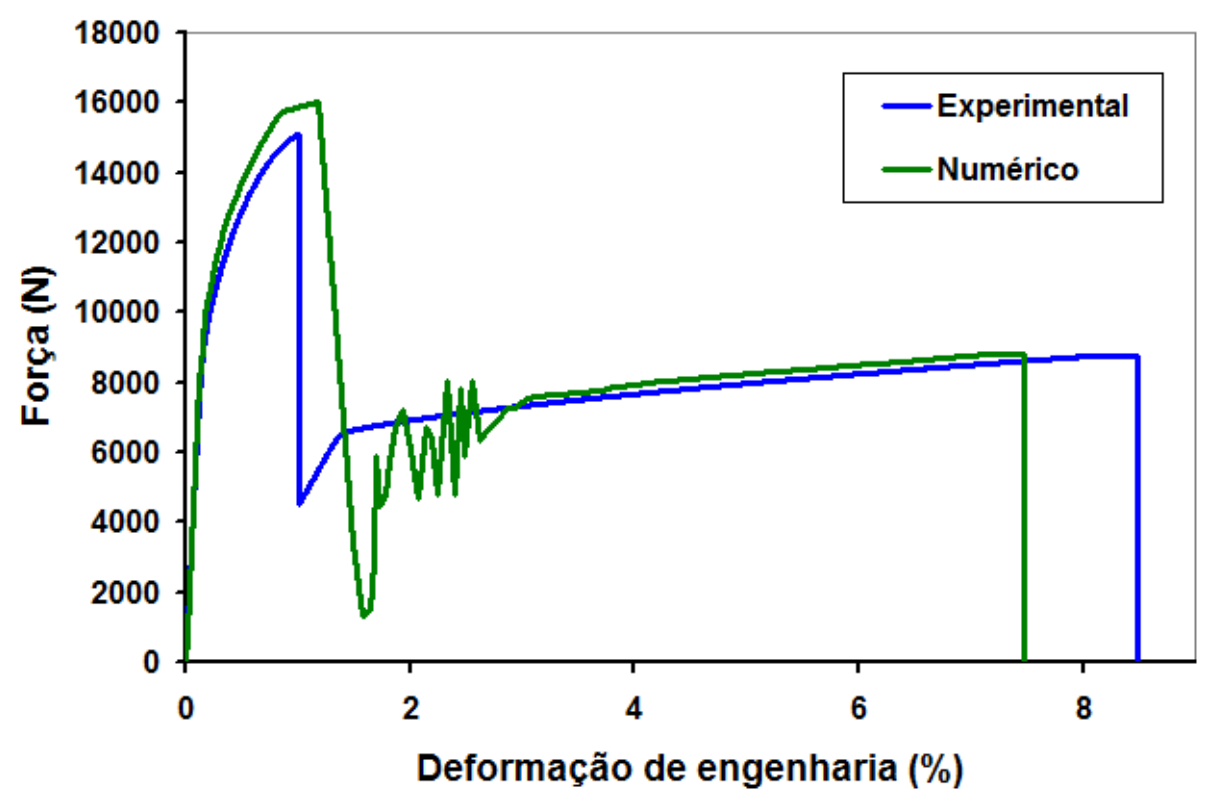

Figura 60. Resultado da simulação para o critério de Xue-Wierzbicki

Este critério representou com uma razoável acuracidade a falha no material, como pode ser verificado na Figura 60, além de gerar uma falha simétrica em torno do entalhe 3. 


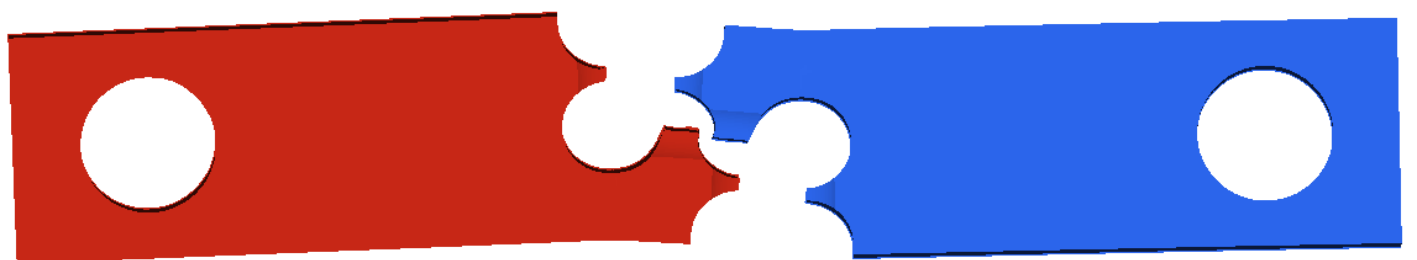

Figura 61. Resultado da simulação para o critério de Xue-Wierzbicki

\subsection{Discussão dos resultados}

Com relação aos critérios baseados em um único valor de calibração, foi obtido um bom resultado para o critério da máxima deformação equivalente. Devese ressaltar que os resultados ruins dos critérios da máxima tensão cisalhante e do critério de Cockcroft Latham dependem dos valores utilizados na calibração, os quais geralmente são calibrados para atender um maior número de casos de testes experimentais de diferentes espécimes. Com relação aos critérios de falha baseados no fator de triaxialidade, obteve-se um bom resultado com o critério de falha de Johnson-Cook, apesar de sua simplicidade. Para o critério de falha de BaoWierzbicki, somente a falha em alta triaxialidade foi prevista com boa acuracidade. Assim, pode-se dizer que este critério teve um resultado ruim levando em consideração a sua complexidade. Para o critério de falha de Xue-Wierzbicki um bom resultado pôde ser obtido. Deve-se destacar que o critério de Xue-Wierzbicki é o único critério avaliado aqui que também é função do ângulo de Lode.

Com relação ao formato de falha dos espécimes, esperava-se que ocorresse falha simétrica. No entanto em alguns critérios de falha verificou-se uma falha não simétrica em torno do entalhe central. Isso ocorreu devido ao fato de haver pequena rotação em torno do entalhe central, o que gerava o início de duas trincas de lados opostos de forma não simétrica, como ilustrado na Figura 54 para o critério de Cockcroft-Latham. Para o critério de Bao-Wierzbicki, inclusive, quase ocorreu a liberação de um fragmento do entalhe central pelo fato de haver ruptura nãosimétrica.

Foi provado que o espécime Bifailure é útil para o benchmark de critérios de falha. No entanto, uma limitação do referido espécime é o fato de ser possível 
avaliar apenas duas triaxialidades diferentes. Desse modo, recomenda-se para trabalhos futuros a possibilidade do projeto de um espécime como o Bifailure com falha em três triaxialidades diferentes, provavelmente tornando diferentes as geometrias dos entalhes 1 e 2 . 


\section{CONCLUSÕES}

Após um estudo detalhado da teoria de falha em materiais dúcteis, concluiuse que a falha é influenciada por parâmetros como triaxialidade, nível de deformação plástica e, de acordo com a literatura mais atual, ângulo de Lode. Dessa forma, foi obtida a geometria de um corpo de prova especial de ensaio de tração para benchmark de critérios de falha em dois estados de tensão distintos, o estado de tensão de alta triaxialidade e o estado de tensão próximo ao cisalhamento puro.

O espécime especial foi denominado Bifailure, sendo que a segunda geometria obtida para o mesmo resultou em baixa rotação da região central do espécime durante o teste, o que proporcionou a obtenção de estado de tensão próximo ao cisalhamento puro na região central, além de medidas mais precisas com o extensômetro.

A fim de ser possível a comparação de desempenho entre diferentes critérios de falha, uma subrotina especial foi desenvolvida para o programa comercial de elementos finitos $L S-D y n a^{\circledR}$. Verificou-se através da simulação que critérios de falha mais simples, como o baseado na máxima deformação plástica equivalente, puderam gerar resultados satisfatórios para o espécime em questão. Inclusive, um critério de falha tradicional como o de Johnson-Cook gerou resultados melhores do que critérios de fundamentação mais complexa, como o de Bao-Wierzbicki e XueWierzbicki.

Acredita-se que os critérios de falha mais simples representam melhor situações de falha similares àquelas que ocorrem nos espécimes utilizados para a calibração. Por exemplo, o critério de falha de Cockcroft-Latham e da máxima deformação plástica equivalente possuem apenas um único parâmetro de calibração. Dessa forma, não há um valor crítico ótimo comum a todos os tipos de falha. Se forem feitos vários testes, a diferentes condições, pode-se utilizar um valor que atenda razoavelmente bem a maior quantidade possível de situações.

Para trabalhos futuros, propõe-se um reprojeto do espécime Bifailure com três entalhes de geometria diferentes, o que poderia proporcionar a falha em três estados de triaxialidade diferentes ao invés de dois, como é o caso do espécime atual. 


\section{REFERÊNCIAS}

ALVES, M.; DRIEMEIER, L. A bi-failure specimen for accessing the performance of failure criteria. SEM - Society of Experimental Mechanics, Inc. Symposium on Plasticity and Impact (including Blast) Mechanics (IMPLAST2010), Providence, Rhode Island USA, 2010.

ALVES, M.; JONES, N. Influence of hydrostatic stress on failure of axisimmetric notched specimens. Journal of Mechanics and Physics of Solids 47, p. 643-667, 1999.

BAI, Y.; WIERZBICKI, T. A new model of metal plasticity and fracture with pressure and Lode dependence. International Journal of Plasticity 24, p. 1071-1096, 2008.

BALLARD, J. Brittle Fracture. Virginia Tech Materials Science and Engineering, 1997. Disponível em: <http://www.sv.vt.edu/classes/MSE2094

_NoteBook/97ClassProj/exper/ballard/www/ballard.html >. Acesso em: 12 fev. 2012.

BAO, Y.; TREITLER, R. Ductile crack formation on notched Al2024-T351 bars under compression-tension loading. Materials Science and Engineering A 384, p. 385394, 2004.

BAO, Y.; WIERZBICKI, T. On the fracture locus in the equivalent strain and stress triaxiality space. International Journal of Mechanical Sciences 46, p. 81-98, 2004.

BAO, Y.; WIERZBICKI, T. On the cut-off value of negative triaxiality for fracture. Engineering of Fracture Mechanics 72(7), p. 1049-69, 2005.

BARDET, J. P. Lode dependence for isotropic pressure-sensitive elastoplastic materials. Journal of Applied Mechanics 57, p. 498-506, 1990.

BARSOUM, I.; FALESKOG, J. Rupture mechanisms in combined tension and shear - experiments. Int. J. Solids Struct. 44 (6), p. 1768-1786, 2007.

BØRVIK, T. et al. A computational model of viscoplasticity and ductile damage for impact and penetration. European Journal of Mechanics: A/Solids 29, p. 685-712, 2001. 
BØRVIK, T. et al. Effects of target thickness in blunt projectile penetration of Weldox 460 E steel plates. International Journal Impact Engineering 28, p. 413-464, 2003.

BØRVIK, T. et al. Perforation of AA5083-H116 aluminium plates with conical-nose steel projectiles - experimental studies. International Journal of Impact Engineering 30(4), p. 367-384, 2004.

BØRVIK, T.; DEY, S.; CLAUSEN, A. H. Perforation resistance of five different highstrength steel plates subjected to small-arms projectiles. International Journal of Impact Engineering 36, p. 948-964, 2009.

BØRVIK, T.; HOPPERSTAD, O. S.; PEDERSEN, K. O. Quasi-brittle fracture during structural impact of AA7075-T651 aluminium plates. International Journal of Impact Engineering 37, p. 537-551, 2010.

BØRVIK, T. et al. Normal and oblique impact of small arms bullets on AA6082-T4 aluminium protective plates. International Journal of Impact Engineering 38, p. 577-589, 2011.

BRIDGMAN, P. W. Studies in Large Plastic Flow and Fracture. McGraw-Hill Inc., 1956.

BRÜNIG, M. et al. A ductile damage criterion at various stress triaxialities. International Journal of Plasticity 24, p. 1731-1755, 2008.

BUGELLI, E.; DRIEMEIER, L. Failure Models Evaluations on Structures Under Low Speed Crash - Experiments and Simulations. Proceedings of the IMPLAST 2010 Conference, USA, 2010.

CALLISTER, W. D. Materials Science and Engineering: An Introduction. John Wiley \& Sons, 2007.

CHOCRON, S.; ERICE, B.; ANDERSON, C. E. A new plasticity and failure model for ballistic application. International Journal of Impact Engineering 38, p. 755-764, 2011.

CHRISTLEIN, J.; HAMBRECHT, T. Safety and lightweight design - not a contradiction. Impact Loading of Lightweight Structures, 2008. 
CHU, C. C.; NEEDLEMAN, A. Void nucleation effects in biaxially stretched sheets. Journal of Engineering Materials and Technology 102, p. 249-256, 1980.

COCKCROFT, M. G.; LATHAM, D. J. Ductility and the workability of metals. Journal Institute Metals 96, p. 33-39, 1968.

DEY, S. et al. On the influence of constitutive relation in projectile impact of steel plates. International Journal of Impact Engineering 34, p. 464-486, 2007.

FRENCH, I. E.; WEINRICH, P. F. The influence of hydrostatic pressure on the tensile deformation and fracture of copper. Metallurgical Transactions A 6A, p. 785-790, 1975.

GAO, X.; KIM, J. Modeling of ductile fracture: significance of void coalescence. Int. J. Solids Struct. 43, p. 6277-6293, 2006.

GRYTTEN, F. et al. Quasi-static perforation of thin aluminium plates. International Journal of Impact Engineering 36, p. 486-497, 2009a.

GRYTTEN, F. et al. Low velocity perforation of AA5083-H116 aluminium plates. International Journal of Impact Engineering 36, p. 597-610, $2009 \mathrm{~b}$.

GURSON, A. L. Continuum theory of ductile rupture by void nucleation and growth: Part I-yield criteria and flow rules for porous ductile media. Journal of Engineering Materials and Technology 99, p. 2-15, 1977.

HOPPERSTAD, O. S. et al. On the influence of stress triaxiality and strain rate on the behavior of a structural steel. Part I: Experiments. European Journal of Mechanics A/Solids 22, p. 1-13, 2003.

JOHNSON, G. R.; COOK., W. H. Fracture characteristics of three metals subjected to various strains, strain rates, temperatures and pressures. Engineering Fracture Mechanics 21(1), p. 31-48, 1985.

JOHNSON, G. R.; HOLMQUIST, T. J. Test data and computational strength and fracture model constants for $\mathbf{2 3}$ materials subjected to large strain, high strain rates, and high temperature. Los Alamos National Laboratory, 1989. Technical Report LA-11463-MS. 
KIM, J.; GAO, X.; SRIVATSAN, T. S. Modeling of crack growth in ductile solids: a three-dimensional analysis. International Journal of Solids and Structures 40, p. 7357-7374, 2003.

KIM, J.; GAO, X.; SRIVATSAN, T. S. Modeling of void growth in ductile solids: effects of stress triaxiality and initial porosity. Engineering Fracture Mechanics 71, p. 379400, 2004.

KIM, J.; ZHANG, G.; GAO, X. Modeling of ductile fracture: application of the mechanism-based concepts. International Journal of Solids and Structures 44, p. 1844-1862, 2007.

LEMAITRE, J. A continuous damage mechanics model for ductile fracture. Journal of Engineering Materials and Technology - Transactions of the ASME 107, p. 83-89, 1985.

LEROY, G. et al. A model of ductile fracture based on the nucleation and growth of voids. Acta Metallurgica 29, p. 1509-1522, 1981.

LING, Y. Uniaxial true stress-strain after necking. AMP Journal of Technology 5, p. 37-48, 1996.

LS-DYNA Keyword Users Manual Version 971. Livermore Software Technology Corporation, 2009.

MALCHER, L.; ANDRADE PIRES, F. M.; CÉSAR DE SÁ, J. M. A. An assessment of isotropic constitutive models for ductile fracture under high and low stress triaxiality. International Journal of Plasticity 30-31, p. 81-115, 2012.

MCCLINTOCK, F. A.; KAPLAN, S. M.; BERG, C. A. Ductile fracture by hole growth in shear bands. International Journal of Fracture Mechanics 2, p. 614-627, 1966.

MCCLINTOCK, F. A. A criterion for ductile fracture by growth of holes. Trans. ASME - Journal of Applied Mechanics 35, p. 363-371, 1968.

OCKEWITZ, A. et al. Damage modelling of automobile components of aluminium materials under crash loading. LS-Dyna Anwenderforum, 2006. 
PICKET, A. K. et al. Failure prediction for advanced crashworthiness of transportation vehicles. International Journal of Impact Engineering 30(7), p. 853872, 2004.

RICE, J. R.; TRACEY, D. M. On the ductile enlargement of voids in triaxial stress fields. Journal of the Mechanics and Physics of Solids 17, p. 201-217, 1969.

SOUZA NETO, E. A.; PERIC, D.; OWEN, D. R. J. Computational Methods for Plasticity. John Wiley \& Sons, 2008.

TENG, X. et al. Numerical prediction of fracture in the Taylor test. International Journal of Solids and Structures 42, p. 2929-2948, 2005.

TENG, X.; WIERZBICKI, T. Evaluation of six fracture models in high velocity perforation. Engineering Fracture Mechanics 73, p. 1653-1678, 2006.

TÖRNQVIST, R. Design of Crashworthy Ship Structures. 2003. 243 p. Tese (Doutorado) - Technical University of Denmark, Copenhagen, 2003.

TVERGAARD, V., Influence of voids on shear band instabilities under plane strain conditions. International Journal of Fracture 17 (4), p. 389-407, 1981.

TVERGAARD, V.; NEEDLEMAN, A. Analysis of the cup-cone fracture in a round tensile bar. Acta Metallurgica 32, p. 157-169, 1984.

URBAN, J. Crushing and Fracture of Lightweight Structures. 2003. 218 p. Tese (Doutorado) - Technical University of Denmark, Copenhagen, 2003.

WALVEKAR, V., Birdstrike analysis on leading edge of an aircraft wing using a smooth particle hydrodynamics bird model. 2010. 65 p. Dissertação (Mestrado) Wichita State University, Wichita, 2010.

WIERZBICKI, T. et al. Calibration and evaluation of seven fracture models. International Journal of Mechanical Sciences 47, p. 719-743, 2005.

WU, P. D. et al. Effects of superimposed hydrostatic pressure on fracture in sheet metals under tension. International Journal of Mechanical Sciences 52(2), p. 236244, 2010. 
XUE, L., Ductile fracture modeling - Theory, experimental investigation and numerical verification. 2007. 228 p. Tese (Doutorado) - Massachusetts Institute of Technology, Cambridge, 2007.

XUE, L.; WIERZBICKI, T. Ductile fracture initiation and propagation modeling using damage plasticity theory. Engineering Fracture Mechanics 75, p. 3276-3293, 2008.

YAMASHITA, M.; GOTOH, M.; SAWAIRI, Y. Axial crush of hollow cylindrical structures with various polygonal cross-sections - numerical simulation and experiment. Journal of Materials Processing Technology 140, p. 59-64, 2003. 


\section{APÊNDICE A - CALIBRAÇÃO DOS CRITÉRIOS DE FALHA DA MECÂNICA DO CONTÍNUO}

Percebe-se que, em ensaios em corpos de prova, o fator de triaxialidade e ângulo de Lode não são constantes durante todo o teste, conforme Figura 62. Dessa forma, aqui será descrito um método de calibração dos critérios de falha da mecânica do contínuo que são baseados na variável cumulativa de dano:

$$
D=\int_{0}^{\bar{\varepsilon}_{f}} \frac{d \bar{\varepsilon}_{p}}{\varepsilon_{c}}
$$

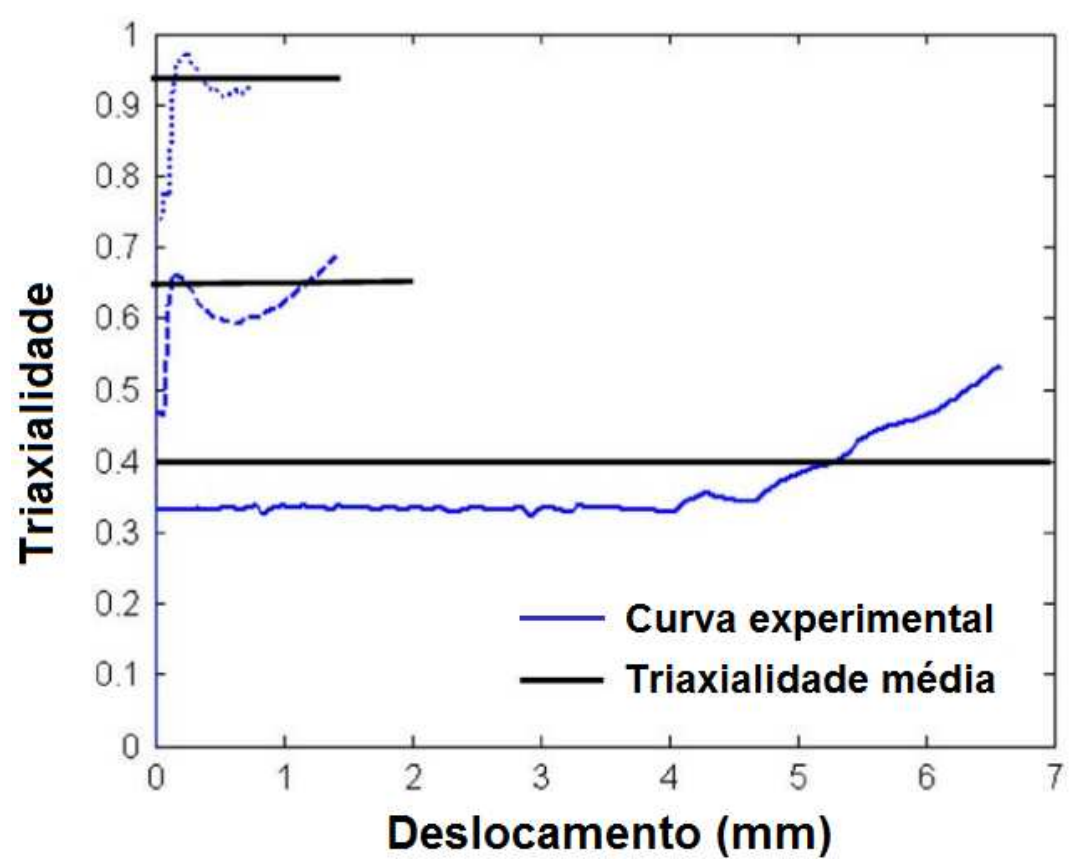

Figura 62. Obtenção do fator de triaxialidade médio para diferentes experimentos. Adaptado de Bao e Wierzbicki (2004).

O processo de calibração será exemplificado aqui para o critério de falha de Johnson-Cook, que apresenta a seguinte função de deformação de falha $\varepsilon_{c}$ (dependente apenas do fator de triaxialidade $\eta$ ):

$$
\varepsilon_{c}=D_{1}+D_{2} \cdot \exp \left(D_{3} \cdot \eta\right)
$$


Aqui é necessário calibrar três parâmetros: $D_{1}, D_{2}$ e $D_{3}$. Assim são necessários, no mínimo, três testes experimentais em diferentes valores de triaxialidade $\eta$. Neste caso, geralmente são realizados testes em cisalhamento puro ( $\eta$ próximo de zero) e testes de tração uniaxial de espécimes com e sem entalhe (altos valores de $\eta$ ). Depois de realizados os testes experimentais, o próximo passo é realizar simulações em elementos finitos desses testes experimentais. Neste passo, é possível empregar na simulação modelos constitutivos que não são afetados pelo dano no material (sem perda de resistência mecânica induzida por dano). Verifica-se na literatura que nesta fase são empregados modelos de plasticidade que requerem uma curva tensão-deformação verdadeira do material ou modelos de plasticidade como o de von Mises. O objetivo da simulação numérica dos experimentos é extrair a deformação plástica e os componentes de tensão ou deformação da região onde ocorre ruptura dos corpos de prova, no momento de ruptura. Sabe-se, por exemplo, que para espécimes com entalhe é possível que a ruptura ocorra na região com o maior valor de triaxialidade, ou seja, no centro dos entalhes e não no raio de curvatura dos mesmos. Assim, sabendo o local de ocorrência de falha nos experimentos, nas simulações deve-se obter para o elemento onde ocorreria a falha a deformação plástica equivalente, e neste caso, o fator de triaxialidade. No entanto, o fator de triaxialidade a ser obtido do elemento que falha é um valor médio ao longo de todo o histórico de carregamento do elemento durante a simulação. Esse valor médio é dado pela fórmula:

$$
\eta_{m}=\frac{1}{\bar{\varepsilon}_{f}} \int_{0}^{\bar{\varepsilon}_{f}} \frac{\sigma_{m}}{\bar{\sigma}} d \bar{\varepsilon}_{p}
$$

onde $\sigma_{m}$ é a tensão hidrostática e $\bar{\sigma}$ é a tensão equivalente. Deste modo, para o elemento onde ocorre a falha deve ser obtida a deformação de falha e o fator de triaxialidade médio dado pela fórmula acima. A razão de ser utilizado um fator de triaxialidade médio ao invés de um fator de triaxialidade no instante de falha vem do fato de o equacionamento a seguir poder ser aplicado: 


$$
D=\int_{0}^{\bar{\varepsilon}_{f}} \frac{d \bar{\varepsilon}_{p}}{\varepsilon_{c}(\eta)}=\frac{1}{\varepsilon_{c}(\bar{\eta})} \int_{0}^{\bar{\varepsilon}_{f}} d \bar{\varepsilon}_{p}=\frac{\bar{\varepsilon}_{f}}{\varepsilon_{c}(\bar{\eta})}
$$

Para $D=1$, temos: $\bar{\varepsilon}_{f}=\varepsilon_{c}(\bar{\eta})$, o que possibilita a calibração. Deste modo, obtidas as deformações de falha e as triaxialidades médias de ruptura para cada espécime é possível obter os parâmetros de falha utilizando a função de deformação de falha $\varepsilon_{c}(\eta)$ e o método dos mínimos quadrados, e a partir daí montar um gráfico que corresponderia ao lugar geométrico de falha, como o gráfico da Figura 63.

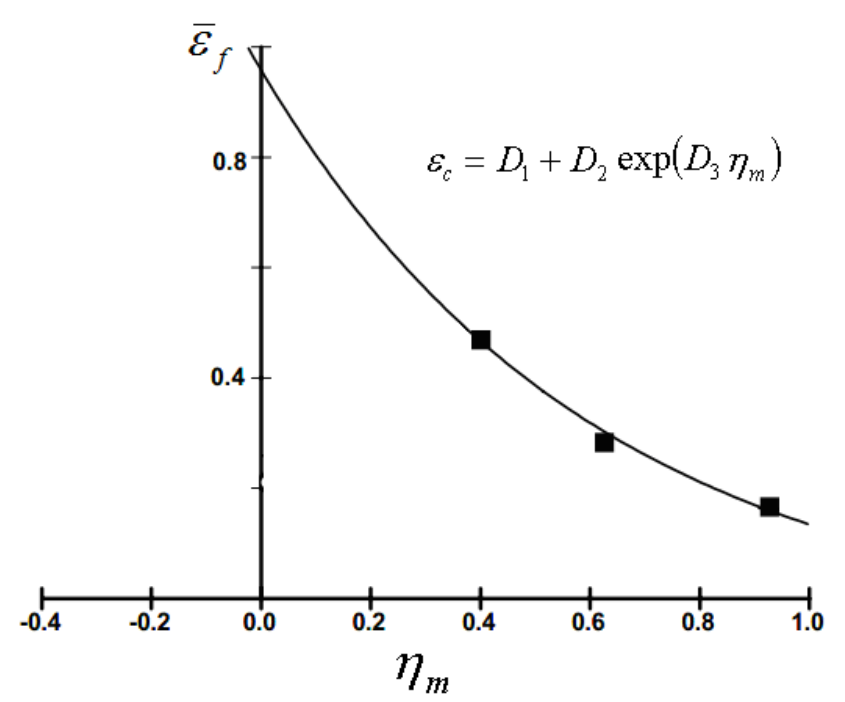

Figura 63. Obtenção do lugar geométrico de falha a partir dos valores de deformação de falha e triaxialidade média obtidos numericamente.

Um ponto importante a ser considerado é que para a calibração e obtenção dos parâmetros de falha o fator de triaxialidade $\eta$ na equação de deformação de falha $\varepsilon_{c}$ torna-se o fator de triaxialidade médio $\eta_{m}$. 


\section{APÊNDICE B - SUBROTINA IMPLEMENTADA NO LS-DYNA}

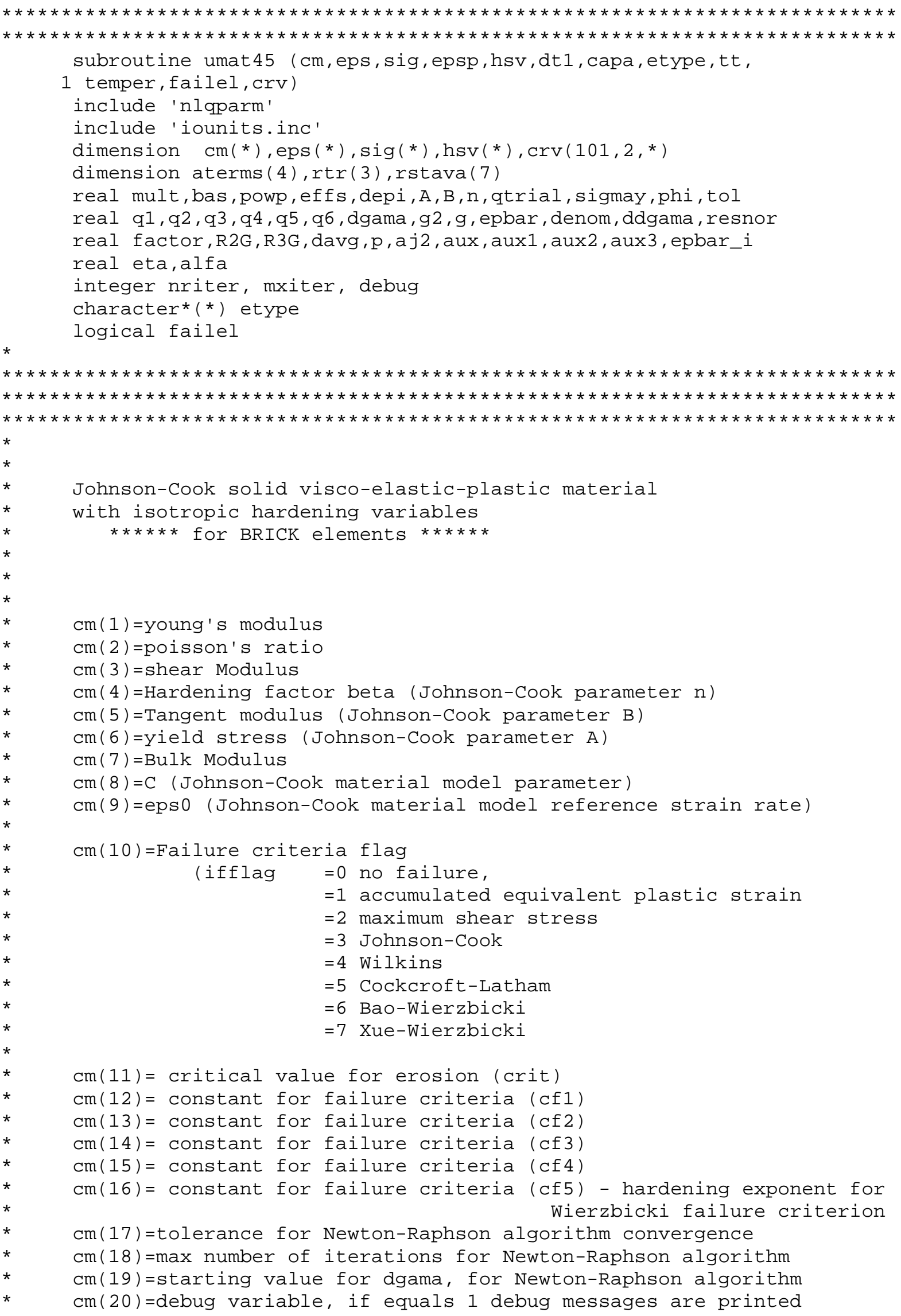

Johnson-Cook solid visco-elastic-plastic material

with isotropic hardening variables

$\star \star \star \star * *$ for BRICK elements $\star * \star \star * *$

$\mathrm{cm}(1)=$ young's modulus

$\mathrm{cm}(2)=$ poisson's ratio

$\mathrm{cm}(3)=$ shear Modulus

$\mathrm{cm}(4)=$ Hardening factor beta (Johnson-Cook parameter $\mathrm{n}$ )

$\mathrm{cm}(5)=$ Tangent modulus (Johnson-Cook parameter $\mathrm{B}$ )

$\mathrm{cm}(6)=y i e l d$ stress (Johnson-Cook parameter A)

$\mathrm{cm}(7)=$ Bulk Modulus

$\mathrm{cm}(8)=\mathrm{C}$ (Johnson-Cook material model parameter)

$\mathrm{cm}(9)=e p s 0$ (Johnson-Cook material model reference strain rate)

$\mathrm{cm}(10)=$ Failure criteria flag

(ifflag =0 no failure,

$=1$ accumulated equivalent plastic strain

$=2$ maximum shear stress

$=3$ Johnson-Cook

$=4$ Wilkins

$=5$ Cockcroft-Latham

$=6$ Bao-Wierzbicki

$=7$ Xue-Wierzbicki

$\mathrm{cm}(11)=$ critical value for erosion (crit)

$\mathrm{cm}(12)=$ constant for failure criteria (cf1)

$\mathrm{cm}(13)=$ constant for failure criteria (cf2)

$\mathrm{cm}(14)=$ constant for failure criteria (cf3)

$\mathrm{cm}(15)=$ constant for failure criteria (cf4)

$\mathrm{cm}(16)=$ constant for failure criteria (cf5) - hardening exponent for

Wierzbicki failure criterion

$\mathrm{cm}(17)$ =tolerance for Newton-Raphson algorithm convergence

$\mathrm{cm}(18)=\max$ number of iterations for Newton-Raphson algorithm

cm(19)=starting value for dgama, for Newton-Raphson algorithm

$\mathrm{cm}(20)=$ debug variable, if equals 1 debug messages are printed 


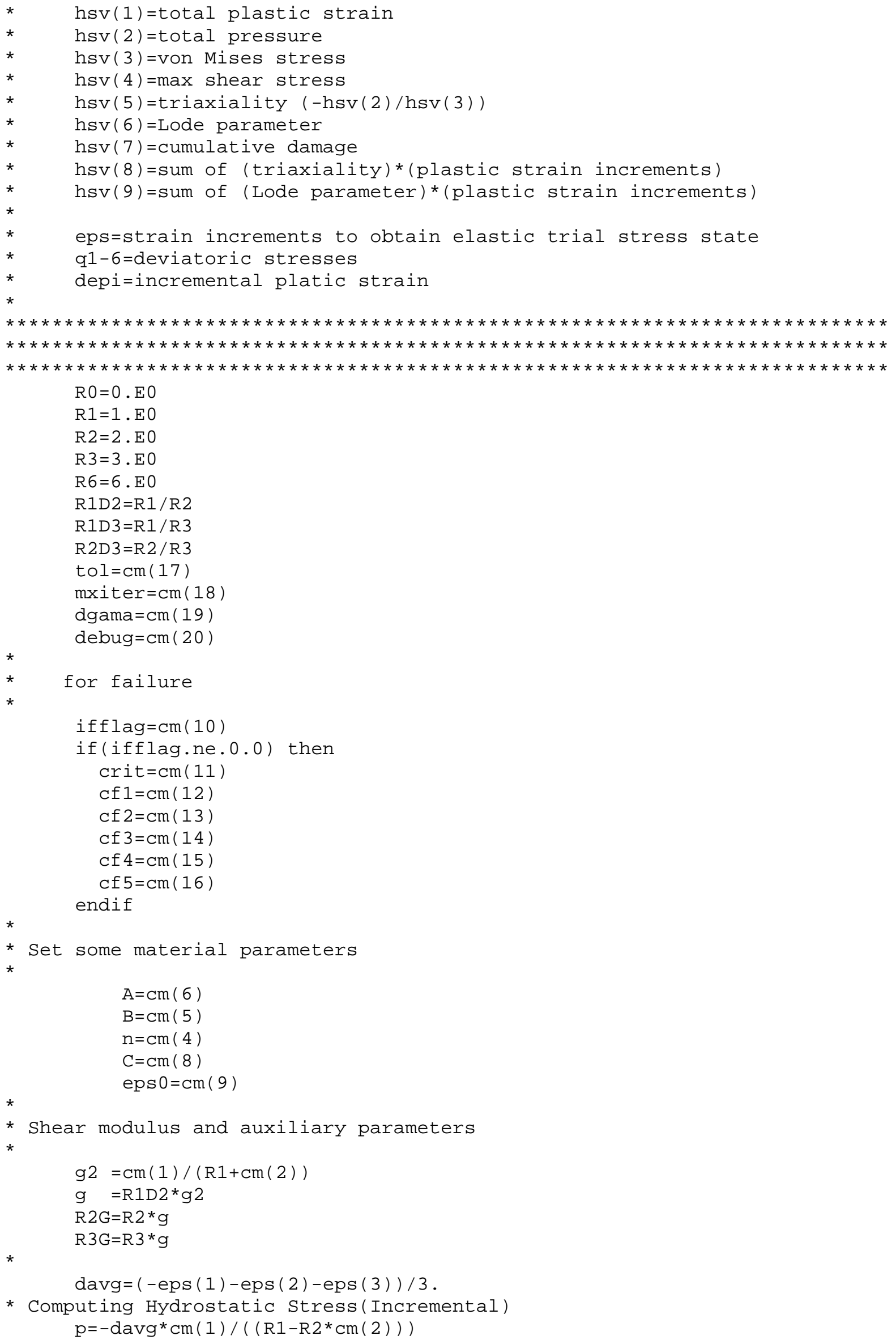


* Updating Total Pressure

hsv $(2)=h s v(2)-p$

* Computing Trial Stress

$\operatorname{sig}(1)=\operatorname{sig}(1)+\mathrm{p}+\mathrm{g} 2 *(\operatorname{eps}(1)+$ davg $)$

$\operatorname{sig}(2)=\operatorname{sig}(2)+p+g 2 *(\operatorname{eps}(2)+$ davg $)$

$\operatorname{sig}(3)=\operatorname{sig}(3)+p+g 2 *(\operatorname{eps}(3)+$ davg $)$

$\operatorname{sig}(4)=\operatorname{sig}(4)+g^{*} \operatorname{eps}(4)$

$\operatorname{sig}(5)=\operatorname{sig}(5)+g^{\star} \operatorname{eps}(5)$

$\operatorname{sig}(6)=\operatorname{sig}(6)+g^{\star} \operatorname{eps}(6)$

*

* Computing Deviatoric Stress

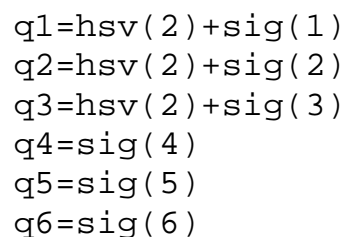

$a j 2=q 4 * q 4+q 5 * q 5+q 6 * q 6+(q 1 * q 1+q 2 * q 2+q 3 * q 3) / 2$.

if (debug.eq.1) then

write $(59, *) \quad \operatorname{sig}(1)=$ ', $\operatorname{sig}(1)$

write $(59, *) \cdot \operatorname{sig}(2)=', \operatorname{sig}(2)$

write $\left(59,{ }^{*}\right) \operatorname{sig}(3)=', \operatorname{sig}(3)$

write $(59, *) \cdot \operatorname{sig}(4)=1, \operatorname{sig}(4)$

write $(59, *) \quad ' \operatorname{sig}(5)=', \operatorname{sig}(5)$

write $(59, *) \cdot \operatorname{sig}(6)=', \operatorname{sig}(6)$

write $\left(59,{ }^{*}\right)$ 'hsv(2) = ', hsv(2)

write $(59, *)$ 'aj2 = ', aj2

endif

*

* Calculation of equivalent stress and flow function

qtrial $=\operatorname{sqrt}(R 3 * a j 2)$

sigmay $=A+B *(e p s p * * n)$

if (debug.eq.1) then

write $(59, *)$ 'initial_dgama $=$ ', dgama

write $(59, *)$ 'R3G $=$ ', R3G

write $(59, *)$ 'initial qtrial $=$ ', qtrial

endif

write $\left(59,{ }^{*}\right)$ 'initial sigmay $=$ ', sigmay

*

* Begin strain rate effect

if (C.ne.RO) then

$\mathrm{d} 1 \mathrm{~d}=\operatorname{eps}(1)+\mathrm{davg}$

$\mathrm{d} 2 \mathrm{~d}=\operatorname{eps}(2)+\mathrm{davg}$

$\mathrm{d} 3 \mathrm{~d}=\operatorname{eps}(3)+\mathrm{davg}$

$\mathrm{d} 4 \mathrm{~d}=\operatorname{eps}(4)$

$\mathrm{d} 5 \mathrm{~d}=\operatorname{eps}(5)$

$\mathrm{d} 6 \mathrm{~d}=\mathrm{eps}(6)$

$\mathrm{ds}=\mathrm{d} 4 \mathrm{~d} * \star \mathrm{R} 2+\mathrm{d} 5 \mathrm{~d} * \star \mathrm{R} 2+\mathrm{d} 6 \mathrm{~d} * \star \mathrm{R} 2$

* Computing effective strain

aux $=R 2 *(d 1 d * \star R 2+d 2 d * * R 2+d 3 d * \star R 2+R 2 * d s) / R 3$

if (aux.ne.RO) then

effs=sqrt (aux)

else

effs $=R 0$

end if

* Computing strain rate

if (tt.ne.RO) then

effs=effs/dt 1 


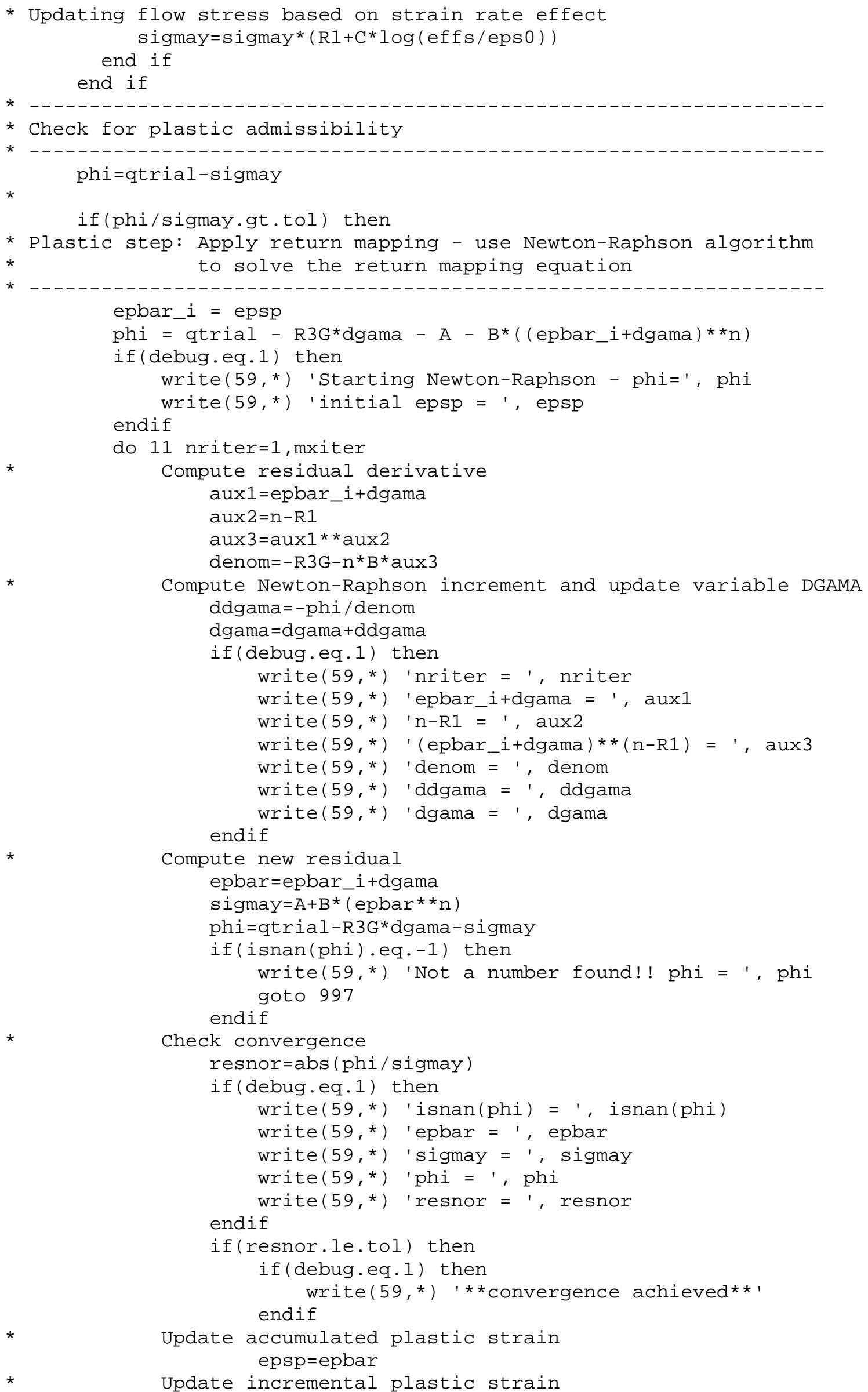




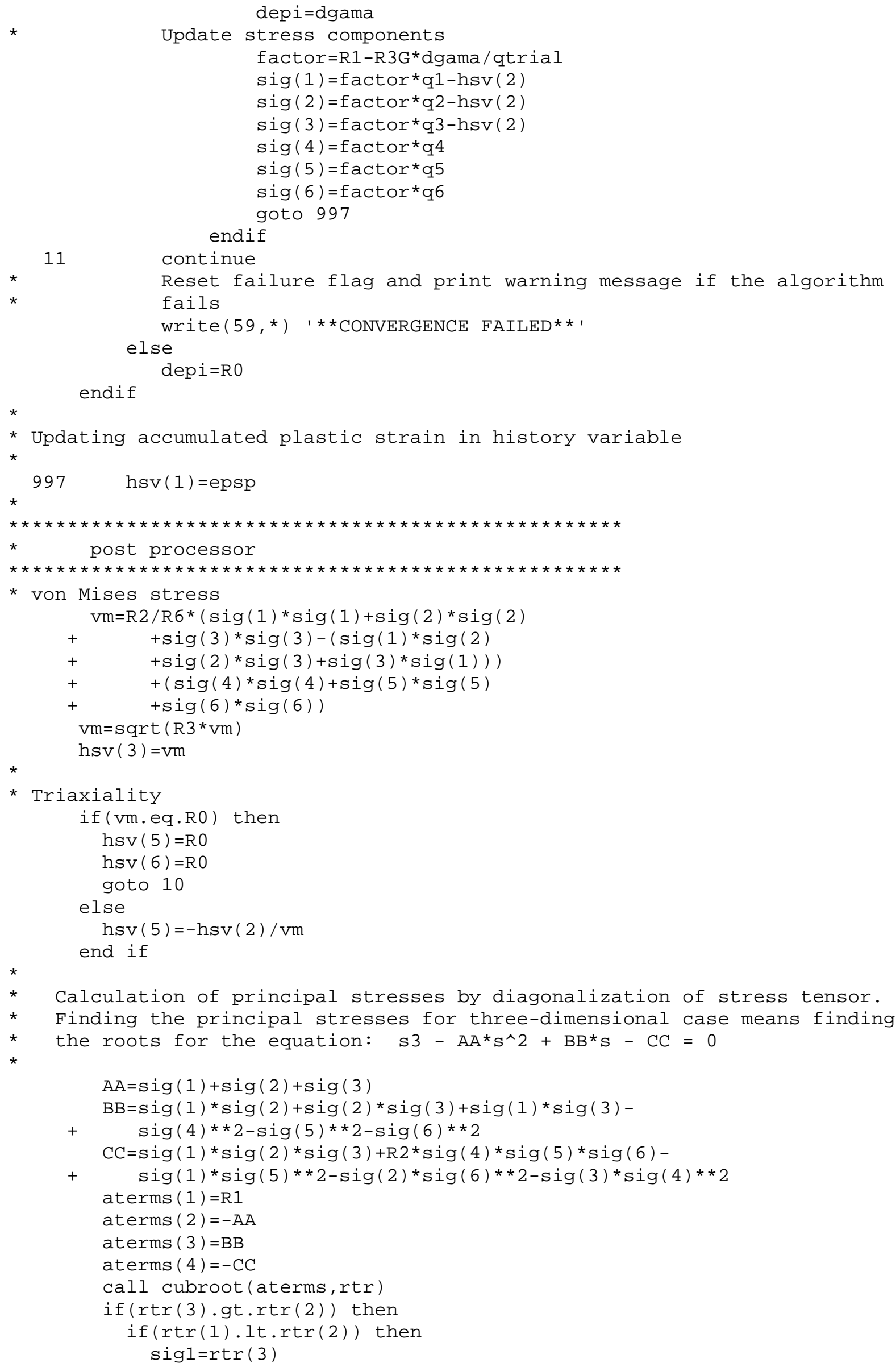




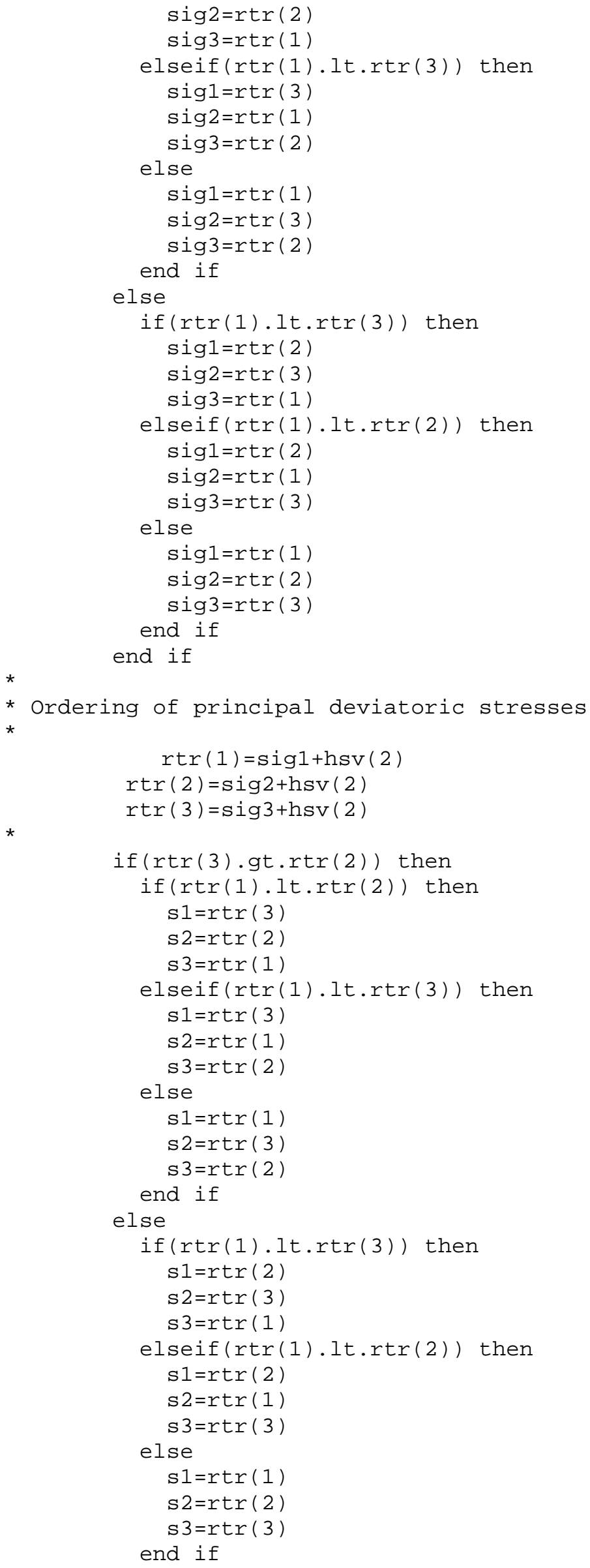


end if

* Max shear stress

hsv $(4)=\operatorname{abs}(\operatorname{sig} 1-\operatorname{sig} 3) / R 2$

*

* Lode parameter $\operatorname{hsv}(6)=1 .-(6 . / 3.1416) * \operatorname{atan}((2 . *(\operatorname{sis} 3) /(\operatorname{si}-\mathrm{s} 3)-1.) / \operatorname{sqrt}(3)$.

* Calculation of integrals for definition of average triaxiality and

* average Lode parameter hsv ( 8) =hsv (8) +hsv (5)*depi hsv $(9)=\operatorname{hsv}(9)+\operatorname{hsv}(6) * \operatorname{depi}$

*

* Calculation of principal strain increments by diagonalization of * tensor made by components of strain increments.

* Finding the principal stresses for three-dimensional case means finding * the roots for the equation: $\mathrm{s} 3-\mathrm{AA}^{\star} \mathrm{S}^{\wedge} 2+\mathrm{BB}^{\star} \mathrm{S}-\mathrm{CC}=0$

*

$A A=\operatorname{eps}(1)+\operatorname{eps}(2)+\operatorname{eps}(3)$

$\mathrm{BB}=\operatorname{eps}(1) \star \operatorname{eps}(2)+\operatorname{eps}(2) \star \operatorname{eps}(3)+\operatorname{eps}(1) \star \operatorname{eps}(3)-$

$+$

$\operatorname{eps}(4) \star \star 2-\operatorname{eps}(5) \star \star 2-\operatorname{eps}(6) \star \star 2$

$\mathrm{CC}=\operatorname{eps}(1) \star \operatorname{eps}(2) \star \operatorname{eps}(3)+\mathrm{R} 2 * \operatorname{eps}(4) \star \operatorname{eps}(5) \star \operatorname{eps}(6)-$

$+\quad \operatorname{eps}(1) \star \operatorname{eps}(5) \star \star 2-\operatorname{eps}(2) \star \operatorname{eps}(6) \star \star 2-\operatorname{eps}(3) \star \operatorname{eps}(4) \star \star 2$

aterms $(1)=\mathrm{R} 1$

aterms $(2)=-A A$

aterms $(3)=B B$

aterms $(4)=-C C$

call cubroot (aterms, rtr)

if (rtr(3).gt.rtr(2)) then

if(rtr(1).1t.rtr(2)) then

eps1=rtr (3)

eps2 $=r t r(2)$

eps $3=r t r(1)$

elseif(rtr(1).1t.rtr(3)) then

eps1=rtr $(3)$

eps2 =rtr $(1)$

$\operatorname{eps} 3=r t r(2)$

else

$\operatorname{eps} 1=\operatorname{rtr}(1)$

eps2 =rtr $(3)$

$\operatorname{eps} 3=\operatorname{rtr}(2)$

end if

else

if(rtr(1).lt.rtr(3)) then

eps $1=r t r(2)$

$\operatorname{eps} 2=\operatorname{rtr}(3)$

eps $3=r t r(1)$

elseif(rtr(1).lt.rtr(2)) then

eps1=rtr (2)

$\operatorname{eps} 2=r t r(1)$

eps $3=r t r(3)$

else

$\operatorname{eps} 1=r t r(1)$

$\operatorname{eps} 2=r t r(2)$

$\operatorname{eps} 3=r t r(3)$

end if

end if 


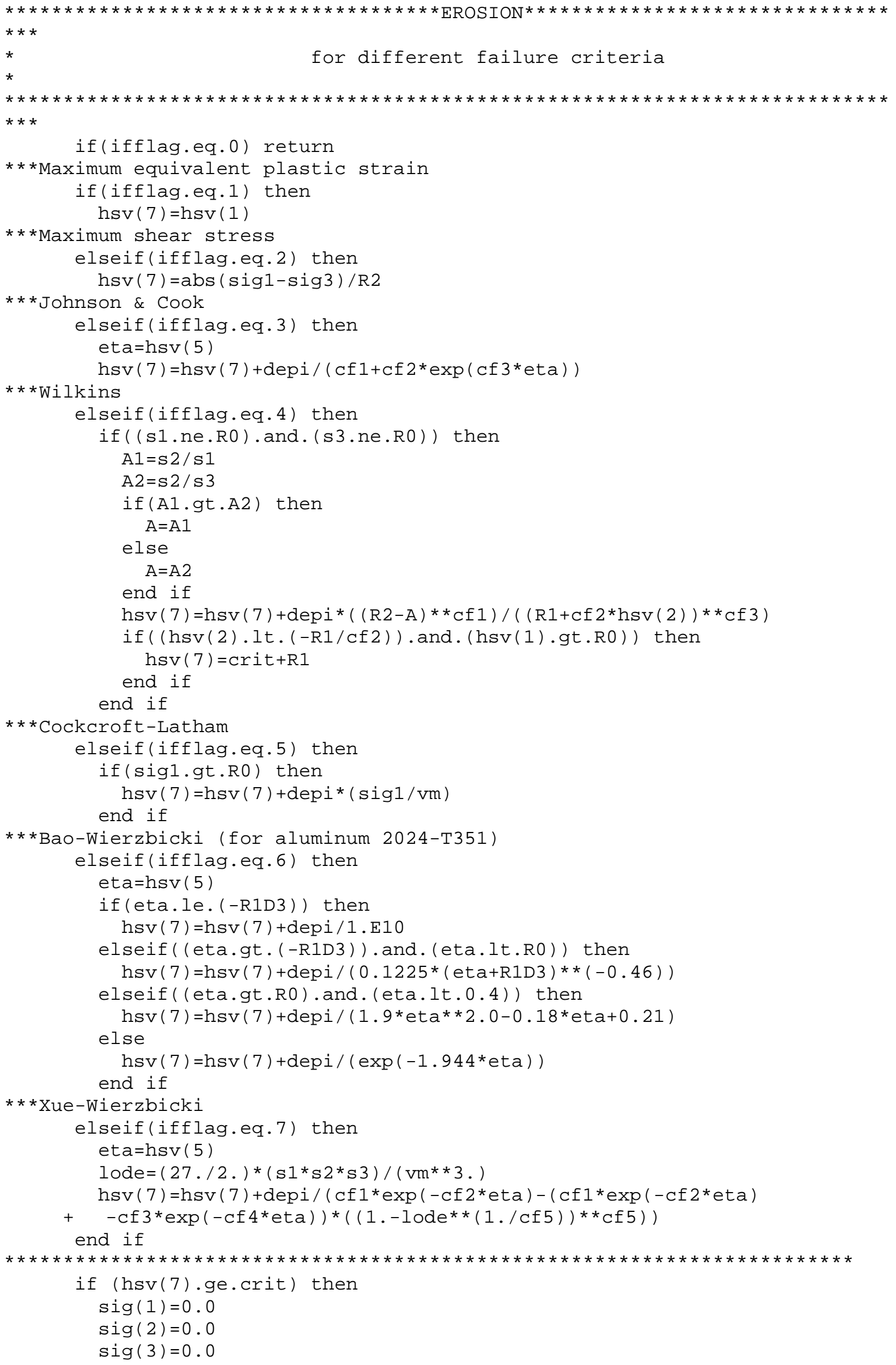




$$
\begin{aligned}
& \operatorname{sig}(4)=0.0 \\
& \operatorname{sig}(5)=0.0 \\
& \text { sig }(6)=0.0 \\
& \text { failel }=. \text { true. } \\
& \text { end if } \\
& \text { return } \\
& \text { end }
\end{aligned}
$$

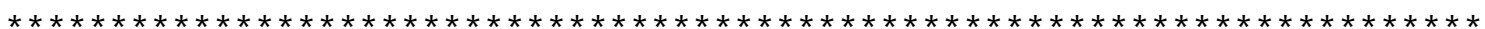

